\title{
AT-LINE BENZENE MONITOR FOR MEASURING BENZENE IN PRECIPITATE HYDROLYSIS AQUEOUS (U)
}

by W. J. Jenkins

Westinghouse Savannah River Company

WSRC-RP--92-1215

Savannah River Site

Aiken, South Carolina 29808

Other Authors:

This paper was prepared in connection with work done under Contract No. DE-AC09-89SR18035 with the U. S. Department of Energy. By acceptance of this paper, the publisher and/or recipient acknowledges the U.S. Government's right to retain a nonexclusive, royalty-free license in and to any copyright covering this paper, at $g$ with the right to reproduce and to authorize others to reproduce all or part of the copyrighted paper. 


\section{DISCLAIMER}

This report was prepared as an account of work sponsored by an agency of the United States Government. Neither the United States Government nor any agency thereof, nor any of their employees, makes any warranty, express or implied, or assumes any legal liability or responsibility for the accuracy, completeness, or usefulness of any information, apparatus, product, or process disclosed, or represents that its use would not infringe privately owned rights. Reference herein to any specific commercial product, process, or service by trade name, trademark, manufacturer, or otherwise does not necessarily constitute or imply its endorsement, recommendation, or favoring by the United States Government or any agency thereof. The views and opinions of authors expressed herein do not necessarily state or reflect those of the United States Government or any agency thereof.

This report has been reproduced directly frem the best available copy.

Available to DOE nd DOE contractors from the Office of Scientific and Technical Informati. O. Box 62, Oak Ridge, TN 37831; prices available from (615) $576-8401$.

Available to the public from the National Technical Information Service, U. S. Department of Commerce, 5285 Port Royal Rd., Springfield, VA 22161. 


\section{WESTINGHOUSE SAVANNAH RIVER COMPANY SAVANNAH RIVER TECHNOLOGY CENTER}

WSRC-RP-92-1215

Keywords: DWPF, DWPT, PHA, PR, Hydragard $^{\mathrm{TM}}$, Benzene, Liquid Sampler, PRBT, Analytical, Process Control

Retention: Permanent

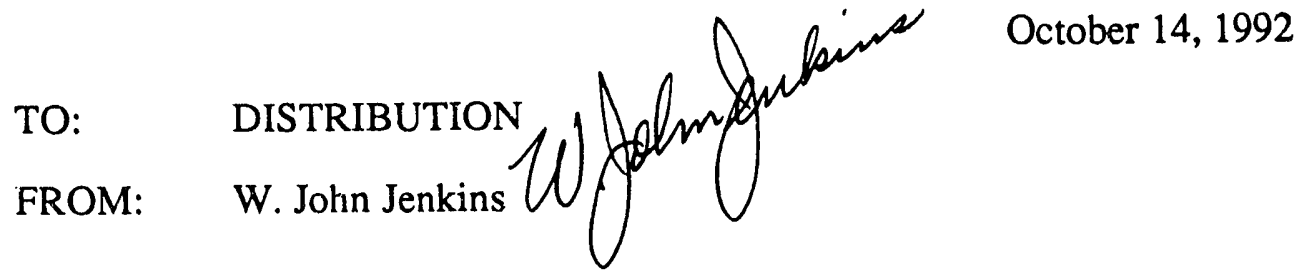

\section{AT-LINE BENZENE MONITOR FOR MEASURING BENZENE IN PRECIPITATE HYDROLYSIS AOUEOUS (U)}

ATTACHMENTS: Benzene Monitor System Report (U), WSRC-TR-92-478. Statistical Analysis of the At-line Benzene Monitor Study (U), SCS-ASG-92-066.

\section{SUMMARY}

A highly accurate and repeatable at-line benzene monitor (ALBM) has been developed to measure the benzene concentration in precipitate hydrolysis aqueous (PHA) in the DWPF. This analyzer was conceived and jointly developed within SRTC by the Analytical Development and the Defense Waste Process Technology Sections with extensive support from the Applied Statistics Group and the TNX Operations Section. It is recommended that

- an ALBM specifically adapted to DWPF analytical requirements be used to measure benzene in PHA,

- calibrations be performed using a $10 \%$ methanol solution matrix (for standard stability), and

- based on experience gained in development at TNX, the services of ADS and ASG be employed to both adapt the ALBM to DWPF requirements and develop statistical control procedures.

\section{BACKGROUND}

To prevent possible formation of a flammable mixture in the Precipitate Reactor Bottoms Tank (PRBT), it is a DWPF Process Requirement (PR) that the benzene in the PHA be less than $30 \mathrm{ppm} .{ }^{[1]}$ However, there has been much concern about obtaining an accurate and repeatable measurement because of the extreme volatility of benzene and the physical 
design of the Hydragard ${ }^{\mathrm{TM}}$ liquid sampler and sample vial.[2] In order to assure the needed timing of an acceptable measurement technique, development was divided into two parts: 1) a "work-around sampler" for cold chemical runs (CCR),[3] and 2) a permanent solution compatible with radioactive operation. After completion of the first portion, two analyzers were selected for further development; an adaptation of an on-line optical analyzer developed for use during the "work-around sampler" testing and a modified Hydragard ${ }^{\mathrm{TM}}$ using a solvent extraction technique. [4] Because of the complexity and difficulty of the solvent extraction technique, the on-line analyzer (simplified to at-line use) was selected for final development and testing.

\section{DISCUSSION}

\section{Analyzer - Summary of Attachment 1}

The recommended analyzer employs absorption spectrophotometry adapted to remote measurement using fiber optics. Only the sample interface (optical cell) is contained within the shielded cell and is connected by electrical and fiber optic cables to the remaining components located in a clean area. The liquid phase benzene concentration is measured by recirculating air through the sample until the concentration in the vapor has equilibrated. The vapor benzene concentration is then measured by an ultraviolet-visible spectrophotometer.

During development and testing, both on the bench and on the full scale SRAT (Sludge Receipt and Adjustment Tank) at TNX, the analyzer has demonstrated the following advantages:

- ease of and methods to calibrate,

- operation using peanut vials filled from the existing Hydragard ${ }^{\mathrm{TM}}$ sampler,

- precision $(\sim 0.5 \%$ at $1 \sigma)$ better than the purge and trap method,

- direct measurement without pretreatment,

- analytical time of $\sim 5$ minutes (required once per 43 hour precipitate hydrolysis cycle), and

- production of no waste stream other than the sample itself, which is also required for other analyses.

The general steps in performing an analysis are:

1) The sample is collected using the existing Precipitate Reactor Hydragard ${ }^{\mathrm{TM}}$ sampler and placed in the ALBM sample holder.

2) The sample ID is input to the ALBM computer and the measurement sequence initiated. A reference measurement using air is automatically performed.

3) Using a lever action, the operator raises the vial into position when prompted engaging the sample vial with the ALBM sample interface and beginning the sample analysis. 
4) The sample is purged by the recirculating air and the absorption spectrum is measured after a set period of time. The spectrum is used to calculate the liquid phase concentration.

Because of the basic design, the liquid sample volume to analyzer gas volume ratio is very important. Operational experience at TNX confirmed that sample vial fill-volume is a very important parameter to be controlled. (That is, the analysis is incorrect if the vial is not sufficiently filled.) Visual and/or solution mass checks will be necessary to ensure the vial is sufficiently filled prior to analysis using the ALBM.

Statistics - Summary of Attachment 2

Bench scale and full scale testing and data analysis proceeded in six phases:

Phase 1. Initial calibration using water solution matrix Precision was good; but observed systematic bias was attributed to system modifications and changes in sample volumes after water calibration.

Phase 2. First experimental design

A statistically designed experiment (fractional factorial) was prepared to investigate solution matrix (water, PHA), sample temperature $\left(80^{\circ} \mathrm{F}, 140^{\circ} \mathrm{F}\right)$, optical cell temperature $\left(85^{\circ} \mathrm{C}, 95^{\circ} \mathrm{C}\right)$, and benzene concentration $(10 \mathrm{ppm}, 50$ ppm).

Phase 3. Analysis of data from first test

Sample temperature and the solution matrix $x$ standard concentration interaction were significant at the 5\% level. The variability for repeated ALBM measurements was not the same across all samples. However, the largest standard deviation within repeated measurements was only $0.85 \mathrm{ppm}$.

Phase 4. Second experimental design and data analysis

This experiment investigated the ALBM when calibrated with water solution standards and used to measure standards prepared with other solution matrices (PHA, 10\% methanol). There was no evidence of statistically significant differences among the variances of the repeat measurements across all the standards. The largest standard deviation measured was $0.47 \mathrm{ppm}$. Calibration curves indicated a measurement bias on the PHA and $10 \%$ methanol standards when the ALBM was calibrated with the water solution matrix; the measured biases were 1.30 and 1.32 , respectively. Stability measurements on the PHA and $10 \%$ methanol matrix standards indicated no statistically significant change in concentration over a two hour period. The $10 \%$ methanol matrix standard was used for Phase 6.

Phase 5. Third experimental design and data analysis

Benzene spiking tests were performed using the full scale SRAT at TNX. Tank samples taken over time (the benzene concentration decreases with time as benzene evaporates from the tank) and standards prepared in the $10 \%$ methanol matrix were measured with the ALBM calibrated with water solution standards. The largest standard deviation for repeatability across all samples was only $0.57 \mathrm{ppm}$ and there was no evidence of an inconsistency in the repeatability of the data.

The importance of sample vial fill-volume was clearly demonstrated when some exceptionally low benzene values were measured in partially filled vials. 
Phase 6. Calibration using $10 \%$ methanol standards

The ALBM was calibrated using the $10 \%$ methanol matrix standards and the data on PHA standards collected in Phase 4 were reanalyzed. No inconsistencies in the repeatability of the data were indicated using the five measurements available for each standard. The largest standard deviation was only $0.28 \mathrm{ppm}$. Results from this analysis indicate the ALBM value for a sample with a true benzene concentration of $30 \mathrm{ppm}$ would be greater than 28.5 ppm at a $99 \%$ confidence level.

\section{REFERENCES}

[1] R. A. Jacobs and R. E. Eibling, WSRC-IM-91-2 PROCESS REQUIREMENTS PRECIPITATE HYDROLYSIS, DWPFPR-S03 Rev. 1 (U), January 27, 1992.

[2] L. F. Landon, WSRC-RP-91-1064, BENZENE ANALYSIS OF AQUEOUS PRODUCT PRODUCED DURING PRECIPITATE HYDROLYSIS (U), October 23, 1992.

[3] W. J. Jenkins, WSRC-RP-92-852, TECHNICAL BASIS FOR "WORK-AROUND" PR SAMPLER (U), June 29, 1992.

[4] R. E. Eibling, WSRC-RP-92-566, DWPF BENZENE ANALYSIS: COLD CHEMICAL AND RADIOACTIVE OPERATION (U), April 24, 1992. 
Keywords: Benzene, Analyzer, DWPF, Fiber Optics Spectrophotometry

\title{
Retention: Permanent
}

October 12, 1992

\author{
TO: $\quad$ W. J. Jenkins, 704-1T \\ FROM: R.R. Livingston, 773-A $10 / 12 / 22$ \\ CC: Distribution
}

BENZENE MONITOR SYSTEM REPORT (U)

\section{SUMMARY}

Two systems for monitoring benzene in aqueous streams have been designed and assembled by the Savannah River Technology Center, Analytical Development Section(ADS). These systems were used at TNX to support sampling studies of the full-scale "SRAT/SME/PR" and to provide real-time measurements of benzene in Precipitate Hydrolysis Aqueous(PHA) simulant. This report describes the two ADS Benzene Monitor System (BMS) configurations, provides data on system operation, and reviews the results ot scoping tests conducted at TNX. These scoping tests will allow comparison with other benzene measuremnt options being considered for use in the Defense Waste Processing Facility (DWPF) laboratory. A report detailing the preferred BMS configuration statistical performance during recent tests has been issued under separate title: Statistical Analyses of the At-line Benzene Monitor Study, SCS-ASG-92-066.

The current BMS design, called the At-line Benzene Monitor (ALBM), allows remote measurement of benzene in PHA solutions. We have demonstrated the ability to calibrate and operate this system using peanut vials from a standard Hydragard sampler. The equipment and materials used to construct the ALBM are similar to those already used in other applications by the DWPF lab. The precision of this system ( $\pm 0.5 \%$ Relative Standard Deviation(RSD) at 1 sigma) is better than the purge \& trap - gas chromatograpy reference method currently in use. Both BMSs provide a direct measurement of the benzene that can be purged from a solution with no sample pretreatment. Each analysis requires about five minutes per sample, and the system operation requires no special skills or training. The analyzer's computer software can be tailored to provide desired outputs. Use of this system produces no waste stream other than the samples themseives (i.e. no organic extractants).

Derivative Classifier:

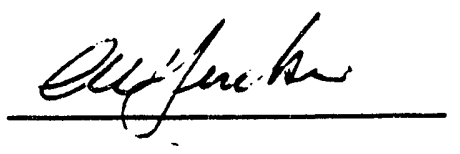




\section{INTRODUCTION}

In January 1992, the DWPF need for a benzene analysis method was first discussed with ADS. This measurement is needed to provide the benzene content of PHA before transfer from the Precipitate Reactor(PR) to the Precipitate Reactor Bottoms Tank(PRBT). The benzene concentration needs to be less than 30 parts per million(ppm) before transfer in order to guarantee that benzene vapor in the PRBT off gas system does not exceed the benzene Lower Explosive Limit(Reference 2). The sample from PR will contain approximately one weight percent suspended solids. This sample(PHA) will be at about 50 degrees centigrade $\left({ }^{\circ} \mathrm{C}\right)$, have an acidic component of about 0.1 molar(M) formic acid, and a salt content of around 0.5 $\mathrm{M}$ (Reference 3). The PHA solids are black in color and prevent direct measurement of benzene in solution by absorption spectrophotometry.

ADS experience with absorption spectrophotometry has demonstrated its usefulness for remote process measurements(Reference 4). This technique is well adapted to remote measurement by use of fiber optics. To minimize the amount of space required in the shielded cells and the number of contaminated system components, only the sample interface is contained in the shielded cells. Electrical control lines and fiber optics provide the connection to system components located in the clean area.

In addition to the size requirements imposed by available equipment space inside the DWPF shielded cells, plumbing changes in the current DWPF sampling system are strictly limited. The first BMS delivered to TNX in mid March was an online analyzer designed to operate unattended in a continuous mode. This analyzer would make measurements based upon operator-selected sampling frequency and control the instrument's process interface. This first analyzer (Figure 1) worked satisfactorily to support initial mixing \& sampling tests on ihe PR (Reference 5 ). This system was capable of meeting the size restrictions given by DWPF but would require plumbing changes. Several key problems were identified in this first system: 1) solenoid valve failures resulted from sample plugging and corrosion, 2) sample vessel filling and emptying were dependent on process flows and pressures that were difficult to control, and 3) quality control(QC) checks would require an additional valve and fluid pump.

The most recent design is called an At-Line Benzene Monitor(ALBM). This system: 1) requires no DWPF plumbing changes, 2) uses no valves, and 3) uses a standard DWPF sampling vial for each measurement (Figure 2). This new design allows for QC samples and recalibration when needed without any changes from the sample measurment configuration. However, process solutions must be manually sampled using existing laboratory sampling techniques. This sample is then transfered to the ALBM and measured from the sample container. User input is required to initiate analyzer measurement of each sample. Training requirements are minimal for the cell operators and lab analysts because the ALBM prompts the user at each step. 
The ALBM described above was delivered to TNX in July 1992. This system was used for additional testing of the PR sampling system and documentation of benzene loss rate from the full scale SRAT/SME/PR. Similar results for benzene loss from PR were obtained from the ALBM system as from earlier use of the online analyzer(Reference 1). The online analyzer measured one sample every four minutes while the ALBM system required about six minutes per sample. The recent statistical studies conducted by Defense Waste Processing Technical(DWPT), Applied Statistics Group (ASG) and ADS show that the ALBM system is capable of excellent precision and accuracy even under process conditions. In summary, the ASG report documents that the ALBM is capable of making bias free benzene measurements in the needed concentration range. The statistical study also provides an evaluation of instrument calibration, a comparison of synthetic and process solutions, and documentation of process studies. With the current ALBM, the $95 \%$ confidence interval for a $30 \mathrm{ppm}$ standard is 28.9 to $32.0 \mathrm{ppm}$.

\section{DISCUSSION}

Operation of the online and ALBM systems are based upon the same principles:

1. Volatile organic componds can be purged from aqueous solutions using air or other gases.

2. For fixed volumes of liquid and gas, the vapor concentration of a volatile organic has an equilibrium value.

3. The equilibrium concentration of volatile organic in the confined space above a solution is related to the initial concentration of volatile organic in solution.

The benzene concentration of PHA cannot be measured directly in the sample solution by absorption spectrophotometry because not enough light can get through the sample solution (too black). To get around this problem, the ALBM uses a pump to recirculate air through the liquid sample in closed loop. The air containing purged benzene vapor is continuously pumped through an optical cell and back into the sample container where it bubbles through the sample solution (Figure 3). This process is called a "Recycling Purge". The UV spectrum of benzene is very unique(Figure 4) and can be readily identified for quantitation using an ultravioletvisible (UV-Vis) spectrophotometer. The concentration of benzene in a sample is directly related to the amount of UV light absorbed at certain wavelengths as light passes through the optical cell. Figure 5 explains the principles used in absorption spectrophotometry for calculating component concentrations from absorption data.

We can monitor the change in benzene concentration versus time from start of purge sequence(i.e. measurements are started when the recirculating air pump is swiched on). The change in benzene concentration with time is called a purge profile (Figure 6). The purge profile is affected by sample temperature, gas flow rate, salt content of sample and analyzer gas volume. The purge profile can be used to detect leaks in tubing or other analyzer components, because under normal operation the benzene vapor concentration will reach a maximum and stay at this 
level until the system is vented. In a leaking system, the benzene vapor concentration will reach a maximum then decline at a rate determined by the leak size.

The ALBM uses the peanut vial sample container as the purge vessel. In this system, the purge time is set at three times the equilibrium time indicated by purge profiles for a given sample type. This $3 \mathrm{X}$ factor allows for minor differences in sample temeperature, ionic strength and purge gas flow rate. The vapor volume of the ALBM system is about ten times the sample volume. This causes most of the benzene to be extracted from a typical PHA sample ( 90\% at $30 \mathrm{ppm})$. The ALBM's attainable sensitivity and detection limit are functions of 1 ) analyte extraction efficiency/sample volume relationship and 2) the optical cell path length.

The optical cell is maintained at a set temperature $\left( \pm 0.1^{\circ} \mathrm{C}\right)$ above the maximum sample temperature to prevent condensation of sample on the optical cell windows. Condensation on optical components causes scattering of light similar to fogging-up a bathroom mirror. Increasing optical cell temperature above the maximum dew point has a negative effect of reducing the benzene absorption signal. Observation of the online system benzene measurements plotted against time, before temperature control was stabilized $\left( \pm 5^{\circ} \mathrm{C}\right.$ swings), revealed a sawtooth pattern that correlates with optical cell temperature. As optical cell temperature increased, the measured benzene concentration decreased thus demonstrating an inverse relationship between absorption signal and optical cell temperature. Benzene absorption, in the expected concentration range (up to $100 \mathrm{ppm}$ in solution) is linear with concentration(Figure 7). Because samples in this concentration range behave acording to Beer's Law, increasing path length will give lower detection limits and greater sensitivity. Air flow through the optical cell is stopped for absorption measurements except when collecting a purge profile.

The pump used to move the air/benzene mix through the ALBM is a minature diaphram pump. The diaphram and seals are made of viton and the other wetted components are Kynar. This pump operates on $6-12 \mathrm{VDC}$ for flow control. Pump speed is set to minimize transfer of sample solutions from the purge vessel into the sample vial interface which also serves as a vapor-liquid separator. Connections between the pump, optical cell, and sample vial interface are made with aproximately $3 / 32$ inch inside diameter(ID) Viton tubing(\#14). This size allows excellent friction fit with $1 / 8$ inch outside diameter $(O D)$ stainless steel tubing. The optical cell (Figure 8) and sample vial interface (Figure 9) are manufactured from stainless steel and have Swagelok tube connections for analyzer plumbing. The purge tube is fitted with a $2 \mu \mathrm{M}$ stainless steel frit supplied by Mott Metalurgical Supply Company to produce small air bubbles. This process reduces the time required for benzene to reach equilibrium in the vapor space.

The connections to the optical cell are 1/8 inch tubing for air/benzene flow and $1 / 2$ inch Swagelok stainless fittings for fiber optic lens assemblies. The fiber optic lens assembly (Figure 10) provides a seal for the optical cell and allows light from the fiber optic to pass through the air/benzene mix. Light from a UV-Vis lighi source (located outside the cell) is focused onto the end of a fiber optic. This fiber optic is 
run into the shielded cell and attached to the first lens assembly. Light from this fiber is columnated by the lens, travels through the optical cell and is refocused by a second lens onto another fiber optic. The second fiber optic is attached to a Diode Array Spectrophotometer(DAS) on the outside of the shielded cell. The DAS(Hewlett Packard 8452), IBM PC compatible computer, pump power supply \& temperature control (supplied by SRTC Equipment Engineering Section), and light source are housed in a single cabinet outside the shielded cell. For UV measurement applications, the current spectrophotometer is limited to about 20 meters of fiber optic cable in each direction(i.e. a total of $40 \mathrm{M}$ ).

Cables from the optical cell temperature control and pump power are run into the shielded cell along with the fiber optics. The optical cell is heated with two 150 watt cartridge heaters that operate on 110 volt(v) alternating current(AC). The optical cell temperature is measured by a Resistance Temperature Detector(RTD) and controlled with a proportional temperature controller (Figure 11). Temperature is maintained independentally without input from DAS or computer. The pump is switched on/off by using pin \#25 of the DAS serial part. This pin of the DAS is software controlled, and allows $+5 \mathrm{v}$ direct current(DC) supplied on another pin of the serial interface to complete a circuit to ground when closed. Completing this circuit closes a relay to supply current at selected voltage to the air pump (Figure 11).

An IBM Industrial Computer with HPIB (IEEE-488) interface controls the DAS. Any IBM PC compatible computer may be used although a $16 \mathrm{MHz}$ or faster machine with math coprocessor is recommended. Sample absorbance data and instrument control signals are passed back and forth via the HPIB interface. Sample measurements are made based upon software set-up parameters. These parameters include wavelength range, integration time, and number of scans for the spectrophotometer. The spectrophotometer uses this data to control a shutter on the UV-Vis light source.

The ALBM measures the absorption signal of benzene between a wavelength range of approximately 240 and 270 nanomenters(nM). The light source is a deuterium lamp that has high UV output between 190 and $350 \mathrm{nM}$ (Figure 12). This lamp is held in a housing that allows alignment of the lamp filament so that light can be aligned and focused with appropriate spot size on a fiber optic. The spectrophotometer shutter is mounted between the focusing optics and the fiber optic adapter. The lamp is provided with a power supply that provides very stable light intensity. This type lamp typically has a 1500 hour lifetime and a one year shelf life. Alignment and focusing of the light source is aided by software supplied with the ALBM.

The software used on this analyzer is a revision of code used for several years at SRTC. This program provides many options for system operation, but has been adapted for specific user interface needed by the ALBM. In general, this code (1) reads instrument setup parameters from disk, (2) requests necessary user input like sample identification, number of samples and timing information for start of analysis then (3) controls sample measurement sequence and (4) calculates benzene 
concentration from absorption spectrum. Benzene concentration is calculated based upon a Principle Component Regression(PCR) model calculated during instrument calibration. The PCR model is essentially a multidimensional calibration curve that compensates for the effects of other sample constituents on benzene concentration.

Calibration of ALBM will not be needed on a frequent basis. Because absorption spectrophotomety uses a ratio technique, corrections are continously made for changes in lamp intensity, plus fiber and other optical changes. A new calibration may be required to compensate for changes in system configuration like replacing spectrophotometer or optical cell. Other changes like lamp, fibers, pump, shutter or compuer should not require a new calibration. The process of building calibration models for prediction of unknown samples' benzene concentration includes data processing to enhance the benzene signal.

Because the benzene signal has relatively narrow peaks, a second derivative can be used to separate benzene signal from large slowly charging background signal (Figure 13). This improves the quality of benzene measurements especially in the presence of other organic va "urs like formic acid. Since this type model uses many different wavelengths to $\mathrm{co}_{2} \mathrm{~L}_{\mathrm{B}}, \mathrm{is}$ a benzene concentration, the computer is able to provide a warning signal when the measured spectra do not "look" like benzene. Compounds similar to benzene like toluene or phenol have very different absorption spectra(Figure 4) and would produce a large residual ratio. The residual signal is a goodness of fit statistic used to alert operators of possible interfering chemicals.

Samples are measured on the ALBM according to the following general steps:

1) Sample is collected using the normal Hydragard ${ }^{\mathrm{TM}}$ sampler then placed one at a time in the ALBM sample vial holder.

2) The ALBM computer is provided with the sample ID and told to initiate measurement sequence. The instrument begins by making a reference measusrment with air containing no benzene in the optical cell.

3) The operator is prompted to raise the sample holder using a lever action like found on the Hydragard ${ }^{\mathrm{TM}}$ sampler. This engages the sample vial with the ALBM sample vial interface, and the sample analysis is started.

4) The sample is purged by recirculating air through the sample. An absorption spectrum of benzene in air is measured after a set purge time, and this spectrum is used to calculate sample benzene concentration.

This same data collection sequence is followed for each sample. When standards are measured for instrument calibration, the absorption spectrum is saved on disk for later calculation of a calibration model. Software for creating calibration models also runs on the IBM PC or compatible computer. To maintain QC charts, a standard is substituted for a sample in the above sequence and analyzed in the same manner as a sample. 
liormal operation of the ALBM should include analysis of QC standards. The most logical concentration of standard to assure excellent instrument performance is 30 $\mathrm{ppm}$ because this is the benzene level established for the safe transfer of PHA from PR to PRBT. Standards prepared in $10 \%$ methanol solution have been shown to have similar characteristics to standards prepared in PHA(Reference 1). The first step in preparation of these standards is dilution of pure benzene to approximately $1760 \mathrm{ppm}$ in pure methanol( 1 part in 50). This allows preparation of $30 \mathrm{ppm}$ standard by addition of approximately $3.4 \mathrm{ml}$ stock solution for $200 \mathrm{~mL}$ of standard. These standards are stable for at least two (2) hours when kept in peanut vials with viton solid septa and nearly zero head space. The $1760 \mathrm{ppm}$ stock solution has been stored for up to 2 weeks in a freezer without noticeable change.

Operating experience and system evaluation conducted at TNX has provided excellent operational insight. The primary component of error that must be controlled by procedures is filling of the sample vial. Visual checks and/or solution mass checks should be used to make sure vials are filled within specified limits. Small variations in sample volume will not cause measurements to exceed control limits when peanut vials are completely filled. The fill volume is a parameter that must be matched with calibration because fill volume affects vapor/gas volume, total benzene available for purge and air extraction efficiency. Efforts to correct for these volume changes(i.e. half filled vials) have not been effective.

As currently used at TNX, the ALBM does not produce any waste other than the samples themselves. Therefore, this instrument has the added benefits of supporting waste minimization and the resulting cost savings over solvent extraction methods. The components selected for use in the shielded cells should be functional at high dose rates for reasonable lengths of time (up to 50 megarads for lenses). This system shows promise for being packaged with a very small footprint design that can be maintained for daily operation.

The next ALBM model (beta test unit) will incorporate features necessary for shield cell installation and maintenance. These fixtures include:

1. Individual components with weights $<12 \mathrm{lbs}$.

2. Quick disconnect fittings for power/control cables.

3. Sealed components for corrosion protection of motor windings, etc.

4. Longer pathlength optical cell with $1 / 2$ " diameter light path.

5. Wing nuts for access to in cell system components.

6. Customized software based upon DWPF operating requirements.

7. Use of a faster(386) PC compatible computer.

The changes in optical cell(\#4 above) are desirable because: 1 ) The current system uses an air volume expander tube to improve air extraction efficiency. This additional volume is better used in the optical cell. 2) Increasing light path diameter will improve light throughput thus allowing a longer pathlength and faster measurements. 3) The increased path length will help improve analyzer sensitivity and detection limit. However, the pathlength will also have to be balanced with required length and quality of fiber optic cable to be used. To circumvent this 
difficulty, a different spectrophotometer and detector could be substituted for the Hewlett Packard DAS. Use of this improved detector will allow extension of fiber optic beyond the present 20 meter limit.

Additional work should be done before completion of the ALBM Beta te nodel to optimize the system vapor volume. Some adjustment of this parameter is provided by the optical cell light path diameter and length; however, these dimensions must be balanced against the limits given for component size and weight that can be moved into the shielded cells. Optimum vapor volume can be measured using the current ALBM and then divided between the optical cell and sample interface during design of the beta test unit.

At present, we view use of this system like any other lab instrument for QA purposes. The software is docuniented by comments in source code and a manuscript user's manual (Reference 6), and the system reliability will be checked by repeat measurements of QC standards. 


\section{REFERENCES}

1. Statistical Analyses of the At-line Benzene Monitor Study (U), SCS-ASG92066, T.B. Edwards, September 1991.

2. SRAT and PRBT Vapor Flamability... WSRC-RP-90-0793, R.A. Jacobs, June 1991.

3. Vapor pressure of Benzene over Acid Hydrolysis Product WSRC-TR-91-165 D.D. Walker, April 1991.

4. Online Fiber-Optic Spectrophotometry DP-MS-88-186, D.R. VanHare et al, February 1989.

5. Technical Basis for "Work-Around" PR Sampler WSRC-RP-92-852, W.J. Jenkins, June 1992.

6. SRS Instrument Control and Data Reduction Programs Manual WSRC-TR91-0103, B.R. Buchanan et al, July 1991.

7. Ultraviolet Spectra of Aromatic Compounds, Robert Friedel \& Milton Orchin, John Wiley \& Sons, 1951.

8. Laboratory Notebook, WSRC-NB-92-44, R.R. Livingston, starting March 1992

\section{LIST OF FIGURES}

\section{FIGURE\#}

1

\section{TITLE}

Online Benzene Monitor System Components

Online Analyzer Sample Interface

Atline Benzene Monitor Sample Interface

UltraViolet Spectra of Atomatic Compounds

Absorption Spectroscopy

Purge Profile for ALBM

Linearity of Purged Benzene

Optical Cell Drawing

Liquid-Vapor Seperator/Sample Vial Interface

Fiber-Optic Lens Assembly

Temp. Pump Control Circuits

Deuterium La:np Spectrum

Benzene Absorption Spectra - 2nd Derrivative

Correction for Background Signal 
FIGURE 1

\section{ONLINE BENZENE MONITOR SYSTEM COMPONENTS}

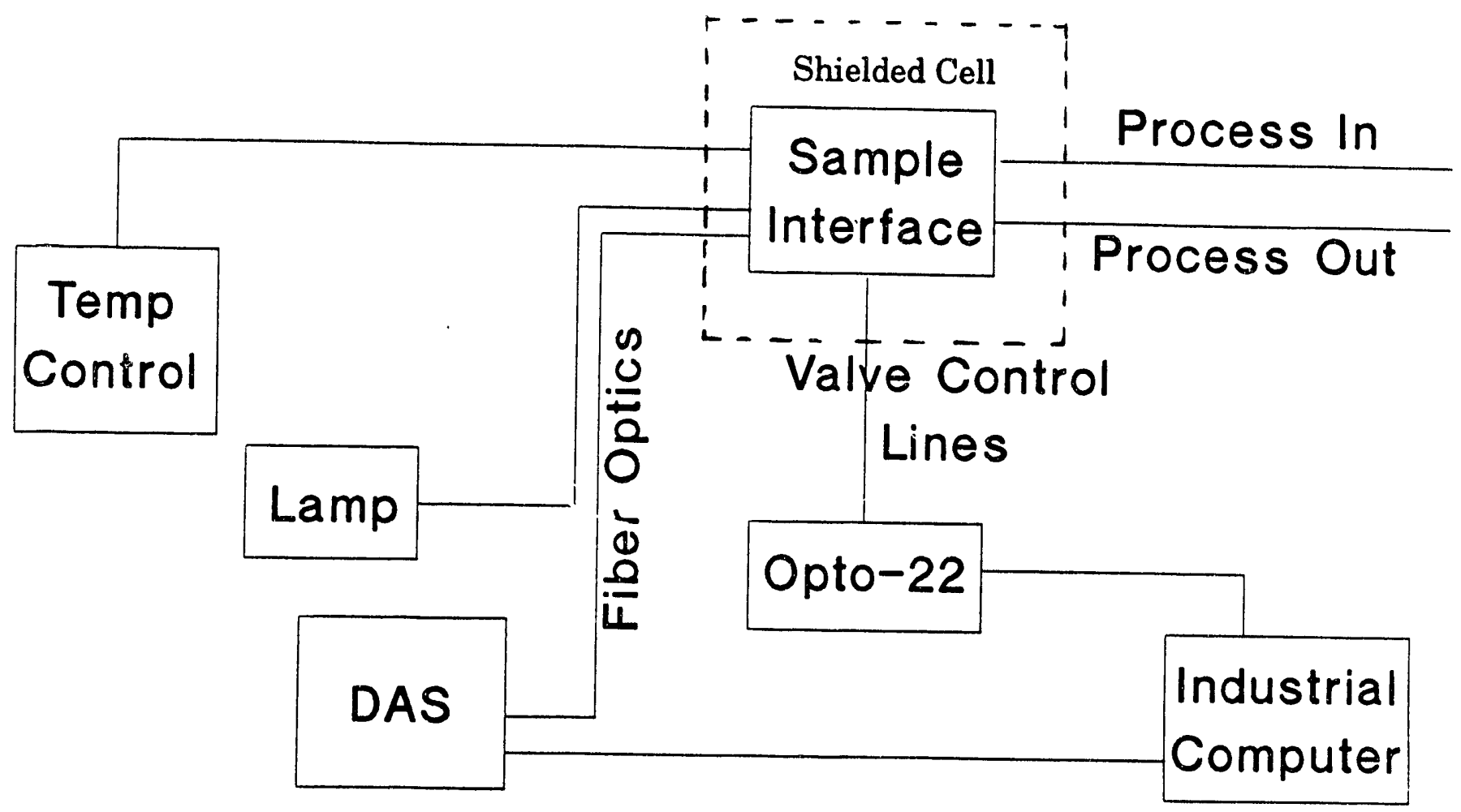




\section{FIGURE 2}

\section{ONLINE ANALYZER SAMPLE INTERFACE}

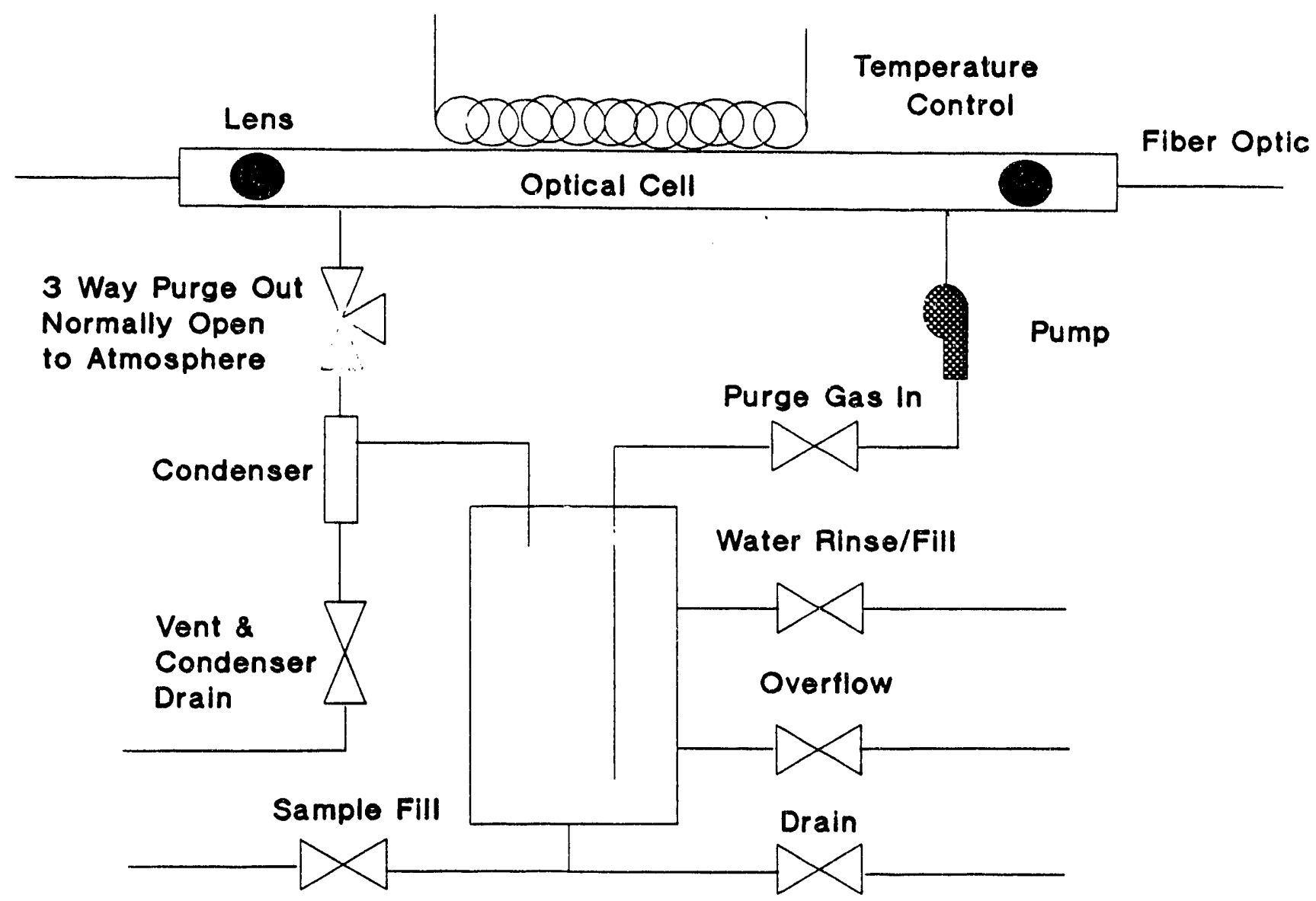


FIGURE 3

\section{ATLINE BENZENE MONITOR SAMPLE INTERFACE}

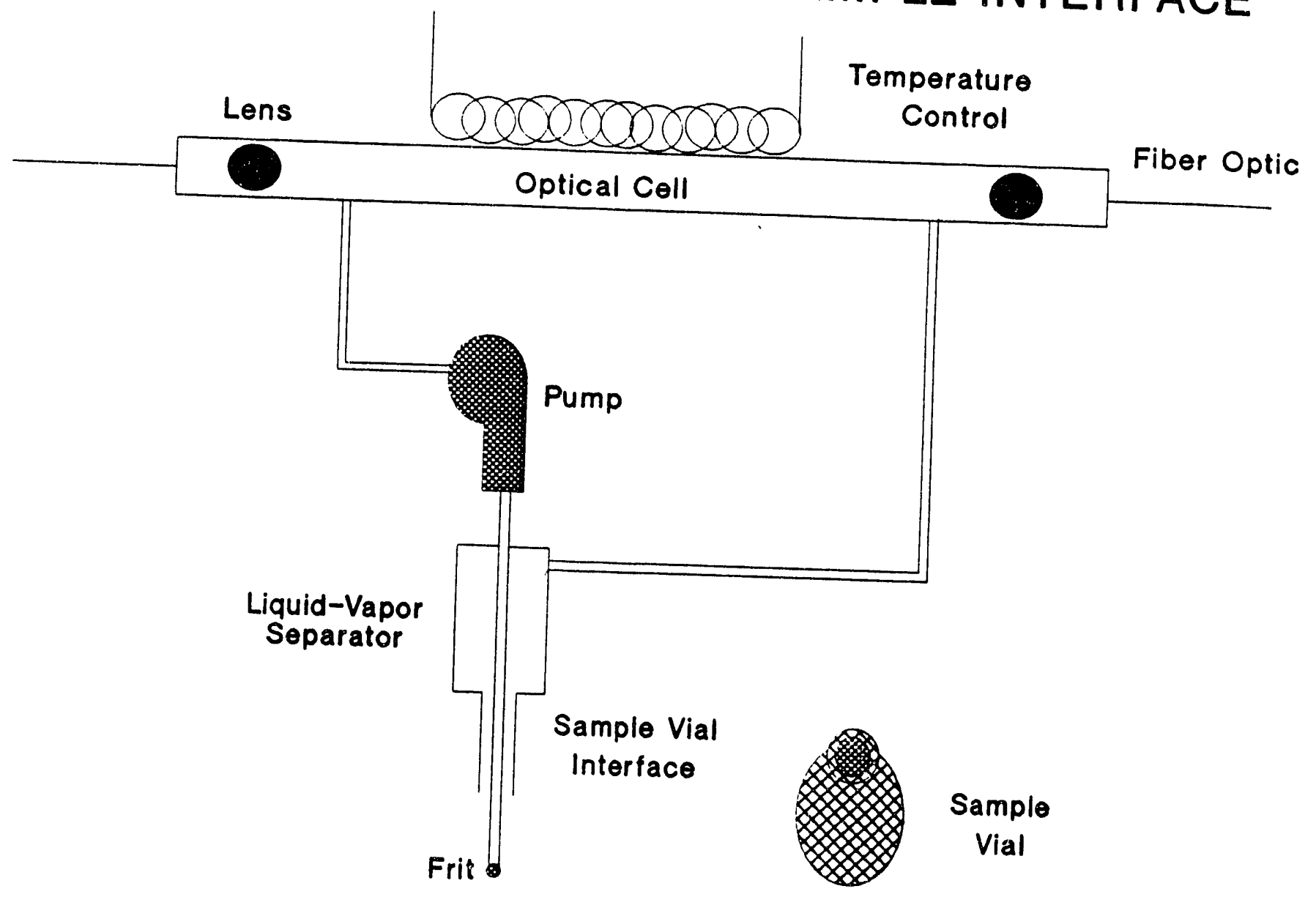




\section{FIGURE 4}

\section{UltraViolet Spectra of Atomatic Compounds}
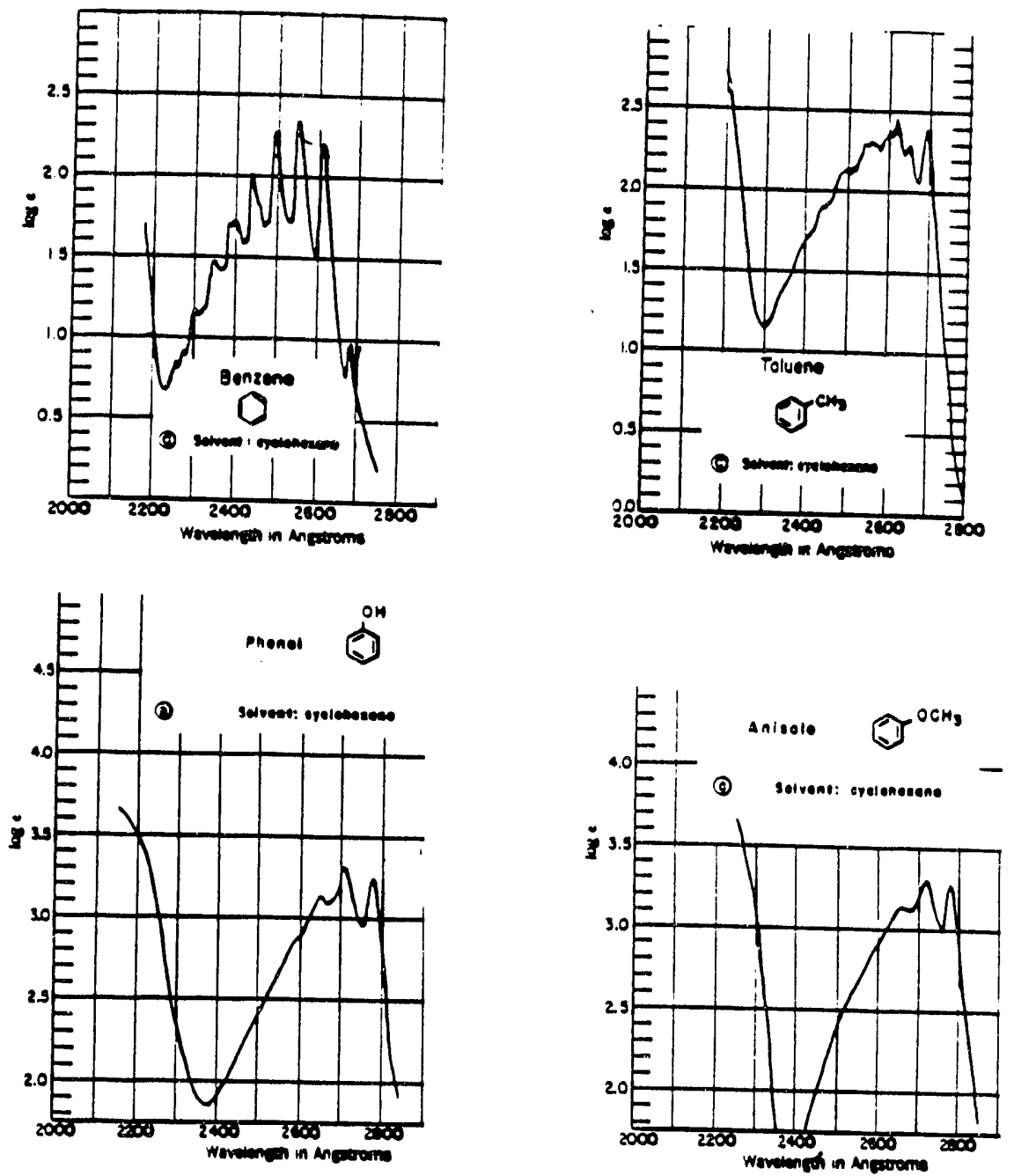
FIGURE 5

\section{Absorption Spectroscopy $A(v)=-\log \left(I(v) / I_{0}(v)\right)$}

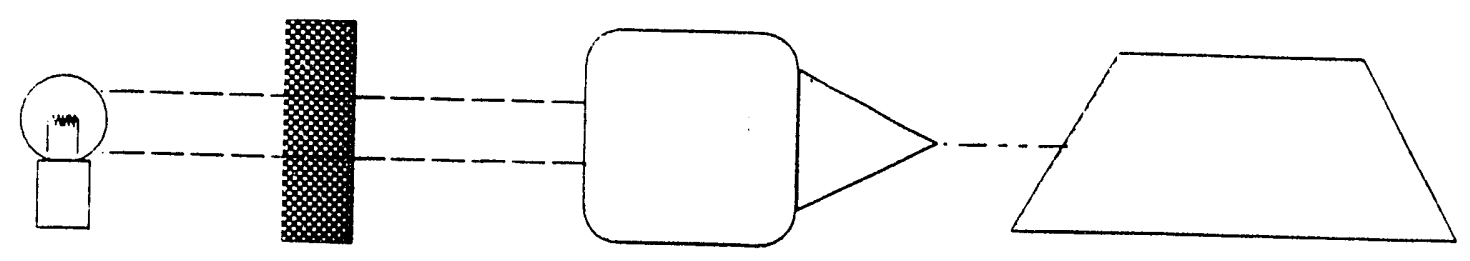

Light Sample Detector Interpreter

$$
\text { Conc. }=A(v) * E(v) / \text { Pathlength }
$$

Measure Intensity of light at many colors without sample present - $I_{0}(v)$ and with sample present -- I(v) 


\section{FIGURE 6}

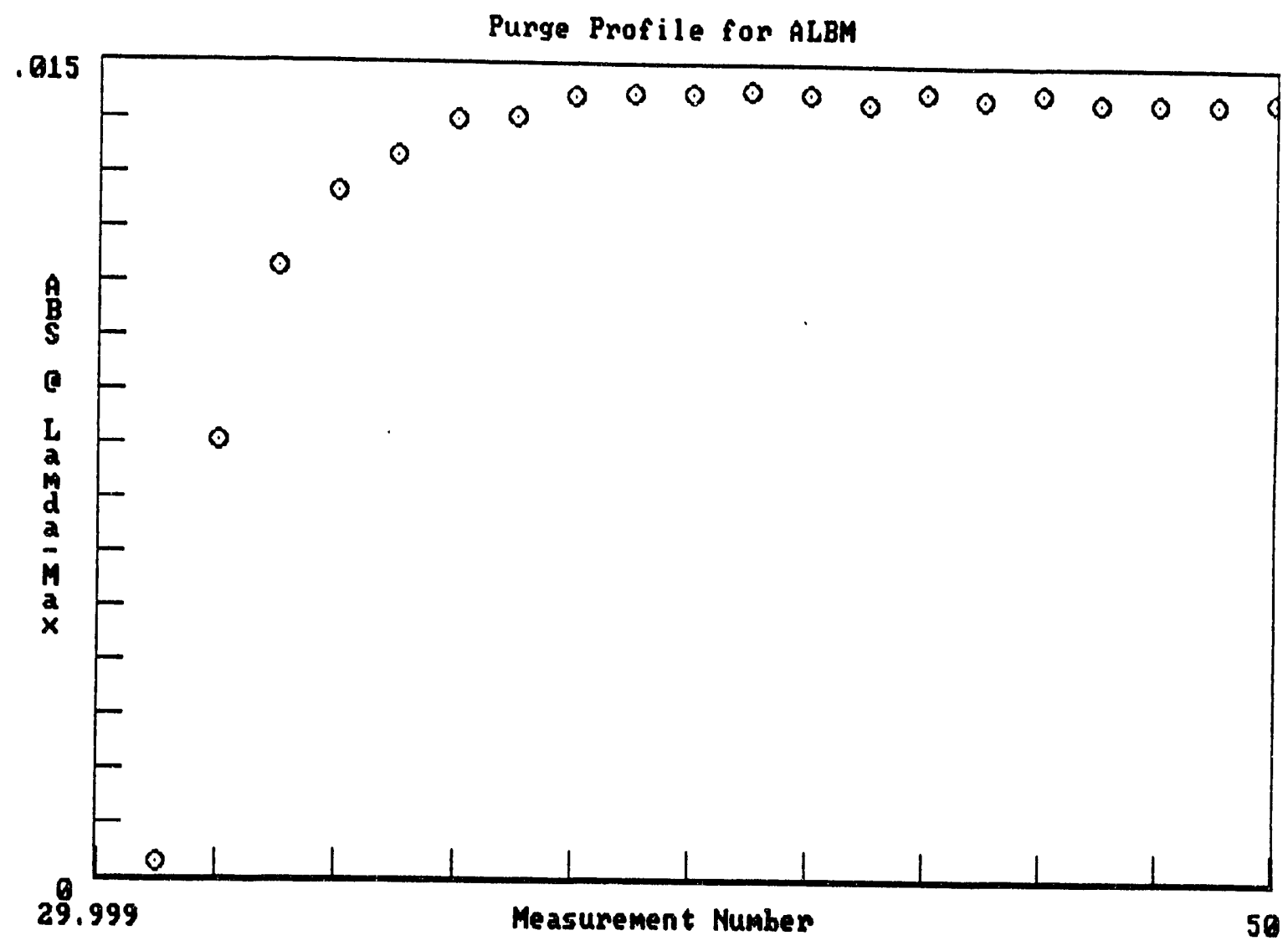

1Plot 2Math 3Select 4MLR 5CLS 6PCR TPLS 8Predic 9Save 10EXIT 


\section{FIGURE 7}

\section{Linearity of Purged Benzene}

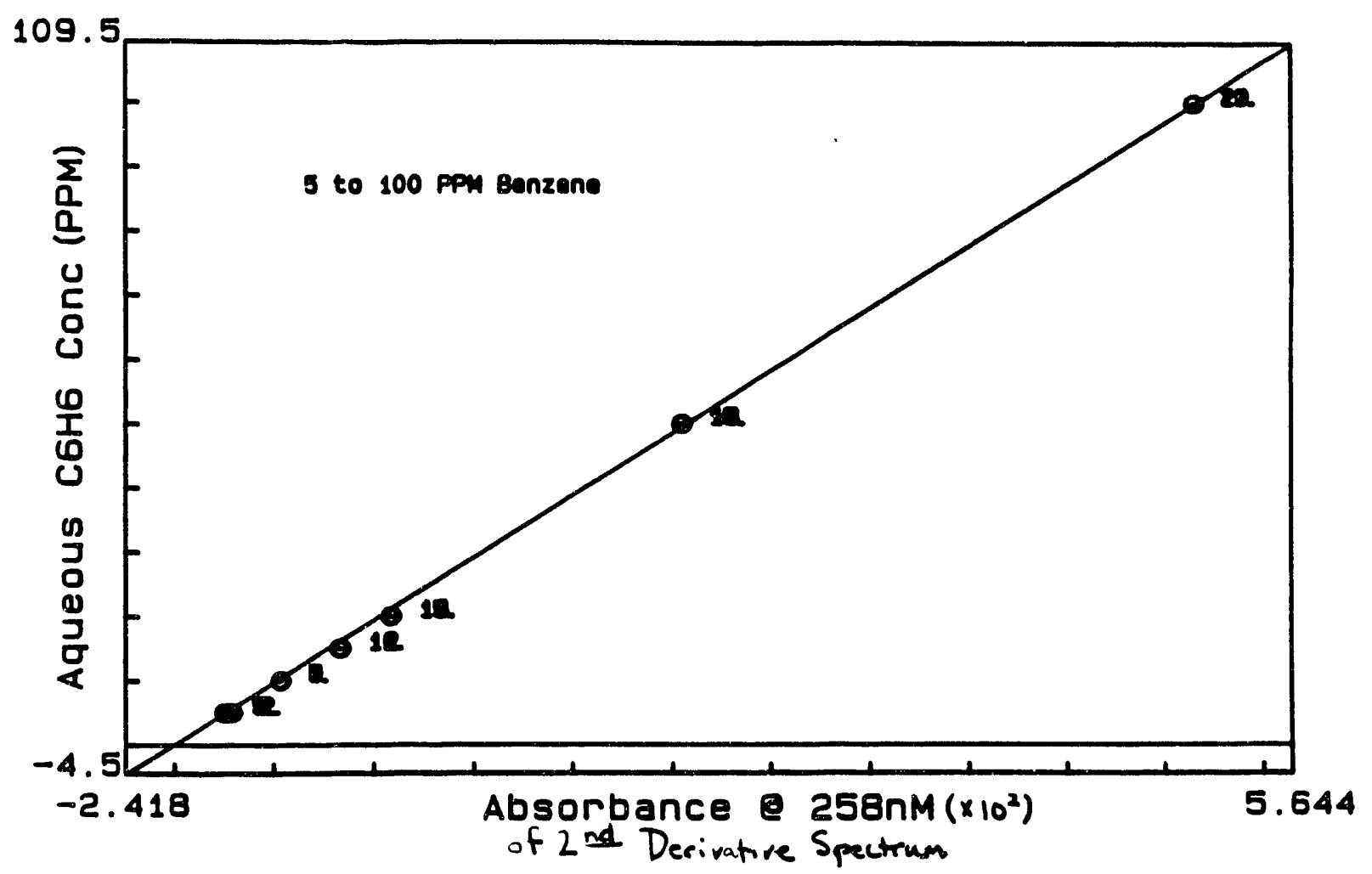




\section{FIGURE 8}

\section{Optical Cell Drawing}

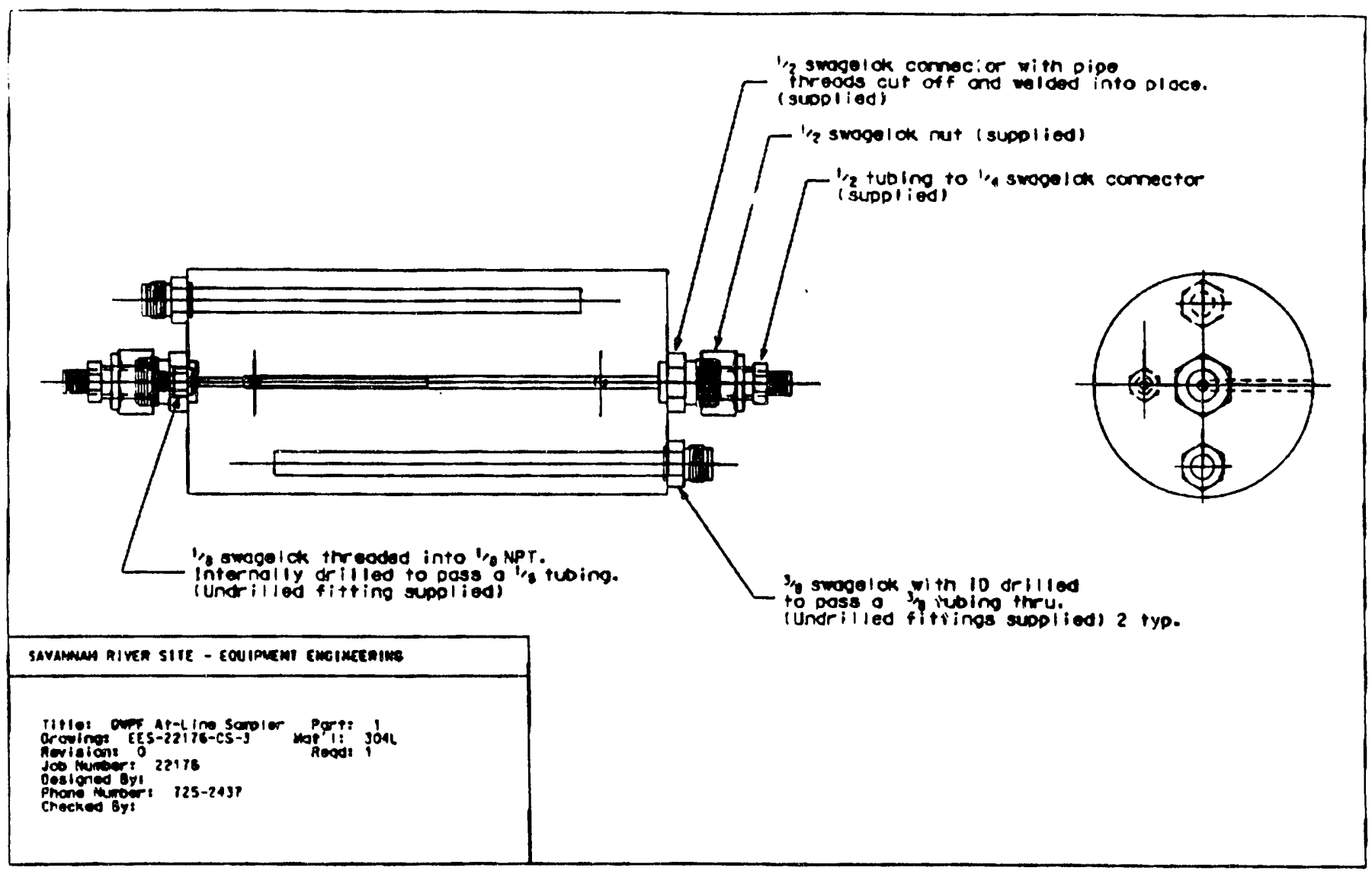

rue, sep 29, 1997. 1:43:J6 AH 


\section{FIGURE 9}

\section{Liquid-Vapor Separator}

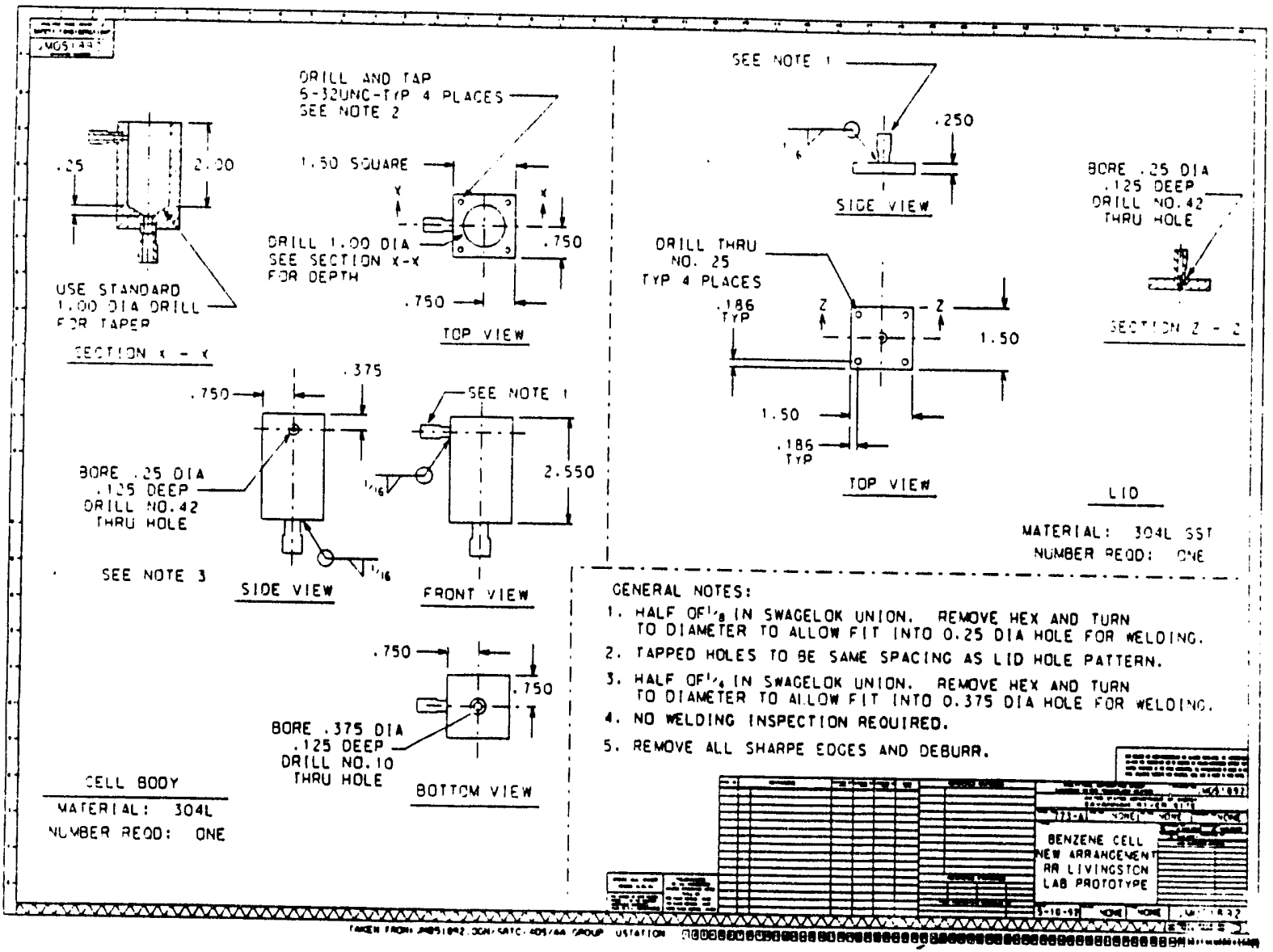




\section{FIGURE 10}

\section{Fiber-Optic Lens Assembly}

Teflon heat shrink tubing

(FEP AWG-0)
$1 / 4^{\prime \prime}-1 / 2^{\prime \prime}$ Swagelok Reducer (\# 400-R-8-S/S)

\section{$0.44^{\prime \prime} 1 D-.012^{\prime \prime}$ recovered wall}

Stainless Steel

SMA short adapter (OFTI \# 300-45MA-2210)
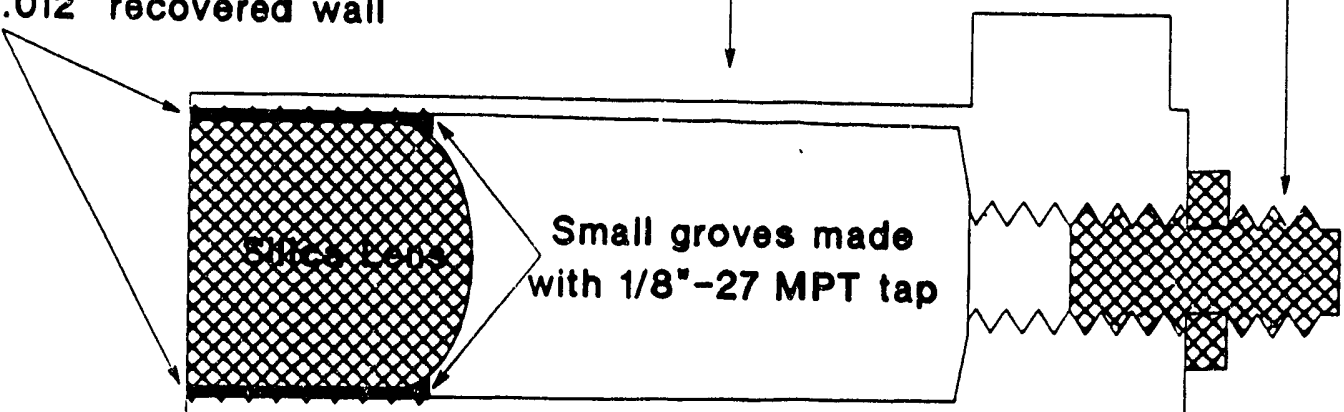

$1.142^{\prime \prime}+1-.004^{\prime \prime}$ $(29.0 \mathrm{~mm}+/-.1 \mathrm{~mm})$

(1). Mount $1 / 2^{\prime \prime}$ barrel of reducer in lathe - remove $1 / 4^{\prime \prime}$ fitting

(2). Drill and tap reducer for 1/4-36 tap - install SMA adapter

(3). Ream inside of reducer with \#8 tapered ream (.3971-.5050)

(4). Tap 1/2" reducer with 1/8" MPT tap

(5). Smooth ID of reducer with 450 grit emory cloth

(6). Srink TEFLON tubing on lens and trim

(7). Press lens and tubing into reducer until flush

(8). Heat assembly to 150 deg $C$ - then press lens into reducer again

(9). Repeat step \#8 until lens no longer creeps during heating 


\section{FIGURE 11}

\section{Temperature \& Pump Control Circuits}

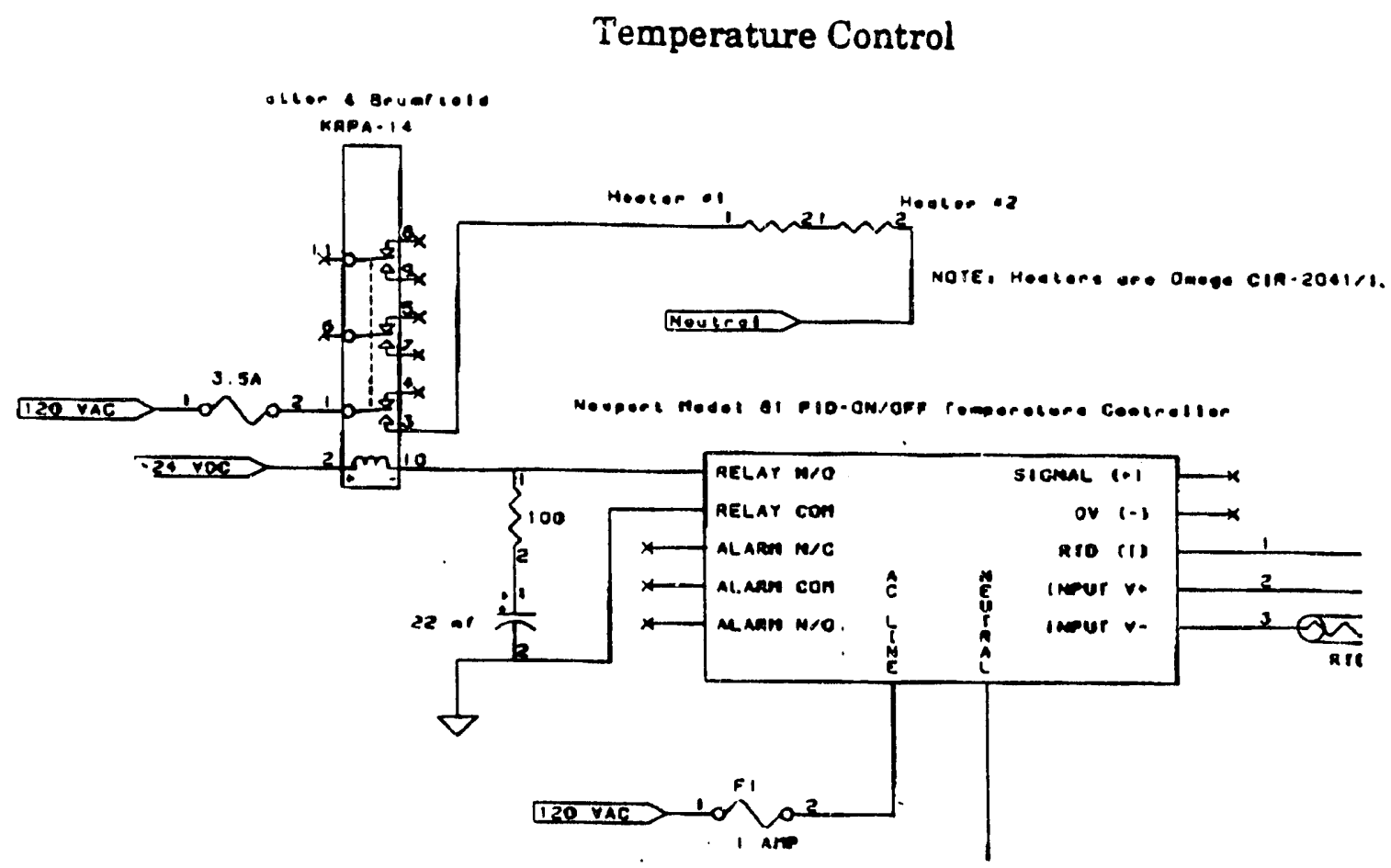

Pump Control

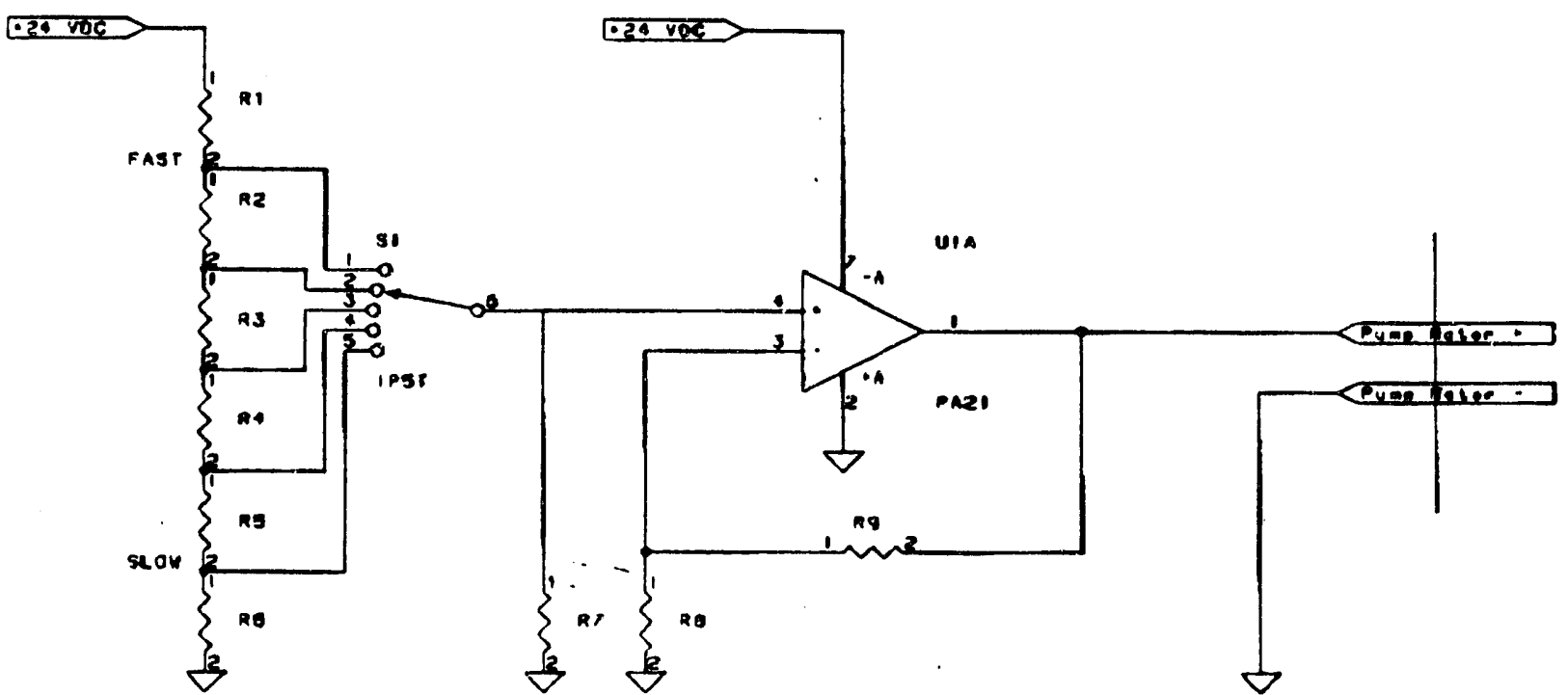




\section{FIGURE 12}

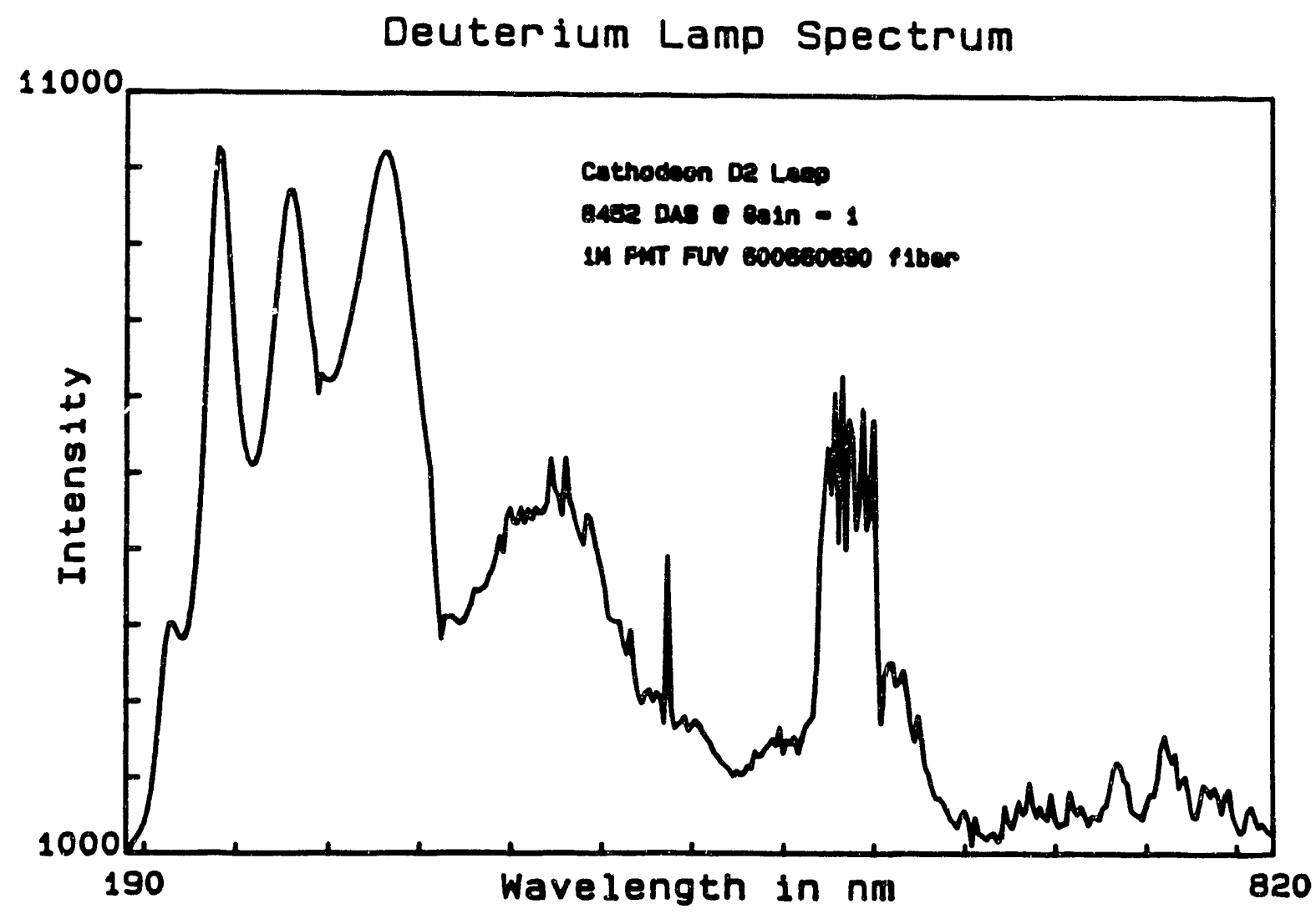




\section{FIGURE 13}

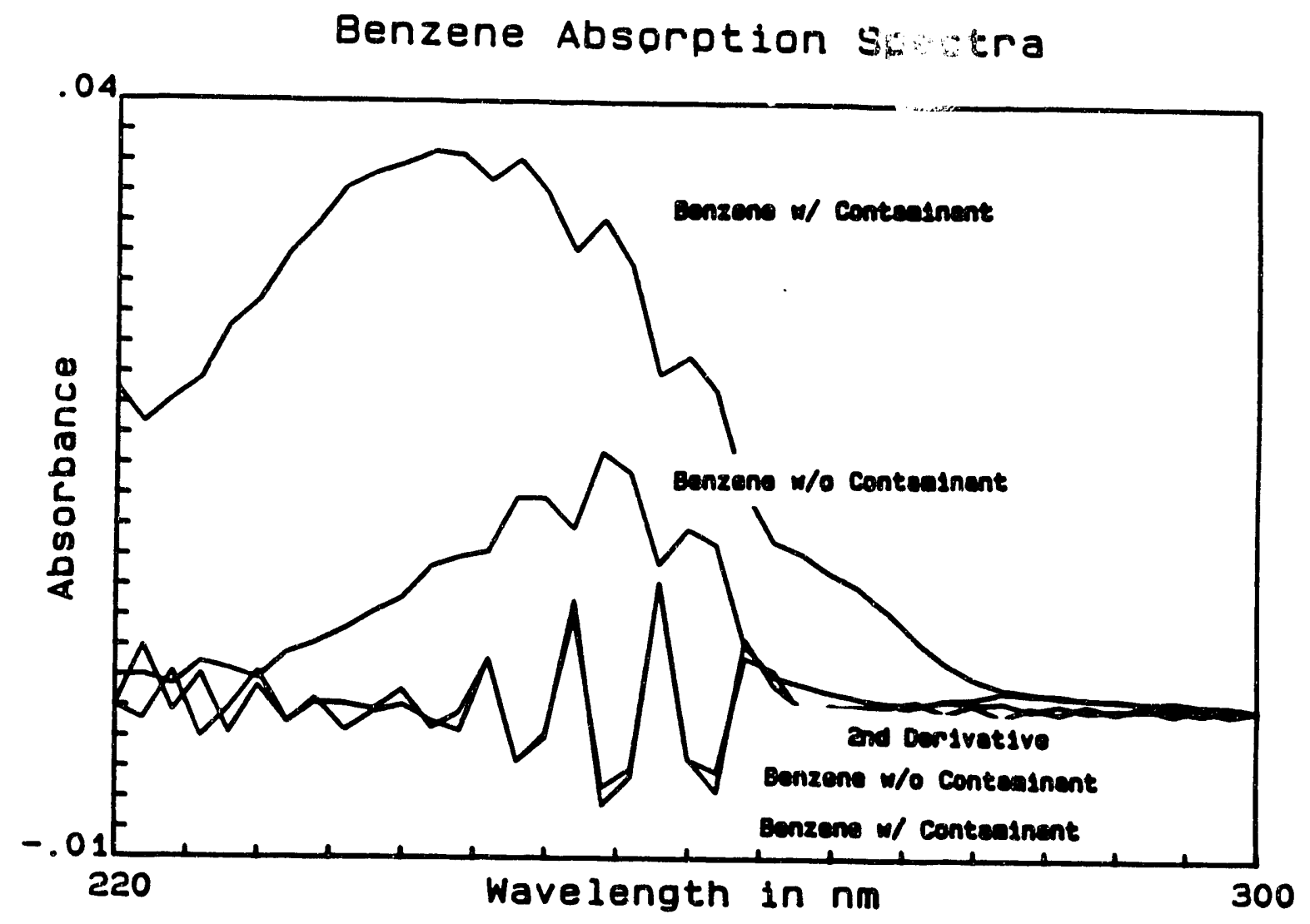


INTER-OFFICE MEMORANDUM

Westinghouse Savannah River Company

NRTSC

Technology

On Time

On Target

SCS-ASG-92066

Task 92-022-0

Non-critical Data

September 16, 1992

To:

W.J. Jenkin 704-1T, Rm 210

From:

T. B. Edwards,

773-42A, Rm 125

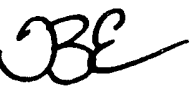

$\infty:$

\begin{tabular}{|c|c|c|c|c|c|}
\hline $\begin{array}{l}\text { M.A. } \\
\text { J.T. } \\
\text { R.E. } \\
\text { C.W. } \\
\text { R.R. } \\
\text { P.E. } \\
\text { C.T. }\end{array}$ & $\begin{array}{l}\text { Baich, } \\
\text { Carter, } \\
\text { Eibling, } \\
\text { Jenkins, } \\
\text { Livingston, } \\
\text { O'Rourke, } \\
\text { Randall, } \\
\text { - }\end{array}$ & $\begin{array}{l}704-T \\
704-1 T \\
704-T \\
773-A \\
773-A \\
773-A \\
704-T\end{array}$ & $\begin{array}{l}\text { M.R. } \\
\text { C. E. } \\
\text { E.W. } \\
\text { L.F. } \\
\text { J.C. } \\
\text { J.R. } \\
\text { C.P. }\end{array}$ & $\begin{array}{l}\text { Buckner, } \\
\text { Coffey, } \\
\text { Holtzscheiter } \\
\text { Landon, } \\
\text { Marek, } \\
\text { Pelfrey, } \\
\text { Reeve, }\end{array}$ & $\begin{array}{l}773-A \\
773-A \\
r, 773-A \\
704-1 T \\
704-T \\
773-42 A \\
773-42 A\end{array}$ \\
\hline
\end{tabular}

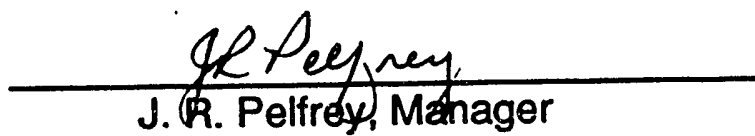

Date:

$9.28-92$

\section{STATISTICAL ANALYSES OF THE AT-LINE BENZENE MONITOR STUDY (U)}

\section{Summary}

The experiments outlined in this report have provided an opportunity to gain valuable insight into the calibration and use of the At-line Benzene Monitor (ALBM). This report describes the statistical analyses completed in support of these experiments. Factors affecting the calibration process such as solution matrix and sample temperature have been investigated. Repeatability studies indicate a consistent set of ALBM values for each sample even with as few as five measurements. The process of preparing benzene standards was also 
investigated. Standards prepared using a solution matrix of $10 \%$ methanol were found to be stable for least a two hour period, which is thought to be sufficient time for use during calibrations and calibration checks.

The ALBM, after being calibrated using $10 \%$ methanol standards, performed well in analyzing samples prepared using a Precipitate Hydrolysis Aqueous (PHA) solution matrix. A linear calibration curve was found to fit these data well. Such a calibration curve can be used to determine a lower prediction limit for ALBM measurements corresponding to a true benzene concentration of 30 parts per million (ppm). For the example of the $10 \%$ methanol calibration used in this study, a tower $99 \%$ limit for the ALBM value corresponding to a $30 \mathrm{ppm}$ benzene in PHA standard is $28.5 \mathrm{ppm}$.

It is recommended that the Applied Statistics Group (ASG) work with the Analytical Development Section (ADS) to provide further statistical support for the ALBM. Statistical control charts or methodologies should be implemented as part of the procedures used for calibrations and calibration checks. Operational procedures can also benefit from the use of statistics. Control charts for repeatability of ALBM measurements of a given sample should be developed. A lower prediction limit on the ALBM measurement for a true benzene level of $30 \mathrm{ppm}$ can be used to develop appropriate operational limits for the Precipitate Reactor (PR) based on the ALBM measurements.

\section{Introduction}

Over the course of the past few weeks, a great deal of work has been completed on the prototype At-line Benzene Monitor (ALBM) which is being developed by the Analytical Development Section (ADS) of SRTC for use at DWPF. Personnel from the Applied Statistics Group (ASG) and DWPT along with those from ADS have been working on the evaluation of this monitor and methods for its calibration and use.

This report traces through the statistical analyses that have been conducted to support this evaluation effort. These analyses were completed in several phases; each of which will be discussed below.

JMP for the Apple Macintosh personal computer and SAS-PC for the IBM personal computer were used during these analyses. Both of these statistical software packages are by SAS Institute Inc.

\section{Statistical Analyses}

Phase 1. Initial Calibration using Wate: Solution Matrix

A calibration of the monitor was completed by the Analytical

Development Section (ADS) using a water solution matrix, samples at 
82 degrees Fahrenheit $\left({ }^{\circ} \mathrm{F}\right)$ and standards at four benzene concentrations $(0,5,30$, and 75 parts per million).

A set of seven standards were then prepared and analyzed by ADS. These standards were prepared using a water solution matrix; they were analyzed using the ALBM at low $\left(80^{\circ} \mathrm{F}\right)$ and high $\left(140^{\circ} \mathrm{F}\right)$ sample temperatures. Eleven ALBM measurements of the benzene in parts per million (ppm) were recorded for each standard. These data were provided to ASG for analysis and are given in Table 1.1 of Appendix A.

Repeatability of the Measurements

The repeatability of the measurements from the ALBM for each standard was investigated. The standard deviation of the repeated measurements for each standard at each sample temperature (which will be called a set) appears in Table 1.2 of Appendix A. Statistical tests that these variances are equal across all the sets, provided in Table 1.3 of Appendix A, indicate that there are significant differences among the sets. Measurements taken at the higher sample temperature are judged to have equal variances since the Prob>F values are greater than 0.05 . Lower sample temperature seems to lead to more variability within the repeated measurements. However, the largest standard deviation within a set of repeat measurements is only $0.16 \mathrm{ppm}$.

\section{Calibration Curve}

Calibration curves, which were linear and quadratic in the standard concentration and which included sample temperature, were investigated. The average benzene values in ppm for the sets of repeated measurements were used in this part of the study. Table 1.4 in Appendix A provides the results from the quadratic fit. Each of the parameters in the model is seen to be statistically significant at the $5 \%$ level since their corresponding values in the Probs|t| column are all less than 0.05 . The root mean square error is $0.14 \mathrm{ppm}$. The root mean square error is a measure of the scatter about the calibration curve.

\section{Predicted Benzene Measurements}

Table 1.5 in Appendix A shows predicted benzene measurements and the associated prediction limits for standard concentration and sample temperature combinations using the quadratic calibration curve. These prediction intervals are at the $95 \%$ confidence level. 
Thus, the interval $(21.4,22.2)$ is a $95 \%$ prediction interval for the ALBM value corresponding to a true benzene level of $30 \mathrm{ppm}$ when the sample temperature is at $140^{\circ} \mathrm{F}$. The bias seen here was attributed to system modifications and changes in sample volume after water calibration. This bias could have been corrected for within the ALBM and was, therefore, not considered a problem.

Phase 2. First Experimental Design

The next phase of the study involved an investigation into factors thought to have an effect on the calibration and measurement processes. These factors were identified as the solution matrix, sample temperature, optical cell temperature, and benzene concentrations of the standards. An experiment was needed to test for and estimate the effects of these factors as well as the following two-way interactions:

solution matrix $\mathrm{x}$ standard concentration,

solution matrix $x$ sample temperature, and

standard concentration $\mathrm{x}$ sample temperature.

Two levels were selected for each of the factors and a replicated, fractional factorial design developed. The levels were:

\section{Low (-1) High (1)}

$\begin{array}{llll}\text { Solution Matrix: } & \text { Water } & \text { PHA } & \\ \text { Sample Temperature: } & 80 & 140 & \text { degrees Fahrenheit } \\ \text { Optical Cell Temperature: } & 85 & 95 & \text { degrees Celsius } \\ \text { Benzene Concentration: } & 10 & 50 & \text { ppm }\end{array}$

The experiment was randomized to support its being conducted over two days. The complete design is provided in Table 2.1 of Appendix A.

\section{Phase 3. Analysis of Experimental Results}

Standards were prepared and analyzed using the ALBM by ADS according to the fractional factorial design outlined in Phase 2. The ALBM calibration was the same as in the Phase 1 study. The resulting data, which are in Table 3.1 of Appendix $A$, were provided to ASG. The summary data by sample is given in Table 3.2 in Appendix A. A variable of interest for this study was the difference between the measured and the standard benzene concentrations (the last two 
columns of Table 3.2 with standards -1 and 1 representing 10 and 50 ppm, respectively).

Significant Factors and Interactions

The data were analyzed using the JMP package and the main effects and interactions were estimated. The results are provided in Table 3.3 of Appendix A. Sample temperature and the solution matrix $x$ standard concentration interaction are each significant at the $5 \%$ level since their respective values in the Probs $|t|$ column are less than 0.05 .

Repeatability of Measurements

Table 3.4 of Appendix A shows that the variability of the repeated ALBM measurements is not the same across all samples as noted by the Prob>F values being less than 0.05 . The largest standard deviation within the repeated measurements for a sample is only 0.85 ppm.

Phase 4. Second Experimental Design and Analysis

A second experiment was designed to investigate the behavior of the ALBM calibrated with a water solution matrix as in Phase 1 when used to analyze standards prepared with other solution matrices. This experiment involved standards prepared with both a $10 \%$ methanol solution matrix and with a precipitate hydrolysis aqueous (PHA) solution matrix. For the $10 \%$ methanol solution matrix, five standards were prepared at each of the following benzene concentrations (in ppm): $0,8.5,30$, and 50. For the PHA solution matrix, 5 standards were prepared at 0 and $30 \mathrm{ppm}$ and 4 standards were prepared at $50 \mathrm{ppm}$. This test was conducted by ADS and the resulting data are provided in Table 4.1 of Appendix A. The purpose of this study was to investigate the stability of the $10 \%$ methanol standards and to study the performance of water solution matrix calibrations in measuring standards prepared with these other solution matrices.

\section{Repeatability of Measurements}

Repeatability of the ALBM for each standard was investigated. Five repeat measurements were recorded for each standard. The variance for each set of five values was computed. Table 4.2 in Appendix A provides the results of a statistical test for equality of 
these variances across all the standards. There is no evidence of statistically significant differences among the variances. The largest standard deviation within a set of repeated measurements is only $0.47 \mathrm{ppm}$.

\section{Calibration Curve}

Calibration curves were determined for the standards prepared with each of the two solution matrices using the summary data provided in Table 4.3 of Appendix A. Both linear and quadratic fits were performed. Tables 4.4 and 4.5 in Appendix A provide these results. These curves indicate that there is a bias in using the ALBM which has been calibrated for a water solution matrix to analyze standards prepared with $10 \%$ methanol or PHA solution matrices. This bias is seen in the estimated coefficient for the linear term for each fit being different from unity and is consistent across the two types of solution matrices. For the linear calibration curves, these estimated coefficients are 1.32 for $10 \%$ methanol and 1.30 for PHA.

\section{Stability of Standards}

Tables 4.6 and 4.7 in Appendix A provide the results of the analysis of the benzene standards over time for $10 \%$ methanol and PHA solution matrices, respectively. A linear regression of the ALBM measurements on time was determined for each standard benzene concentration for each of the two solution matrices. There is no significant linear relationship between these ALBM measurements and time at the $5 \%$ level for any benzene concentration. This is evident by the Prob>F values being greater than 0.05 for each of the regressions. Since there is no problem with stability over the two hour period covered in these data, the standards prepared with a $10 \%$ methanol solution matrix were thought to be suitable for use during calibrations. This type of calibration was conducted for Phase 6 discussed below.

Phase 5. Analysis of Tank Samples

An experiment was designed for spiking the Precipitate Reactor (PR) with benzene and then taking samples from the tank. Table 5.1 in Appendix A provides the data from this test. Samples taken from the PR along with standards prepared with a $10 \%$ methanol solution matrix were analyzed. Table 5.2 in Appendix A provides the summary data from this test. The repeatability of the measurements as well as the behavior of the measurements of the benzene in the tank over time are of interest. The ALBM was calibrated as in Phașe 1. 
During this study, the fact that sample volume is a key component to a quality ALBM measurement was reinforced. The benzene values for some samples were exceptionally low due to the vials being partially filled.

Repeatability of the Measurements

Table 5.3 in Appendix A shows the repeatability of the measurements by giving the standard deviation for measurements from each sample. There is no indication of an inconsistency in the repeatability of these data. The largest standard deviation for repeatability across all the samples is only $0.57 \mathrm{ppm}$.

\section{Time Behavior of the Tank Samples}

The natural logs of the benzene measurements were determined and regressed against the time each sample was taken from the PR in order to investigate loss of benzene from the tank. Table 5.4 in Appendix A provides these results. The estimated time coefficient for the natural log model is -0.119 . The equation for the percent benzene loss is given by:

$$
100\left(1-e^{-0.119 h}\right) \%
$$

where $h$ is in hours. Evaluated at $h=1$, the loss is estimated at $11.2 \%$. From a previous study (references 1 and 2), the benzene loss in the PR had been estimated at about $11 \%$ per hou.r.

Phase 6. Calibration using $10 \%$ Methanol Standards

The ALBM was calibrated using the standards prepared with $10 \%$ methanol solution matrices. The PHA standards data collected in Phase 4 were then re-analyzed. These results are provided in Appendix A in Table 6.1. The purpose of this analysis was to investigate the performance of the ALBM and the corresponding calibration curve after the monitor was calibrated with the $10 \%$ methanol standards.

Repeatability of Measurements

Table 6.2 in Appendix A provides the analysis of the repeatability of these measurements. Five measurements are available, for each 
standard and there is no indication of an inconsistency in the repeatability of these data. The largest standard deviation is only $0.28 \mathrm{ppm}$.

\section{Calibration Curve for PHA Standards}

Tables 6.3 and 6.4 of Appendix A provide the results of the development calibration curves for these data. Both quadratic and linear fits were performed. The second degree coefficient for the quadratic fit is not statistically significant and thus, a linear fit is appropriate. Note that the bias that was evident in the calibration curve from the water solution matrix of Phase 4 has been eliminated. This can be seen in the estimate of the linear term (.98) which is near unity. Also, note that the root mean square error is only $0.67 \mathrm{ppm}$.

\section{Predicted Benzene Measurements}

Table 6.5 in Appendix A provides the predicted ALBM measurements along with their associated prediction limits at the $95 \%$ confidence level for standards of 0,30 and $50 \mathrm{ppm}$. Thus, a 95\% prediction interval for the ALBM measurement corresponding to a true value of $30 \mathrm{ppm}$ is given by $(28.9,32.0)$. A $99 \%$ lower prediction interval for the ALBM value for a true benzene value of $30 \mathrm{ppm}$ can also be determined using the standard error from Table 6.5 of 0.699 and a Student's $t$ value of $t .01,12=2.681$ as follows:

$$
\text { Lower 99\% Limit }=30.44-(2.681 \times 0.699)=28.5
$$

Thus, the ALBM value for a sample with a true benzene level of 30 ppm would be greater than $28.5 \mathrm{ppm}$ at a $99 \%$ confidence level.

\section{Inverse Calibration Problem}

The inverse calibration problem --- predicting the true benzene level for a given ALBM measured value --- was also investigated. Appendix $B$ provides the details of this investigation and Table 6.6 of Appendix $A$ lists the SAS-PC program which implements the approach.

The results are presented in Table 6.7 of Appendix A. An upper prediction limit for the true value, $X$, corresponding to a ALBM value, $Y$, at a $99 \%$ confidence level is provided for values of $Y$ ranging from 4 to $40 \mathrm{ppm}$. For a ALBM value of $28 \mathrm{ppm}$ an upper $99 \%$ prediction limit for the true benzene level would be given by $29.42 \mathrm{ppm}$. 
This equation could be incorporated into the ALBM so that measurement results are given at the upper $99 \%$ confidence level.

\section{Conclusions and Recommendations}

Standards prepared with a solution matrix of $10 \%$ methanol were found to be stable over at least a two hour period, which is thought to be sufficient time for use during calibrations and calibration checks. The ALBM, after being calibrated using $10 \%$ methanol standards, performed well in analyzing samples prepared using a PHA solution matrix. A linear calibration curve was found to fit these data well. Such a calibration curve can be used to determine a lower prediction limit for the ALBM measurement corresponding to a true benzene level of $30 \mathrm{ppm}$.

It is recommended that the Applied Statistics Group (ASG) work with the Analytical Development Section (ADS) to provide further statistical support for the ALBM. Statistical control charts or methodologies should be implemented as part of the procedures used for calibrations and calibration checks. Operational procedures can also benefit from the use of statistics. Control charts for repeatability of ALBM measurements of a given sample should be developed. Lower prediction limits on the ALBM measurement for a true benzene level of $30 \mathrm{ppm}$ can be used to develop appropriate operational limits for the Precipitate Reactor (PR) based on the ALBM measurements.

\section{References}

[1] Jenkins, W. John, WSRC-RP-92-852, "TECHNICAL BASIS FOR WORKAROUND' PR SAMPLER (U)", June 29, 1992.

[2] Reeve, C.P., SCS-ASG-92043, "STATISTICAL ANALYSIS OF BENZENE LOSS DATA (U)", June 25, 1992.

[3] Coleman, Hugh W. and W. Glenn Steele. Experimentation and Uncertainty Analysis for Engineers. John Wiley \& Sons, New York, 1989. 
Appendix A: $\quad$ Tables

Table 1.1: Data from Initial Calibration Study

Table 1.2: Initial Calibration Data Summarized by Vial

Table 1.3: Tests for Equal Variances for Repeated Measurements

Table 1.4: Quadratic Calibration Curve for Initial Data

Table 1.5: Predicted Benzene Measurements and Limits

Table 2.1: Fractional Factorial Experiment

Table 3.1: Data from Designed Experiment

Table 3.2: Summary Data from Designed Experiment

Table 3.3: Analysis of Factor Effects and Significant Interactions

Table 3.4: Tests for Equal Variances for Repeated Measurements

Table 4.1: Data from Solution Matrix Study

Table 4.2: Tests for Equal Variances for Repeated Measurements

Table 4.3: Summary of Solution Matrix Data by Sample

Table 4.4: Linear Calibration Fit for Solution Matrix Data

Table 4.5: Quadratic Calibration Fit for Solution Matrix Data

Table 4.6: Time Stability of 10\% Methanol Preparation

Table 4.7: Time Stability of PHA Preparation

Table 5.1: Data from PR Study

Table 5.2: Summary Data from PR Study

Table 5.3: Tests for Equal Variances for Repeated Measurements

Table 5.4: Time Study of PR Data

Table 6.1: PHA Standards with 10\% Methanol Calibration

Table 6.2: Tests for Equal Variances for Repeated Measurements

Table 6.3: Linear Calibration Fit for PHA Standards Data

Table 6.4: Quadratic Calibration Fit for PHA Standards Data

Table 6.5: Predicted Benzene Measurements

Table 6.6: SAS Code for Inverse Prediction Problem

Table 6.7: Inverse Prediction Problem 
Table 1.1: Data from Initial Calibration Study

Soln Matrix (1- water, 0-air)

$\mathrm{Y}=$ benzene measurement (ppm)

Std Conc (ppm)

\begin{tabular}{|c|c|c|c|c|c|c|}
\hline Rows & Sample I & Soln Matrix & Vla11 & Sample Temp & Std Cone & $Y$ \\
\hline 1 & 11 & 9 & 1 & 80 & C. & 0.13157 \\
\hline 2 & 21 & 1 & 1 & 80 & 01 & 0.1149 \\
\hline 3 & 31 & 1 & 1 & 801 & e) & 0.14221 \\
\hline 4 & 4 & 1 & 1 & 80 & 0 & 0.14841 \\
\hline 5 & 5 & 1 & 1 & 80 & 0 & 0.00846 \\
\hline 6 & 6 & 1 & 1 & 80 & 0 & 0.19124 \\
\hline 7 & 7 & 1 & 1 & 80 & 0 & 0.1668 \\
\hline 8 & 8 & 1 & 1 & 80 & 0 & 0.0855 \\
\hline 9 & 9 & 1 & 1 & 80 & 0 & 0.1518 \\
\hline 10 & 10 & 1 & 1 & 80 & 0 & 0.14725 \\
\hline 11 & 11 & 1 & 1 & 80 & 0 & 0.12764 \\
\hline 12 & 12 & 1 & 1 & 120 & 0 & 2.29192 \\
\hline 13 & 13 & 1 & 1 & 120 & 0 & 0.20395 \\
\hline 14 & 14 & 1 & 1 & 120 & 0 & 0.22604 \\
\hline 15 & 15 & 1 & 1. & 120 & 2 & 0.19484 \\
\hline 16 & 16 & 1 & 1 & 120 & 0 & 0.15415 \\
\hline 17 & 17 & 1 & 1 & 120 & 0 & 0,29638 \\
\hline 18 & 18 & 1 & 1 & 120 & 0 & 0.32212 \\
\hline 19 & 19 & 1 & 1 & 120 & 0 & 0.11533 \\
\hline 20 & 20 & 11 & 1 & 120 & 0 & 0.23455 \\
\hline 21 & 21 & 1 & 1 & 120 & 0 & 0.2381 \\
\hline 22 & 22 & 1 & 1 & 120 & 0 & 0.20944 \\
\hline 23 & 23 & 1 & 2 & 80 & 10 & 7.71864 \\
\hline 24 & 24 & 1 & 2 & 80 & 10 & 7.60326 \\
\hline 25 & 25 & 1 & 2 & 80 & 10 & 7.58204 \\
\hline 26 & 26 & 1 & 2 & 80 & 10 & 7,60552 \\
\hline 27 & 27 & 1 & 2 & 80 & 10 & 7.65123 \\
\hline 28 & 28 & $\perp$ & 2 & 80 & 10 & 7,64509 \\
\hline 29 & 29 & 1 & 2 & 80 & 10 & 7.69033 \\
\hline 30 & 30 & 1 & 2 & 80 & 10 & 7.51932 \\
\hline 31 & 31 & 1 & 2 & 80 & 10 & 758928 \\
\hline 32 & 32 & 1 & 2 & 80 & 10 & 7.59883 \\
\hline 33 & 33 & 1 & 2 & 80 & 104 & 7.5579 \\
\hline 34 & 34 & 1 & 2 & 140 & 10 & 8.24771 \\
\hline 35 & 35 & 1 & 2 & 140 & 10 & 8,34416 \\
\hline 36 & 36 & 1 & 2 & 140 & 10 & 8.35106 \\
\hline 37 & 37 & 1 & 2 & 140 & 10 & 8.42275 \\
\hline 38 & 38 & 1 & 2 & 140 & 10 & 8.25816 \\
\hline 32 & 39 & 1 & 2 & 140 & 10 & 8.29113 \\
\hline 40 & 40 & 1 & 2 & 140 & 10 & 8.3047 \\
\hline 41 & 41 & 1 & 2 & 140 & 10 & 8.22375 \\
\hline 42 & 42 & 11 & 2 & 140 & 101 & 8.34427 \\
\hline 43 & 43 & 1 & 2 & 140 & 10 & 8.27869 \\
\hline 441 & 44 & 11 & 2 & 140 & 10 & 8.31104 \\
\hline 45 & 45 & 10 & 3 & 80 & Q & 0.14594 \\
\hline 46 & 46 & 10 & 3 & 82 & 0 & 0.26914 \\
\hline 47 & 47 & 10 & 3. & 80 & 0 & 0.10971 \\
\hline 48 & 48 & 10 & 3 & 80 & 0 & 0.22543 \\
\hline 49 & 49 & 10 & 3 & 80 & 0 & 0.2128 \\
\hline 50 & 50 & 10 & 3 & 80 & 0 & 0.36518 \\
\hline 51 & 51 & 10 & 3 & set & 0 & 0.30561 \\
\hline 52 & 52 & 10 & 3 & 80 & e & 0.11998 \\
\hline 53 & 53 & 10 & 3 & 80 & 0 & 0.22879 \\
\hline 54 & 54 & Le & 3 & 80 & e & 0.1304 \\
\hline 55 & 55 & 0 & 3 & 80 & eI & 0.18948 \\
\hline 56 & 56 & 1 & & 80 & 10 & 8.8 \\
\hline
\end{tabular}


Table 1.1 (Con't): Data from Initial Calibration Study

Soln Matrix (1- water, 0-air)

$\mathrm{Y}=$ benzene measurement (ppm)

Std Conc (ppm)

\begin{tabular}{|c|c|c|c|c|c|c|}
\hline Rowel & Samole 1 & Soln Matrix & Vlal & Sample Tomp & Std Cone I & $Y$ \\
\hline 57 & 57 & 1 & 4 & 80 & $10^{1}$ & 7.30343 \\
\hline 58 & 58 & 1 & 4 & 80 & 101 & 8.0026 \\
\hline 59 & 59 & 1 & 4 & 80 & 101 & 7.94168 \\
\hline 60 & 601 & & 4 & 80 & 101 & 7.99827 \\
\hline 61 & 611 & 1 & 4 & 80 & 101 & 7.91733 \\
\hline 62 & 62 & 1 & 4 & 80 & 101 & 7.85888 \\
\hline 63 & 631 & & 4 & 801 & 101 & 7.8495 \\
\hline 64 & 64 & 1 & 4 & 80 & $10 !$ & 8.063 \\
\hline 65 & 65 & 1 & 4 & 801 & 101 & 786196 \\
\hline 66 & 66 & 1 & 4 & 804 & 101 & 7.94577 \\
\hline 67 & 67 & 1 & 4 & 140 & 101 & 8.11827 \\
\hline 68 & 68 & 11 & 4 & 140 & 101 & 8.29336 \\
\hline 69 & 69 & 1 & 4 & 140 & 101 & 8.22784 \\
\hline 70 & $7 n$ & 1 & 4 & 140 & 101 & 8.24383 \\
\hline 71 & 71 & 1 & 4 & 140 & 101 & 8.33885 \\
\hline 72 & 72 & 1 & 4 & 140 & 101 & 8.16548 \\
\hline 73 & 73 & 1 & 4 & 140 & 101 & 8.27367 \\
\hline 74 & 74 & 1 & 4 & 140 & 101 & 8.29012 \\
\hline 75 & 75 & I1 & 4 & 140 & 101 & 8.15097 \\
\hline 76 & 76 & 11 & 4 & 140 & 101 & 8.11222 \\
\hline 72 & 77 & 11 & 4 & 140 & 101 & 8.17492 \\
\hline 78 & 78 & 11 & 5 & 801 & 301 & 21.23019 \\
\hline 79 & 79 & 11 & 5 & 80 & 301 & 29,11263 \\
\hline 80 & 80 & 11 & 5 & 80 & 301 & 21,16985 \\
\hline 81 & 81 & 1 & 5 & 80 & 301 & 21.13117 \\
\hline 82 & 82 & 1 & 5 & 80 & 301 & 21.07295 \\
\hline 83 & 83 & 1 & 5 & 80 & 301 & 20.97327 \\
\hline 84 & 84 & 1 & 5 & 80 & 301 & 20.92756 \\
\hline 85 & 85 & 11 & 5 & 80 & 30 & 20.87691 \\
\hline 86 & 86 & 11 & 5 & 80 & 30 & 20.9427 \\
\hline 87 & 87 & 1 & 5 & 80 & 30 & 20.97706 \\
\hline 88 & 88 & 1 & 5 & 80 & 30 & 20.81371 \\
\hline 89 & 89 & 1 & 5 & 140 & 301 & 21.69709 \\
\hline 90 & 20 & 11 & 5 & 140 & 301 & 21.70276 \\
\hline 91 & 91 & 1 & 5 & 140 & 301 & 21.73048 \\
\hline 92 & 92 & 1 & 5 & 140 & 301 & 21.81815 \\
\hline 93 & 93 & 1 & 5 & 140 & 301 & 21.71635 \\
\hline 94 & 94 & 1 & 5 & 140 & 301 & 21.74069 \\
\hline 95 & 95 & 1 & 5 & 140 & 301 & 21,79634 \\
\hline 96 & 96 & 1 & 5 & 140 & 301 & 21.7063 \\
\hline 97 & 97 & 1 & 5 & 140 & 301 & 21.6774 \\
\hline 98 & 98 & 1 & 5 & 140 & 301 & 21.64387 \\
\hline 99 & 99 & 1 & 5 & 140 & 301 & 2176217 \\
\hline 100 & 100 & 11 & 6 & 80 & 501 & 33.18953 \\
\hline 101 & 101 & 1 & 6 & 80 & 501 & 33.12656 \\
\hline 102 & 102 & 1 & 6 & 80 & 50) & 33.15739 \\
\hline 103 & 103 & 1 & 6 & 80 & 50 & 32.97876 \\
\hline 104 & 104 & 1 & 6 & 80 & 50 & 32,96033 \\
\hline 105 & 105 & 1 & 6 & 80 & 50 & 32.97533 \\
\hline 106 & 106 & 1 & 6 & 80 & 50 & 32,92765 \\
\hline 107 & 107 & 11 & 6 & 80 & 501 & 32.97259 \\
\hline 108 & 108 & 1 & 6 & 80 & 501 & 32.78265 \\
\hline 109 & 109 & 1 & 6 & 80 & 501 & 32,88462 \\
\hline 110 & 110 & 19 & 6 & 80 & 501 & 32.63007 \\
\hline 111 & 111 & 1 & 6 & 140 & 501 & 33.67671 \\
\hline 112 & 112 & 11 & 6 & 140 & 501 & 33,63881 \\
\hline
\end{tabular}


Table 1.1 (Con't): Data from Initial Calibration Study

Soln Matrix (1- water, 0-air)

$\mathrm{Y}=$ benzene measurement $(\mathrm{ppm})$

\begin{tabular}{|c|c|c|c|c|c|c|c|}
\hline Rows I & Sample I Soln & Matrix I & Viali & Sample & Temp ! & Stol Cone 1 & $\mathbf{Y}$ \\
\hline 1131 & 11311 & 1 & 61 & & 1401 & 501 & 33.73264 \\
\hline 1141 & 19411 & 1 & $6 !$ & & $140 !$ & 501 & 33.71717 \\
\hline 1151 & 11511 & $i$ & 61 & & 1401 & 501 & 33.81948 \\
\hline 116 & 11611 & $!$ & 6 & & 140 & 501 & 33.68389 \\
\hline 117 & $117 \mid 1$ & 1 & 61 & & 140 & 501 & 33.63571 \\
\hline 118 & $918 / 1$ & $i$ & 61 & & 1401 & 501 & 33,63924 \\
\hline 119 & 11911 & 1 & 61 & & 1401 & $5 \mathrm{cl}$ & 33.67085 \\
\hline 120 & 12011 & & 6 & & 140. & 501 & 33,46386 \\
\hline 121 & 12111 & & 6 & & 1401 & 50L L & 33,54355 \\
\hline 122 & 12211 & & 7 & & 801 & 01 & 0.17847 \\
\hline 123 & 12311 & 1 & 7 & & 1301 & 01 & 0.2189 \\
\hline 124 & 12411 & I & 7 & & 801 & 01 & 0.2409 \\
\hline 125 & $125 / 1$ & & 7 & & 801. & 01 & 0.188801 \\
\hline 126 & 12511 & & 71 & & 801 & 01 & 0.13019 \\
\hline 127 & 12711 & & 7 & & 801 & $0 !$ & 0.09407 \\
\hline 128 & $128 / 1$ & & 7 & & 801 & 0 & 0.2267 \\
\hline 1291 & 12911 & & 7 & & 801 & e & 0.2433 \\
\hline 1301 & 13011 & & 7 & & 801 & 13 & 0.28347 \\
\hline 1311 & 13911 & & 7 & & 801 & 01 & c.27036 \\
\hline 1321 & 13211 & & 7 & & 801 & 01 & 0.33717 \\
\hline
\end{tabular}


Table 1.2: Initial Calibration Data Summarized by Vial

$$
Y=\text { benzene measurement (ppm) }
$$

\begin{tabular}{|c|c|c|c|c|c|c|c|}
\hline Rows & $v|a|]$ & Sample Temp & $\mathbf{N}$ & Mean/Std & Concll & Mean(Y ) & $\operatorname{std}(Y)$ \\
\hline 1 & & $\overline{0} \overline{0}$ & $i i$ & & $\overline{0}$ & 0.12670127 & 0.0453066 \\
\hline 2 & 1 & 120 & 11 & & 01 & 0.22607455 & 0.06156212 \\
\hline 3 & 2 & 80 & 11 & & 10 & 7.61467636 & 0.05769302 \\
\hline 4 & 2 & 140 & 11 & & 10 & 8.30703818 & 0.05658214 \\
\hline 5 & 3 & 80 & 11 & & 0 & 0.20931455 & 0.08144695 \\
\hline 6 & 4 & 80 & 11 & & 10 & 7.95391636 & 10.07690086 \\
\hline 7 & 4 & 140 & 11 & & 10 & 8.21723 & 0.07719101 \\
\hline 8 & 5 & 80 & 11 & & 30 & 21.0207273 & 0.13112975 \\
\hline 9 & 5 & 140 & 11 & & 30 & 21.7265091 & 0.05093625 \\
\hline 10 & 6 & 80 & 11 & & 50 & 32.9623164 & 0.16343534 \\
\hline 11 & 6 & 140 & 11 & & 50 & 33.6383555 & 0.07713798 \\
\hline 12 & 7 & 80 & 11 & & 0 & 0.21930282 & 0.06923594 \\
\hline
\end{tabular}


Table 1.3 Tests for Equal Variances for Repeated Measurements

$$
\text { Level }=\text { Vial-Temp Combination }
$$

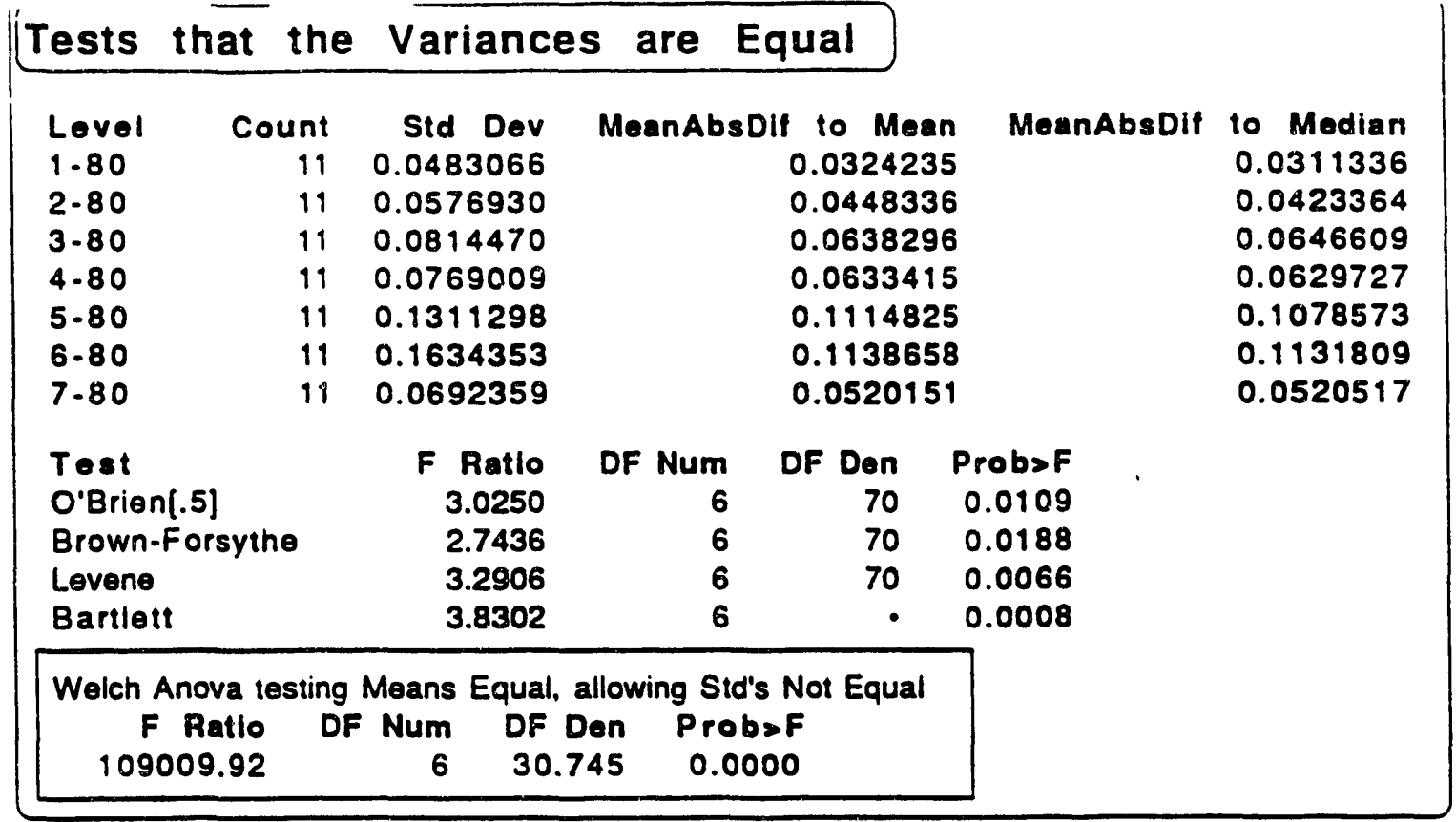

\begin{tabular}{|c|c|c|c|c|c|c|}
\hline Tests that $t$ & the & Varianc & are & Equal & \multirow[b]{2}{*}{ MeanAbsDif } & \multirow[b]{2}{*}{ to Median } \\
\hline Level & unt & Std Dev & \multicolumn{2}{|c|}{ MeanAbsDif to Mean } & & \\
\hline $1-120$ & 11 & 0.0615621 & \multicolumn{2}{|r|}{0.0459450} & & 0.0467155 \\
\hline $2 \cdot 140$ & 11 & 0.0565821 & \multicolumn{2}{|r|}{0.0432889} & & 0.0436527 \\
\hline $4-140$ & 11 & 0.0771910 & \multicolumn{2}{|r|}{0.066234} & & 0.0667236 \\
\hline $5 \cdot 140$ & 11 & 0.0509363 & \multicolumn{2}{|c|}{0.0391426} & & 0.0391327 \\
\hline 6.140 & 11 & 0.0771380 & \multicolumn{3}{|c|}{0.0528767} & 0.0527527 \\
\hline Test & & F Ratio & DF Num & DF Den & \multirow{5}{*}{\multicolumn{2}{|c|}{$\begin{array}{c}\text { ProbsF } \\
0.6012 \\
0.5183 \\
0.5172 \\
0.6203\end{array}$}} \\
\hline O'Brieri.5] & & 0.6917 & 4 & 50 & & \\
\hline Brown-Forsythe & & 0.8204 & 4 & 50 & & \\
\hline Levene & & 0.8222 & 4 & 50 & & \\
\hline Bartlett & & 0.6592 & 4 & - & & \\
\hline \multicolumn{5}{|c|}{$\begin{array}{c}\text { Welch Anova testing Means Equal, allowing Std's Not Equal } \\
\begin{array}{rrrr}\text { F Ratlo } & \text { DF Num } & \text { DF Den } & \text { Prob>F } \\
390949.28 & 4 & 24.837 & 0.0000\end{array}\end{array}$} & & \\
\hline
\end{tabular}


Table 1.4: Quadratic Calibration Curve for Initial Data

$$
Y=\text { benzene measurement }(\mathrm{ppm})
$$

Response: $Y$

\begin{tabular}{|lr|}
\hline Summary of Fit. & \\
\hline Rsquare & 0.999909 \\
Root Mean Square Error & 0.141959 \\
Mean of Response & 12.90891 \\
Observations (or Sum Wgts) & 11 \\
\hline
\end{tabular}

\begin{tabular}{|lrrrr|}
\hline Lack of Fit & & & & \\
Source & DF & Sum of Squares & Mean Square & F Ratlo \\
Lack of Fit & 3 & 0.07457026 & 0.024857 & 1.4953 \\
Pure Error & 4 & 0.06649525 & 0.016624 & Prob>F \\
Total Error & 7 & 0.14106551 & & 0.3439 \\
\hline
\end{tabular}

\begin{tabular}{|lrrrrr|}
\hline Parameter & \multicolumn{2}{l}{ Estimates } & & & \\
Torm & Estimate & Std & Error & t Ratlo & Probs|t| \\
Intercept & -0.5934 & 0.15694 & -3.78 & 0.0069 \\
Std Conc^1 & 0.7617409 & 0.00975 & 78.10 & 0.0000 \\
Std Conc^2 & -0.002146 & 0.00019 & -11.58 & 0.0000 \\
Temp & 0.0103795 & 0.00162 & 6.39 & 0.0004 \\
\hline
\end{tabular}

\begin{tabular}{|c|c|c|c|c|c|c|}
\hline Effect Test & & & & & & \\
\hline $\begin{array}{l}\text { Source } \\
\text { Poly(Std Conc,2) } \\
\text { Temp }\end{array}$ & $\begin{array}{r}\text { Nparm } \\
2 \\
1\end{array}$ & $\begin{array}{r}\text { DF } \\
2 \\
1\end{array}$ & Sum & $\begin{array}{r}\text { of Squares } \\
1395.5196 \\
0.8227\end{array}$ & $\begin{array}{r}\text { F Ratio } \\
34624.47 \\
40.8229\end{array}$ & $\begin{array}{r}\text { Prob>F } \\
0.0000 \\
0.0004\end{array}$ \\
\hline
\end{tabular}


Table 1.5: Predicted Benzene Measurements and Limits

$$
Y=\text { benzene measurement (ppm) }
$$

\begin{tabular}{|c|c|c|c|c|c|c|c|c|}
\hline Rows & Std Conc & Temp & $Y$ & Prodicted Y & Lower & $95 \%$ Indiv $Y$ & Upper & $95 \%$ Indlv Y \\
\hline 1 & 0 & 80 & 0.1287 & 0.23696318 & & -0.1431978 & & 0.61712417 \\
\hline 2 & 10 & 80 & 7.6147 & 7.63981872 & & 7.26996944 & & 8.00966799 \\
\hline 3 & 10 & 140 & 8.307 & 8.2625911 & & 7.87677461 & & 8.64840759 \\
\hline 4 & 0 & 80 & 0.2093 & 0.23696318 & & -0.1431978 & & 0.61712417 \\
\hline 5 & 10 & 80 & 7.9539 & 7.63981872 & & 7.26996944 & & 8,00966799 \\
\hline 6 & 10 & 140 & 8.2172 & 8.2625911 & & 7.87677461 & & 8.64840759 \\
\hline 7 & 30 & 80 & 21.0207 & 21.1582073 & & 20.7456085 & & 21.5708061 \\
\hline 8 & 30 & 140 & 21.7265 & 21.7809796 & & 21,3883603 & & 22.173599 \\
\hline 9 & 50 & 80 & 32.9623 & 32,9601658 & & 32.5381698 & & 33.3821617 \\
\hline 10 & 50 & 140 & 33.6384 & 33.5829382 & & 33.1552619 & & 34.0106144 \\
\hline 11 & 0 & 80 & 0.2193 & 0.23696318 & & -0.1431978 & & 0.61712417 \\
\hline
\end{tabular}


Table 2.1: Fractional Factorial Experiment

Std Conc:

Soln Matrix:

Optical Cell Temp:

Sample Temp:

$\begin{array}{ll}-1(10) & 1(50) \\ -1(\text { water }) & 1(\mathrm{PHA}) \\ -1(85) & 1(95) \\ -1(80) & 1(140)\end{array}$

4 Factors
Design

1. Sid Cone

2. Soln Matrix

3. Optical Cell Ternp

4. Sample Temp

Run Sequence

ppm benzene

degrees Celsius degrees $F$

\begin{tabular}{|c|c|c|c|c|}
\hline Sample & 1 & 2 & 3 & 4 \\
\hline \multicolumn{5}{|l|}{ DAY 1} \\
\hline 18 & 1 & .1 & -1 & 1 \\
\hline 12 & 1 & 1 & .1 & -1 \\
\hline 4 & 1 & 1 & .1 & .1 \\
\hline 28 & 1 & 1 & .1 & .1 \\
\hline 1 & -1 & .1 & -1 & -1 \\
\hline 27 & -1 & 1 & .1 & 1 \\
\hline 9 & .1 & .1 & -1 & -1 \\
\hline 25 & .1 & -1 & -1 & -1 \\
\hline 13 & .1 & -1 & 1 & 1 \\
\hline 29 & -1 & .1 & 1 & 1 \\
\hline 22 & 1 & -1 & 1 & -1 \\
\hline 31 & -1 & 1 & 1 & -1 \\
\hline 24 & 1 & 1 & 1 & 1 \\
\hline 5 & -1 & .1 & 1 & 1 \\
\hline 16 & 1 & 1 & 1 & 1 \\
\hline 23 & -1 & 1 & 1 & -1 \\
\hline
\end{tabular}

DAY 2

$\begin{array}{rrrrr}3 & -1 & 1 & -1 & 1 \\ 10 & 1 & -1 & -1 & 1 \\ 2 & 1 & -1 & -1 & 1 \\ 17 & -1 & -1 & -1 & -1 \\ 20 & 1 & 1 & -1 & -1 \\ 26 & 1 & -1 & -1 & 1 \\ 19 & -1 & 1 & -1 & 1 \\ 11 & -1 & 1 & -1 & 1 \\ & & & & \\ 6 & 1 & -1 & 1 & -1 \\ 14 & 1 & -1 & 1 & -1 \\ 15 & -1 & 1 & ; & -1 \\ 30 & 1 & -1 & 1 & -1 \\ 21 & -1 & -1 & 1 & 1 \\ 7 & -1 & 1 & 1 & -1 \\ 32 & 1 & 1 & 1 & 1 \\ 8 & 1 & 1 & 1 & 1\end{array}$


Table 3.1: Data from Designed Experiment

Meas Conc - benzene measurement in ppm

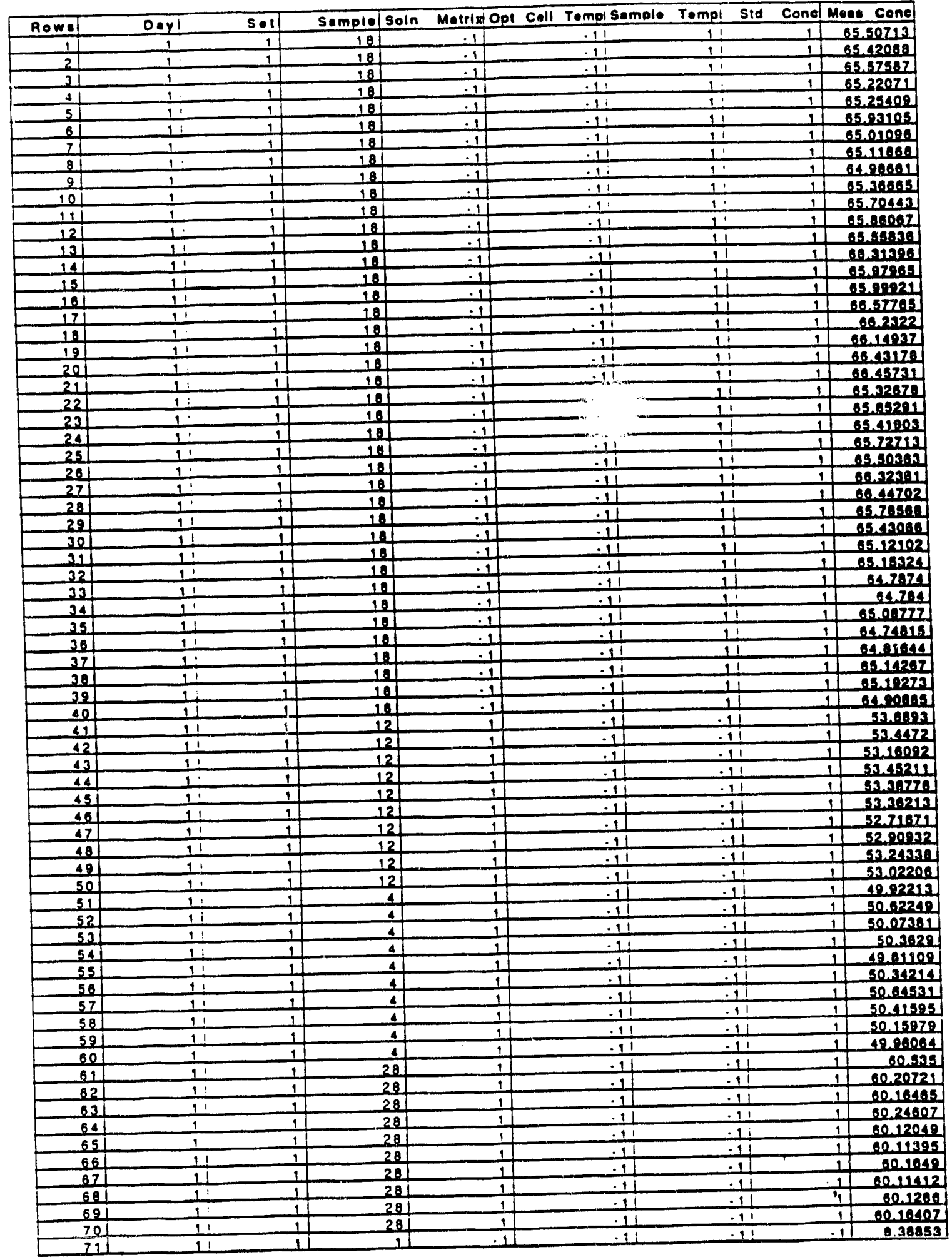


Table 3.1 (con't): Data from Designed Experiment

Meas Conc - benzene measurement in ppm

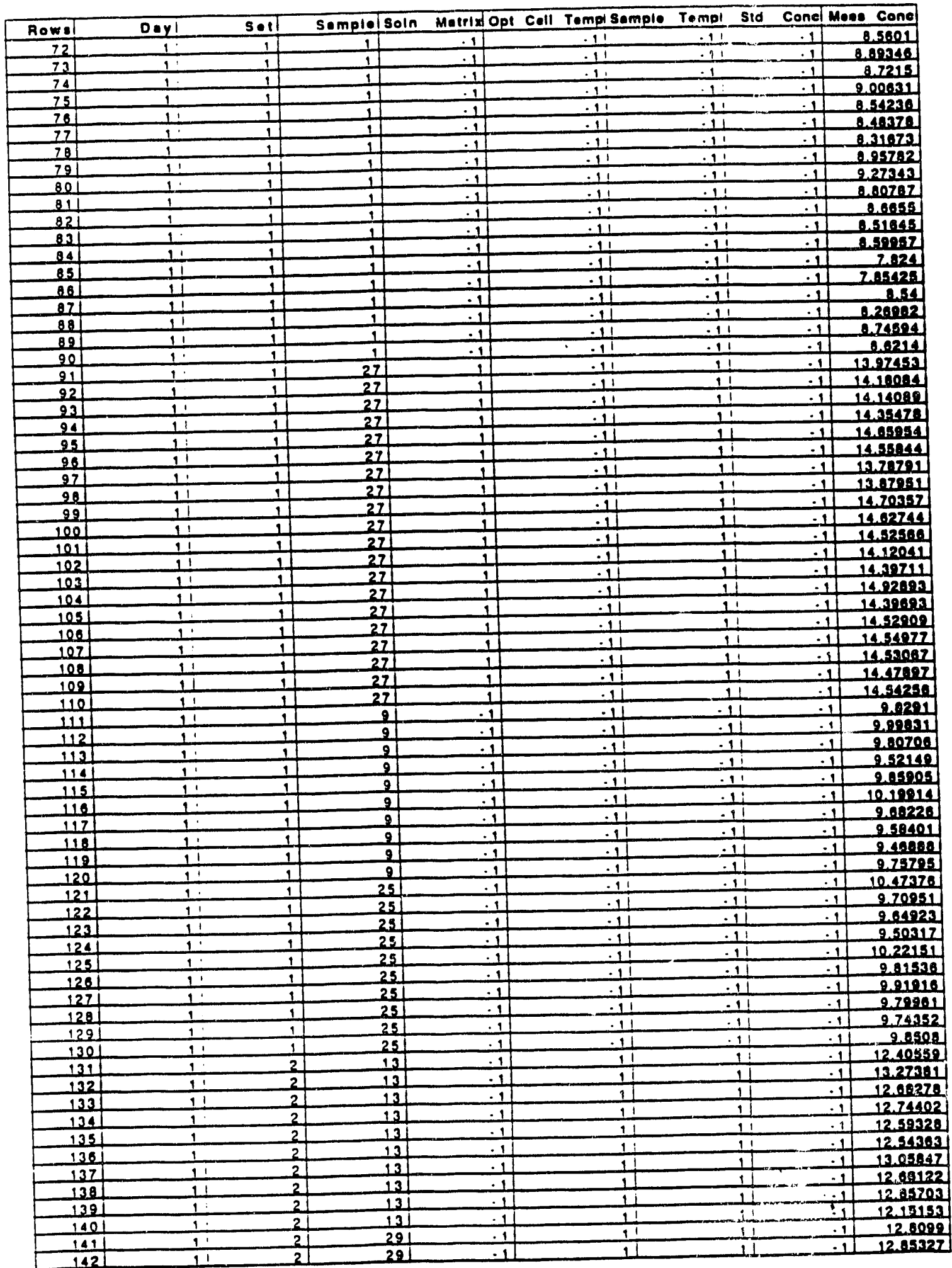


Table 3.1 (con't): Data from Designed Experiment

Meas Conc - benzene measurement in ppm

\begin{tabular}{|c|c|c|c|c|c|c|c|c|c|}
\hline Row 1 & Day & sol & Sampiels & Soln Matrix & Op: & Coll Tempi Semple & Tompl & Std Concl & Mens Cone \\
\hline 143 & 1. & 2 & 29 & .1 & & 11 & 1 & .1 & 12.36515 \\
\hline 144 & 11 & 21 & 29 & .11 & & 11 & 1. & .1 & 13.05966 \\
\hline 145 & 11 & 2 & 29 & .11 & & 11 & 1 & -1 & 12.9899 \\
\hline 146 & $1:$ & 2 & 29 & .11 & & $1:$ & 1. & .1 & 13.36994 \\
\hline 147 & 11 & 2 & 29 & .1 & & 11 & 1. & .1 & 12.93347 \\
\hline 148 & 11 & 2 & 29 & .11 & & 11 & $1:$ & .1 & 12.71732 \\
\hline 149 & $1:$ & 2. & 29 & .11 & & 11 & 11 & $\cdot 1$ & 12.99 .11 \\
\hline 1501 & 11 & 2 & 291 & .11 & & 11 & 11 & -1 & 12.77891 \\
\hline 1511 & 11 & 2 & 221 & -11 & & $1:$ & .11 & 1 & 19.48412 \\
\hline 1521 & 1 & 2 & 221 & -1 & & $1:$ & .11 & 1 & 49.44804 \\
\hline 153 & 1. & 2 & 221 & -1 & & $1:$ & .11 & 1 & 48.84034 \\
\hline 254 & 1 & 2 & 221 & -1 & & 11 & .11 & 1 & 48.97804 \\
\hline 155 & 11 & 2 & 22 & -1 & & 11 & .11 & 1 & 4.728998 \\
\hline 156 & 11 & 2 & 22 & .11 & & 11 & .11 & 1 & 48.97057 \\
\hline 157 & 11 & 2 & 22 & .11 & & 11 & .11 & 1 & 18.0024 \\
\hline 158 & 11 & 2 & 22 & -1 & & 1 & .11 & 1 & 49.2417 \\
\hline 159 & 11 & 2 & 22 & .1 & & 11 & .11 & 1 & 48.89395 \\
\hline 160 & 11 & 2 & 22 & .11 & & 11 & .11 & 1 & 48.67427 \\
\hline 181 & 11 & 2 & 31 & 1 & & 11 & .11 & .1 & 11.77270 \\
\hline 102 & 11 & 2 & 31 & 1 & & 11 & 11 & .1 & 1124996 \\
\hline 163 & 11 & 2 & 31 & 1 & & 11 & .11 & .1 & 1196997 \\
\hline 164 & $1:$ & 2 & 32 & 1 & & 11 & .11 & .1 & 11.43123 \\
\hline 165 & $1:$ & 2 & 31 & 1 & & 11 & .11 & .1 & 11.9119) \\
\hline 186 & 11 & 2 & 31 & 1 & & 11 & $\therefore 11$ & -1 & 11.52102 \\
\hline 167 & 11 & 2 & 34 & 1 & & 11 & -11 & -1 & 11.24534 \\
\hline 188 & 11 & 2 & 31 & 1 & & 1 & -11 & -1 & 12,42051 \\
\hline 169 & 11 & 2 & 31 & 1 & & 11 & -11 & .1 & 11.24189 \\
\hline 170 & 11 & 2 & 31 & 1 & & 11 & -11 & .1 & $11 \mathrm{an} 11 \mathrm{~s}$ \\
\hline 171 & 11 & 2 & 24 & 1 & & 11 & 11 & 1 & 45.1192 \\
\hline 172 & 11 & 2. & 24 & 11 & & 11 & 11 & 1 & 45.770215 \\
\hline 173 & 11 & 2 & 24 & 1 & & 11 & 11 & 1 & 45,7309 \\
\hline 174 & 11 & 2 & 24 & 1 & & 1 & 1: & 1 & 45.9004 \\
\hline 175 & 11 & 2 & 24 & 14 & & 11 & 11 & 1 & 45.19029 \\
\hline 178 & 11 & 21 & 24 & 1 & & 11 & 11 & 1 & 45,49245 \\
\hline 177 & 11 & 2 & 24 & 1 & & 11 & 11 & 1 & 46.07290 \\
\hline 17.1 & 11 & 2 & 24 & 1 & & 11 & 1. & 1 & 46.21712 \\
\hline 179 & 11 & 2 & 24 & 1 & & 11 & $1:$ & 1 & 45.9921 \\
\hline 180 & 11 & 2 & 24 & 1 & & 11 & $1 !$ & 1 & 4.72042 \\
\hline 181 & 11 & 2 & 3 & .11 & & 11 & 11 & .1 & 12.5F929 \\
\hline 182 & 11 & 2 & 5 & .11 & & I1 & 11 & .1 & 12.84508 \\
\hline 183 & 11 & 2 & 5 & -11 & & 11 & 11 & .1 & 12.81791 \\
\hline 184 & 11 & 2 & 5. & .11 & & 11 & 11 & .1 & 12.999200 \\
\hline 185 & 11 & 2 & 5 & -1 & & 11 & 1. & .1 & 13.07727 \\
\hline 186 & 11 & 2. & 5 & .1 & & 11 & 1 & -1 & 13.39534 \\
\hline 187 & $1:$ & 2 & 5 & .1 & & 11 & $1:$ & .1 & 12.4541 \\
\hline 188 & 11 & 2 & 5 & .1 & & 11 & 11 & .1 & 12.:2:21 \\
\hline 182 & $1:$ & 2. & 5 & -1 & & 11 & 11 & $\therefore$ & 13.31961 \\
\hline 190 & 11 & 2 & 5 & .1 & & 11 & 11 & .11 & 13.19059 \\
\hline 121 & 11 & 2 & 5 & -1 & & $1 !$ & 11 & .11 & 12.75942 \\
\hline 192 & 11 & 2 & 5 & .11 & & 11 & 1. & -1 & 12.5824 \\
\hline 193 & 11 & $2]$ & 5 & -1 & & 11 & 11 & .1 & 13,00144 \\
\hline 194 & 11 & 2 & 5 & -1 & & 11 & 11 & -1 & 12.2198. \\
\hline 195 & 11 & 2 & 5 & .1 & & 11 & 1. & -1 & 12.7005 \\
\hline 196 & 11 & 2 & 5 & .1 & & 11 & $1:$ & -1 & 12.57333 \\
\hline 197 & 11 & 2 & 5 & .1 & & 11 & 11 & -1 & 13.12341 \\
\hline 198 & $1 !$ & 2 & 5 & -1 & & 11 & 11 & .1 & 12.93354 \\
\hline 199 & 11 & 2. & 5 & .1 & & 11 & 11 & $\cdot 1$ & 13.11223 \\
\hline 200 & 11 & 2. & 5 & -1 & & 11 & 11 & -1 & 13.030 .9 \\
\hline 2011 & 1 & $2]$ & 16 & 1 & & 11 & 11 & 1 & 45.92014 \\
\hline 202 & 11 & 2 & 16 & 1 & & 11 & $1:$ & 1 & 45.0207 \\
\hline 203 & 11 & 2 & 16 & 1 & & 11 & $1 !$ & 1 & 45.118.3 \\
\hline 204 & 11 & 2 & 16 & 1 & & 11 & 11 & 1 & 4572491 \\
\hline 205 & 11 & 2 & 16 & 1 & & 11 & 11 & 1 & 46,13078 \\
\hline 20.4 & 11 & 2 & 18 & 1 & & $1 !$ & 11 & 1 & $45,48.264$ \\
\hline 207 & 1 & 2 & 161 & 1 & & 11 & 11 & 1 & 15.9926 .6 \\
\hline 208 & 11 & 2 & 16 & 1 & & 11 & 11 & 1 & 45,58920 \\
\hline 202 & 11 & 2. & 16 & 1 & & 11 & 11 & 1 & 45.01040 \\
\hline 210 & 11 & 2 & 18 & 1 & & 11 & 11 & 1 & 452484 \\
\hline 211 & 11 & 2 & 23 & 11 & & 11 & .11 & -1 & 11,10828 \\
\hline 2121 & 11 & 2 & 23 & -1 & & 11 & .11 & -1 & 1117857 \\
\hline 213 & 11 & 2 & 231 & 1 & & 11 & $-1:$ & .11 & 1158.684 \\
\hline
\end{tabular}


$\begin{array}{ll}\text { SC: } & 92066 \\ \text { Tast } & 22-0\end{array}$

Table 3.1 (con't): Data from Designed Experiment

Meas Conc - benzene measurement in ppm

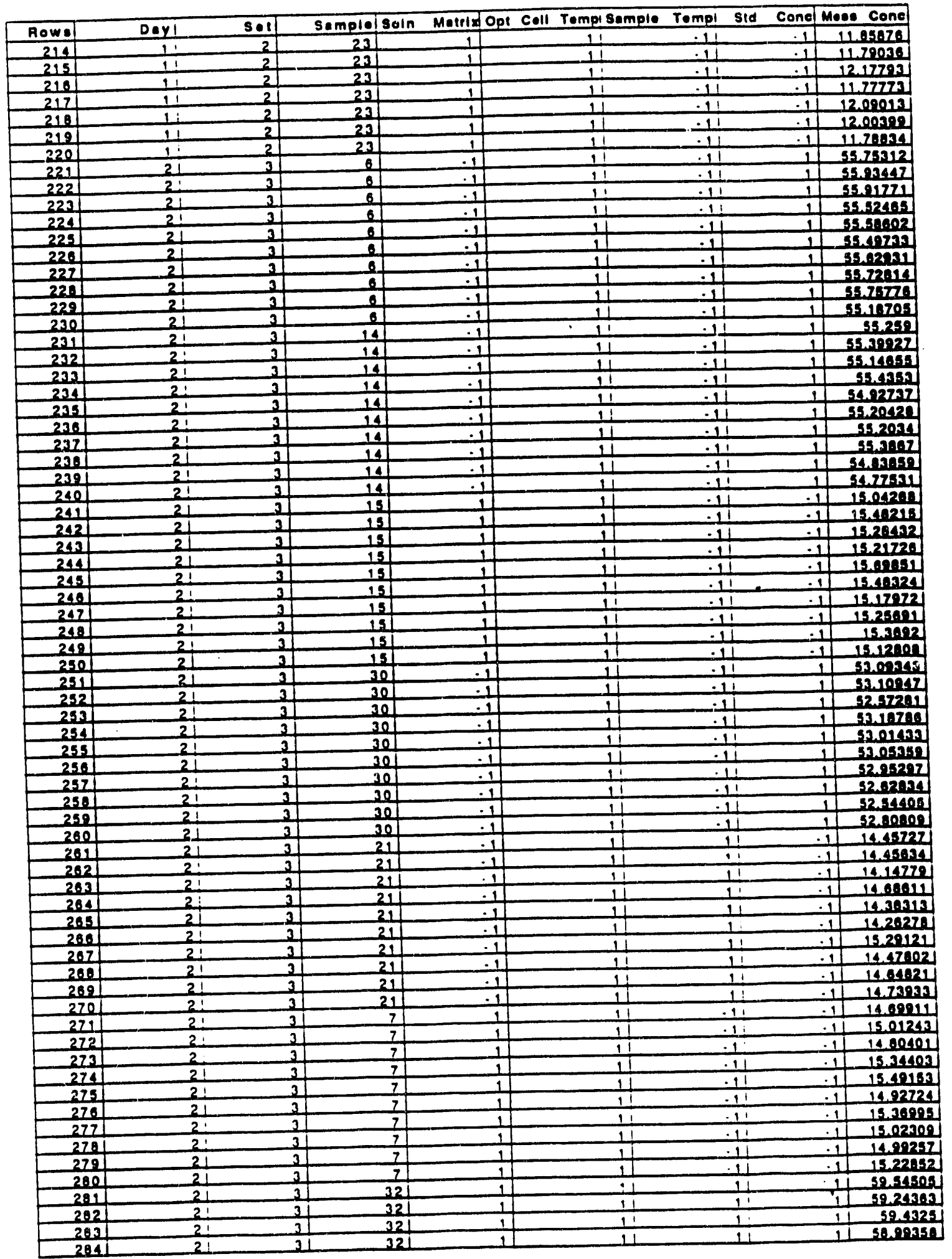


Table 3.1 (con't): Data from Designed Experiment

Meas Conc - benzene measurement in ppm

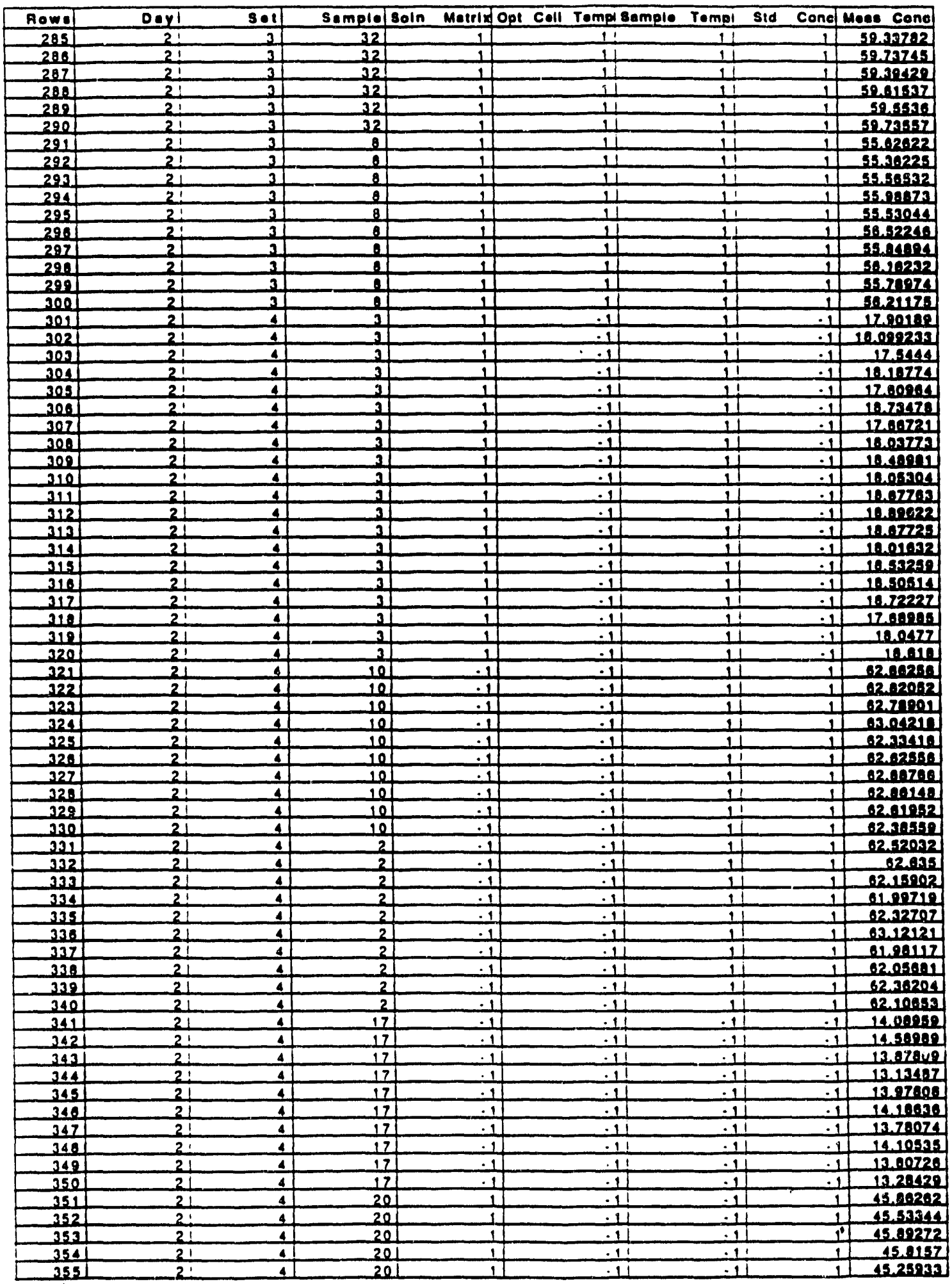


Table 3.1 (con't): Data from Designed Experiment

Meas Conc - benzene measurement in ppm

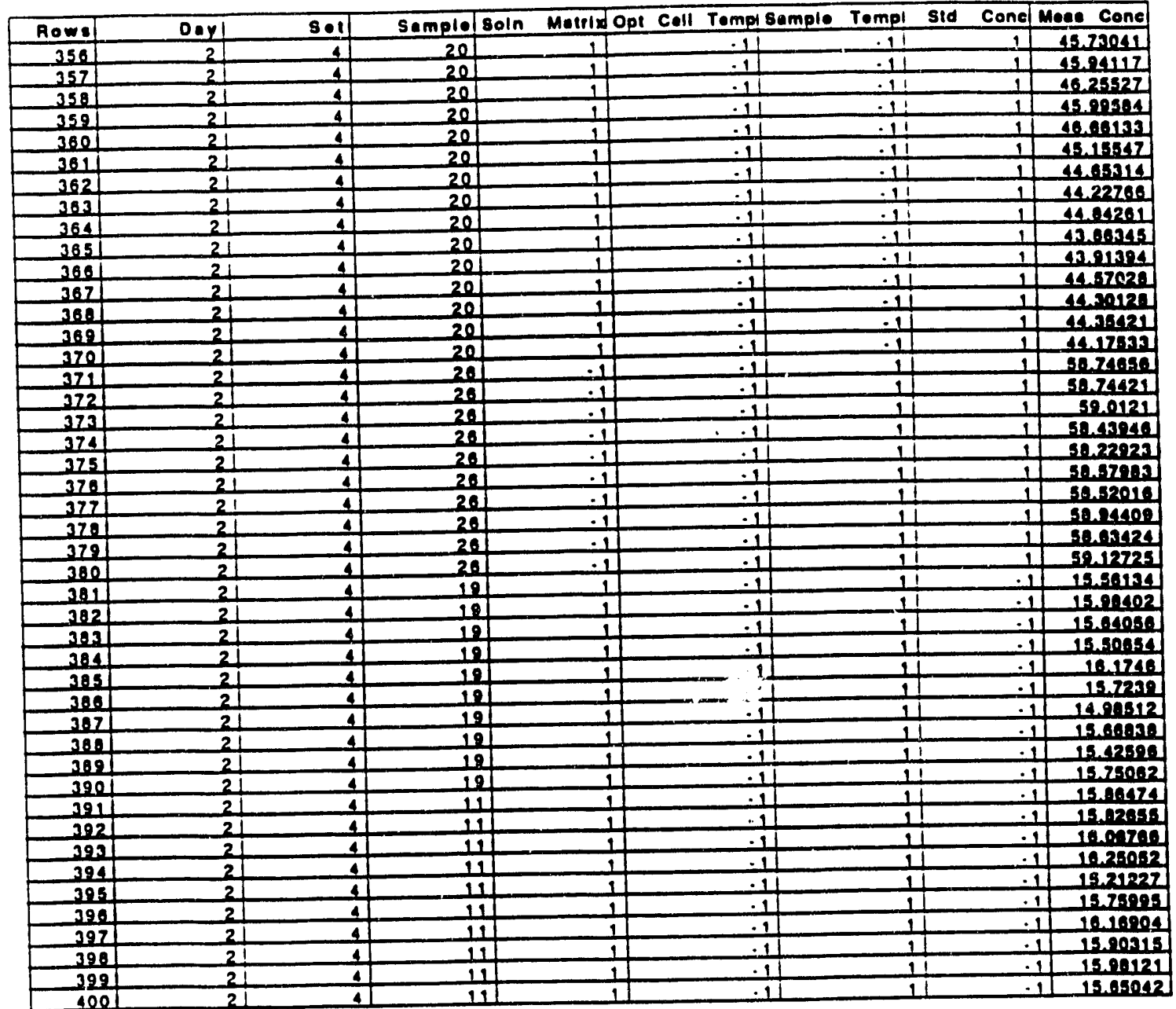


Table 3.2: Summary Data from Designed Experiment

Meas Conc - benzene measurement in ppm $\mathrm{N}=$ number of repeated measurements

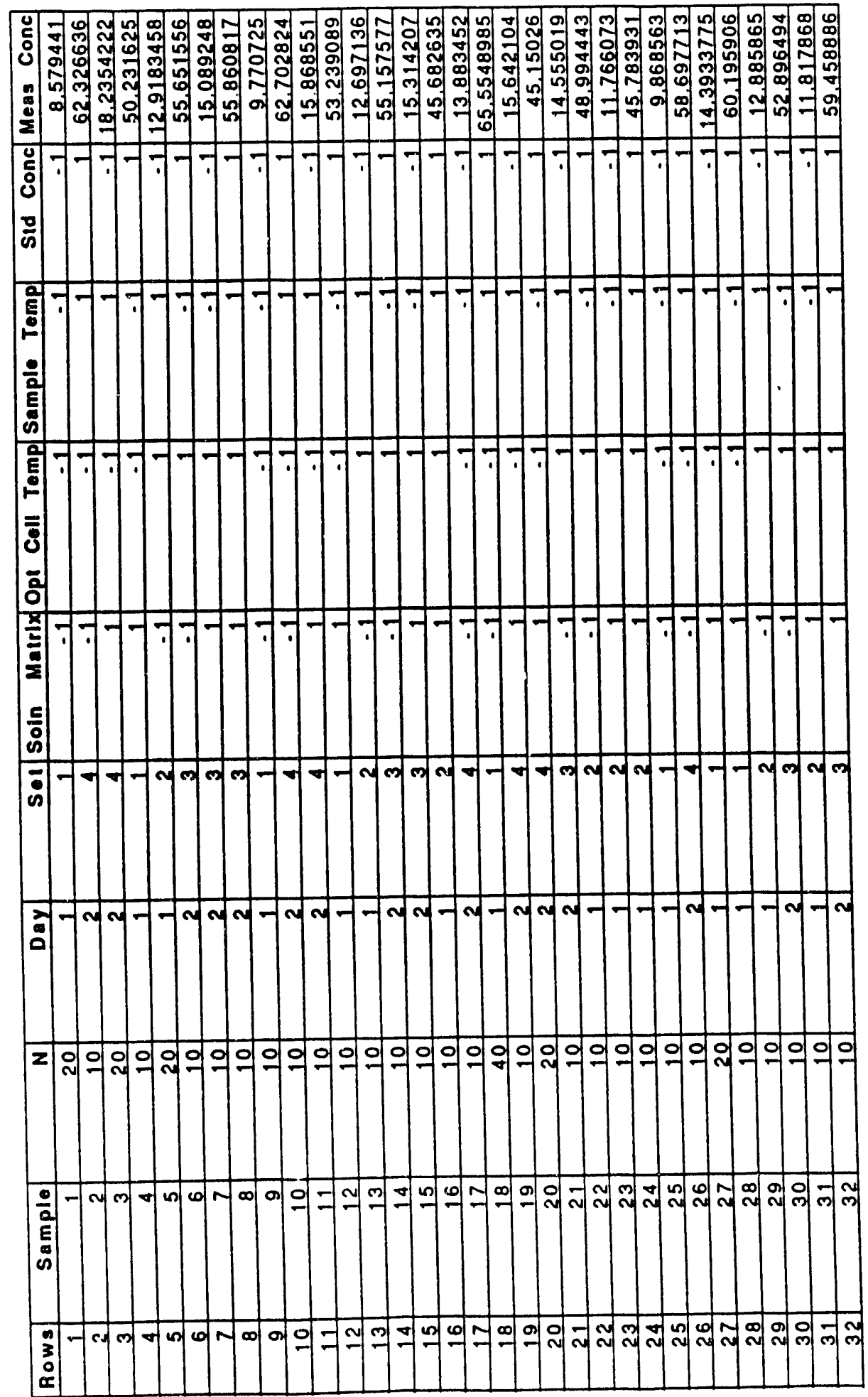


Table 3.3: Analysis of Factor Effects and Significant Interactions

$($ Meas - Std $)=$ Measured Benzene - Standard Benzene $(p p m)$

Response: (Meas - Std)

\begin{tabular}{|lr|}
\hline Summary of Fit & \\
Rsquare & 0.517072 \\
Root Mean Square Error & 3.853278 \\
Mean of Response & 4.089709 \\
Observations (or Sum Wgts) & 32 \\
\hline
\end{tabular}

\section{Parameter Estimates}

\begin{tabular}{|lcrrr|} 
Term & Estimate & Std Error & Ratio & Probs|t| \\
Intercept & 4.089709 & 0.68117 & 6.00 & 0.0000 \\
Soln Matrix & -0.731584 & 0.68117 & -1.07 & 0.2935 \\
Opt Cell Temp & -1.181578 & 0.68117 & -1.73 & 0.0956 \\
Sample Temp & 1.7393011 & 0.68117 & 2.55 & 0.0174 \\
Std Conc & 0.7593717 & 0.68117 & 1.11 & 0.2760 \\
Soln Mat*Std Conc & -2.167103 & 0.68117 & -3.18 & 0.0040 \\
Soln Mat*Sample T & -1.231711 & 0.68117 & -1.81 & 0.0831 \\
Std Conc.Sample T & 0.4201608 & 0.68117 & 0.62 & 0.5432 \\
\hline
\end{tabular}

\begin{tabular}{|lrrrrr|}
\hline Effect Test & & & & & \\
Source & Nparm & DF & Sum of Squares & F Ratio & Prob $>$ F \\
Soln Matrix & 1 & 1 & 17.12689 & 1.1535 & 0.2935 \\
Opt Cell Temp & 1 & 1 & 44.67603 & 3.0089 & 0.0956 \\
Sample Temp & 1 & 1 & 96.80538 & 6.5199 & 0.0174 \\
Std Conc & 1 & 1 & 18.45265 & 1.2428 & 0.2760 \\
Soln Mat"Std Conc & 1 & 1 & 150.28273 & 10.1216 & 0.0040 \\
Soln Mat*Sample T & 1 & 1 & 48.54755 & 3.2697 & 0.0831 \\
Std Conc"Sample T & 1 & 1 & 5.64912 & 0.3805 & 0.5432 \\
\hline
\end{tabular}


Table 3.4: Tests for Equal Variances for Repeated Measurements

Level = sample number

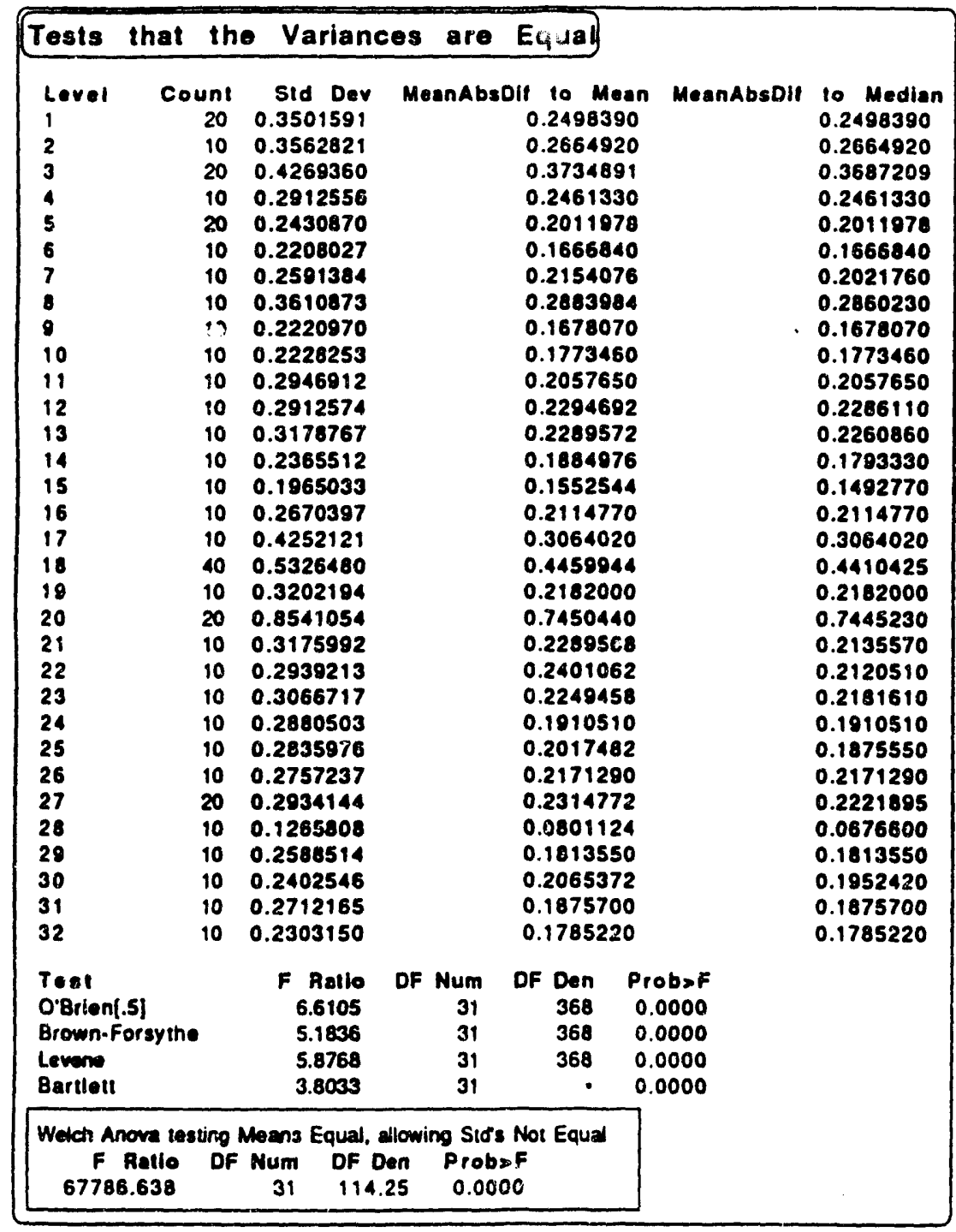


Table 4.1: Data from Solution Matrix Study

Ben Std (ppm) Ben Meas (ppm) Meas Res $=$ Std - Meas $(\mathrm{ppm})$

\begin{tabular}{|c|c|c|c|c|}
\hline Rowassomplels & Soln Matrix & Ben Sid & Ben Meas & Mens Res \\
\hline $1 \mid A B$ & & 0 & .0 .84998 & .084998 \\
\hline $2 / A B$ & & 0 & .034419 & -0.34419 \\
\hline $3 \perp A B$ & & e & .0 .32103 & .0 .32103 \\
\hline$\triangle 1 A B$ & & 0 & .016603 & -0.16603 \\
\hline $5 / A B$ & & 0 & .0 .39295 & .0 .39295 \\
\hline 6112 & $10 \%$ METH & 30 & 39.77394 & 977394 \\
\hline 7112 & $10 \%$ METH & 30 & 39.47152 & 9.47152 \\
\hline 8112 & 10\% METH & 30 & 39.37978 & 9.37978 \\
\hline $9 ! 12$ & $10 \%$ METH & 30 & 39.50319 & 950319 \\
\hline 10112 & $10 \%$ MEIH & 30 & 3921367 & 991367 \\
\hline 11116 & $10 \%$ METH & 50 & 66.47583 & 16.47583 \\
\hline $12 / 16$ & $10 \%$ METH & 50 & 66.35574 & 16.35574 \\
\hline 13116 & $10 \%$ MFIH & 50 & 66.54255 & 16.54255 \\
\hline 14116 & $10 \%$ MEIH & 50 & 66.37568 & 16.37568 \\
\hline 15116 & 10\% MEIL & 50 & 66.57366 & 16.57366 \\
\hline 1614 & 10\% MFIH & 0 & 014261 & 0.14261 \\
\hline 1714 & $10 \%$ MEIH & 0 & .0 .14528 & .014528 \\
\hline 1814 & $10 \%$ METH & 0 & .0 .0323 & .0 .0323 \\
\hline 1914 & $10 \%$ METH & 0 & 0.21277 & 0.21277 \\
\hline 2014 & $10 \%$ METH & 0 & 0.27179 & 0.27179 \\
\hline 2117 & $10 \%$ MEIH & 8.5 & 10.60352 & 2,10352 \\
\hline 2217 & $10 \%$ MEIH & 8.5 & 10.92929 & 2.42929 \\
\hline 2317 & $10 \%$ MEIH & 8.5 & 1122902 & 272902 \\
\hline 2417 & $10 \%$ METH & B.5 & 10.87516 & 2.37516 \\
\hline 2517 & $10 \%$ MEIH & 8.5 & 11.34597 & 2.84597 \\
\hline 26118 & $10 \%$ METH & 50 & 66.09776 & 16.09776 \\
\hline 27118 & $10 \%$ METH & 50 & 65.68311 & 15.68311 \\
\hline 28118 & $10 \%$ MEIH & 50 & 65.89248 & 15.99748 \\
\hline 29118 & 10\% METH & 50 & 65.70853 & 15.70853 \\
\hline 30118 & 10\%.METH & 501 & 65.81303 & 15.81303 \\
\hline 3116 & $10 \%$ METH & 8.5 & 11.01632 & 251632 \\
\hline 3216 & $10 \%$ METH & 8.5 & 10.24755 & 2.44755 \\
\hline 3316 & $10 \%$ METH & 8.5 & 1123273 & 2.73273 \\
\hline 3416 & 10\% MEIH & 8.5 & 11.68676 & 3.18676 \\
\hline 3516 & 10\% METH & 8,5 & 1453977 & 3.03977 \\
\hline 36111 & 10\% MEII & 30 & 39.570 .14 & 9.57064 \\
\hline 37111 & 10\%.MFIH & 30 & 39.91191 & 9201191 \\
\hline 38111 & $10 \%$ METH & 30 & 40.15063 & 10.15063 \\
\hline 39111 & $10 \%$ METH & 30 & 39.95545 & 9.95545 \\
\hline 40111 & 10\% MEIH & 30 & 39.95749 & 9.95749 \\
\hline 4113 & $10 \%$ METH & 2 & .104686 & .104686 \\
\hline 4213 & $10 \%$ METH & e. & .046477 & .0 .46477 \\
\hline 4313 & 10\% METH & 0 & .0 .55638 & .0 .55638 \\
\hline 4413 & $10 \%$ MEIH & 0 & 0.07748 & 0.07748 \\
\hline 4513 & $10 \%$ MFTH & eI & .0 .14036 & .0 .14035 \\
\hline $46 ! 1$ & $10 \%$ METH & 0 & -0.83631 & .0 .83631 \\
\hline 4711 & $10 \% \mathrm{METH}$ & 0 & .0 .76485 & .076485 \\
\hline 4811 & 10\% METH & 0 & .041941 & .0 .41041 \\
\hline 4911 & $10 \%$ METH & 0 & $.0,12111$ & .0 .42111 \\
\hline 5011 & $10 \%$ METH & 0 & .0 .40282 & .040282 \\
\hline 51117 & $10 \%$ MEIH & 50 & 65.60383 & 16.60383 \\
\hline $52 / 17$ & $10 \%$ MEIH & 50 & 66.41769 & 16,41769 \\
\hline $53 / 17$ & $10 \%$ MFTH & 50 & 66.55096 & 16.55096 \\
\hline 54117 & $10 \%$ MEIH & 50 & 66.45265 & 16.45265 \\
\hline 55117 & $10 \%$ METH & 50 & 66.75877 & 16.75877 \\
\hline 5619 & $10 \%$ MEIH & 8.5 & 10.79207 & 2.29207 \\
\hline 5712 & $10 \%$ METH & 8.5 & 1119322 & 269322 \\
\hline 5810 & $10 \%$ METH & 8.5 & 11.25927 & 2.75927 \\
\hline 5919 & $10 \%$ METH & 8.5 & 10.74262 & 224262 \\
\hline 6019 & $10 \%$ MEIH & 8.5 & 11.02168 & 2.52168 \\
\hline silis & $10 \%$ METH & 301 & 37.84676 & 784676 \\
\hline 62114 & $10 \%$ METH & 30 & 38.25079 & 8.25079 \\
\hline 63114 & 10\% MFIH & 30 & 38,28799 & 8.28799 \\
\hline 54114 & $10 \%$ MEIH & 301 & 38.47384 & 847384 \\
\hline 55114 & $10 \%$ METH & 30 & 38.27759 & 827759 \\
\hline 6618 & $10 \%$ METH & 8.5 & 10.54972 & 2.04972 \\
\hline 6718 & 10\% METH & 8.5 & 1107576 & 2.57576 \\
\hline
\end{tabular}


Table 4.1 (con't): Data from Solution Matrix Study

Ben Std (ppm) Ben Meas (ppm) Meas Res = Std - Meas (ppm)

\begin{tabular}{|c|c|c|c|c|}
\hline Rowaisample & Matr|x| & Bon sidl & Ben Mesel & Meas Res \\
\hline 6816 & $10 \%$ MEIH & 8.5 & 1122459 & 2.72459 \\
\hline 6918 & $10 \%$ METH & 8.5 & 1102795 & 2.52795 \\
\hline 7018 & $10 \%$ METH & 8.5 & 1110517 & 2.60517 \\
\hline 7112 & $10 \%$ METH & 0. & .0 .9049 & .02049 \\
\hline 7212 & $10 \%$ METH & 0 & $.0,43429$ & .043429 \\
\hline 7312 & 10\% METH & 0 & .011271 & .0 .11271 \\
\hline 7412 & $10 \%$ METH & 0 & .010967 & .0 .10967 \\
\hline 7512 & $10 \%$ MFTH & 2 & .021274 & .0 .21274 \\
\hline 76119 & $10 \%$ METH & 50 & 65.69588 & $15.6958 \mathrm{~B}$ \\
\hline 77119 & 10\% METH & 50 & 65,90359 & 15.90359 \\
\hline 78119 & $10 \%$ METH & 50 & 66.06059 & 16.06059 \\
\hline 79119 & 10\%. METH & 50 & 65,96348 & 15.96348 \\
\hline$8 0 \longdiv { 1 9 }$ & $10 \% \mathrm{MEIH}$ & 50 & 66.05124 & 16.05424 \\
\hline 81115 & 10\% METH & 30 & 40.1388 & 10.1388 \\
\hline $82 / 15$ & 10\% METH & 30 & 3988678 & 9.88678 \\
\hline 83115 & $10 \%$ MEIH & 30 & 39,60692 & $96069: 2$ \\
\hline 84115 & $10 \%$ MEIH & 30 & 39.86271 & 9.86271 \\
\hline 85115 & $10 \%$ MEIH & 30 & 39.66508 & 9.66508 \\
\hline $86 / 13$ & $10 \%$ METH & 30 & 3932112 & 2.32112 \\
\hline 87113 & $10 \%$ MEIH & 30 & 3923036 & 223036 \\
\hline 88113 & $10 \%$ METH & 30 & 39.57061 & 9.57061 \\
\hline 89113 & 10\% MFIH & 30 & 39.14924 & 2.14924 \\
\hline 90113 & 10\% MEIH & 30 & 40.11661 & 1011661 \\
\hline 91110 & $10 \%$ METH & 8.5 & 10.27459 & 177459 \\
\hline 92110 & $10 \%$ METH & 8.5 & 10.61563 & 2.11563 \\
\hline 93110 & $10 \%$ METH & 8.5 & 10.7662 & 22662 \\
\hline 94110 & $10 \%$ METH & 8.5 & 10.68682 & 2,18682 \\
\hline 95110 & 10\% METH & 8.5 & 10,40623 & 190623 \\
\hline 26120 & $10 \%$ METH & 50 & 63.01056 & 1301056 \\
\hline 97120 & $10 \%$ METH & 50 & 6.3 .12938 & 13.12938 \\
\hline $98+20$ & $10 \%$ METH & 50 & 63.51512 & 13.51512 \\
\hline 99120 & $10 \%$ METH & 50 & 63.14193 & 13.14193 \\
\hline 100120 & $10 \%$ METH & 50 & 63.25729 & 13.25729 \\
\hline 10115 & $10 \%$ METH & 2 & .0 .0734 & .0 .0734 \\
\hline 10215 & $10 \%$ METH & 2 & 0.14545 & 0.14545 \\
\hline $103 \sqrt{5}$ & $10 \%$ METH & 2 & 03176 & 0.3176 \\
\hline $104 / 5$ & $10 \%$ METH & 0 & 0,37907 & 0.37807 \\
\hline $105 \sqrt{5}$ & 10\% MEIH & 0 & 0.80517 & 0.80517 \\
\hline $106 / 35$ & 10\% METH & 50 & 65.26662 & 15.26662 \\
\hline 107135 & $10 \%$ METH & 50 & 65.48147 & 15.48147 \\
\hline 108135 & $10 \%$ METH & 50 & 65.58974 & 15.58974 \\
\hline 109135 & $10 \%$ METH & 50 & 65.87126 & 15.87126 \\
\hline $110 / 35$ & $10 \%$ MEIH & 50 & 66.17568 & 16.17568 \\
\hline 111121 & PHA & 0 & 0,328228 & 0.32828 \\
\hline 112121 & PHA & 0 & 0.44313 & 0.4313 \\
\hline 113121 & PHA & 0 & 0.69627 & 0.69627 \\
\hline 114121 & PHA & 0 & 0222993 & 0.22993 \\
\hline 115121 & $\mathrm{PHA}$ & 2 & 0.61789 & 0.61789 \\
\hline$1 1 6 \longdiv { 3 0 }$ & PHA & 30 & 39.73798 & 9.73798 \\
\hline 117130 & PHA & 30 & 39.93182 & 993182 \\
\hline $118 / 30$ & PHA & 30 & 40.27683 & 10.27683 \\
\hline 119130 & PHA & 30 & 39.93504 & 9.93504 \\
\hline 120130 & $\mathrm{PHA}$ & 30 & 4027122 & 10,27122 \\
\hline 121129 & PHA & 30 & 39.13848 & 9.13848 \\
\hline 122129 & PHA & 301 & 39.25364 & 925336 \\
\hline 123129 & PHA & 30 & 39,3772 & 9.3772 \\
\hline $124 / 29$ & PHA & 30 & 39.38414 & 238414 \\
\hline \begin{tabular}{l|l}
125 & 29 \\
\end{tabular} & PHA & 30 & 39.79652 & 9.79552 \\
\hline 126134 & PHA & 50 & 65.56908 & 15.56908 \\
\hline 127134 & PHA & 50 & 65.83411 & 15.83411 \\
\hline 128134 & PHA & 50 & 66.05009 & 16.05009 \\
\hline 120124 & PHA & 50 & 65.93581 & 15.93581 \\
\hline 130,134 & $\mathrm{PHA}$ & 501 & 66.46484 & 16.46484 \\
\hline 131123 & PHA & 요 & 0.0615 & 0.0615 \\
\hline 132123 & PHA & e & 0.6856 & 0.6856 \\
\hline 133123 & PHA & 0 & 0.77612 & 0.77612 \\
\hline 134123 & $\mathrm{PHA}$ & e] & 0.96831 & 0.96831 \\
\hline
\end{tabular}


Table 4.1 (con't): Data from Solution Matrix Study

Ben Std (ppm) Ben Meas (ppm) Meas Res $=$ Std - Meas $(\mathrm{ppm})$

\begin{tabular}{|c|c|c|c|c|}
\hline Aoweisample & Soln Matrix & Ben Sid! & Ben Meas! & Mees Res \\
\hline 135123 & PHA & 0 & 1,36489 & 136489 \\
\hline$1 3 6 \longdiv { 3 3 }$ & PHA & 50 & 64.68394 & 14.68394 \\
\hline 137133 & PHA & 50 & 6472086 & 14.72086 \\
\hline 138133 & PHA & 50 & 65.11858 & 15.11858 \\
\hline 139133 & PHA & 50 & 65,25486 & 15.25486 \\
\hline 140133 & PHA & 50 & 65.50217 & 15.50212 \\
\hline 141122 & PHA & 0 & 0.52922 & 0.52922 \\
\hline $142 / 22$ & PHA & 0 & 0.74998 & 0.74998 \\
\hline 143122 & PHA & 0 & 0.58 & 0.58 \\
\hline 144122 & PHA & 0 & 1.61764 & 161764 \\
\hline 145122 & PHA & 2 & 095881 & 0.95881 \\
\hline 146128 & PHA & 30 & 40.13964 & 10.13964 \\
\hline 147128 & PHA & 30 & $40 \times 12$ & 10.342 \\
\hline$1 4 8 \longdiv { 2 8 }$ & PHA & 30 & 101082 & 10.1022 \\
\hline 149128 & PHA & 30 & 40.62416 & 10.62416 \\
\hline 150128 & PHA & 30 & 40.0 .25 & 10.0225 \\
\hline 151127 & PHA & 30 & 41.82557 & 11.82557 \\
\hline 152127 & PHA & 30 & 42.14285 & 12.14285 \\
\hline 153127 & PHA & 30 & 4187814 & 11.87814 \\
\hline $154 \mid 27$ & PHA & 30 & $42,0368 \mathrm{Bg}$ & 12.03689 \\
\hline 155127 & PHA & 30 & 4256201 & 12.56201 \\
\hline 156131 & PHA & 50 & 63.40255 & 13.40255 \\
\hline 157131 & PHA & 50 & 63.91504 & 13.91504 \\
\hline 158131 & PHA & 50 & 63.7344 & 13.7344 \\
\hline 159131 & PHA & 50 & 63.91013 & 1391013 \\
\hline 160131 & PHA & 50 & 64.04967 & 14.04067 \\
\hline 161125 & PHA & 0 & 0.78065 & 0.79065 \\
\hline$1 6 2 \longdiv { 2 5 }$ & PHA & 0 & 0.72983 & 0.7792 .3 \\
\hline $163 / 25$ & PHA & 0 & 1.06523 & 106523 \\
\hline $164 \sqrt{25}$ & PHA & 0 & 0.84866 & 0.84966 \\
\hline 165125 & PHA & 요 & 123341 & 123341 \\
\hline $166 / 24$ & $\mathrm{PHA}$ & e] & -102448 & .104448 \\
\hline 167124 & PHA & 0 & .0046686 & .0 .046586 \\
\hline 168124 & PHA & 0 & .0 .031499 & -0.031499 \\
\hline 169124 & PHA & 0 & .0 .040468 & -0.040488 \\
\hline 170124 & PHA & 0 & .0 .3085 & .0 .3085 \\
\hline 171126 & PHA & 30 & 40.49129 & 10.49129 \\
\hline 172126 & PHA & 30 & 40.50966 & 10,50968 \\
\hline $173 \mid 26$ & PHA & 30 & 40.523185 & 10.52385 \\
\hline 174126 & $\mathrm{PHA}$ & 30 & 40.84539 & 10.24539 \\
\hline 175126 & PHA & 30 & 40.98933 & 10.98933 \\
\hline 176132 & PHA & 50 & 66.32249 & 16.32249 \\
\hline 177132 & PHA & 50 & 66.23838 & 16.23838 \\
\hline 178132 & $\mathrm{PHA}$ & 50 & 66.22123 & 16,22123 \\
\hline $179 / 32$ & PHA & 50 & 66.40597 & 16.40597 \\
\hline 180132 & PHA & 50 & 66,25004 & 16.25004 \\
\hline 181100 & $10 \%$ METH & 0 & .0 .69381 & .0 .69381 \\
\hline 182100 & $10 \%$ METH & 2 . & .0 .63082 & .0 .63082 \\
\hline 183100 & $10 \%$ MEIH & 0 & .056337 & .056337 \\
\hline 184100 & $10 \%$ METH & 2 & 0.06718 & 0,06718 \\
\hline 185102 & 10\% METH & 0 & .0 .2317 & .0 .2317 \\
\hline
\end{tabular}


Table 4.2: Tests for Equal Variances for Repeated Measurements Level $=$ sample number

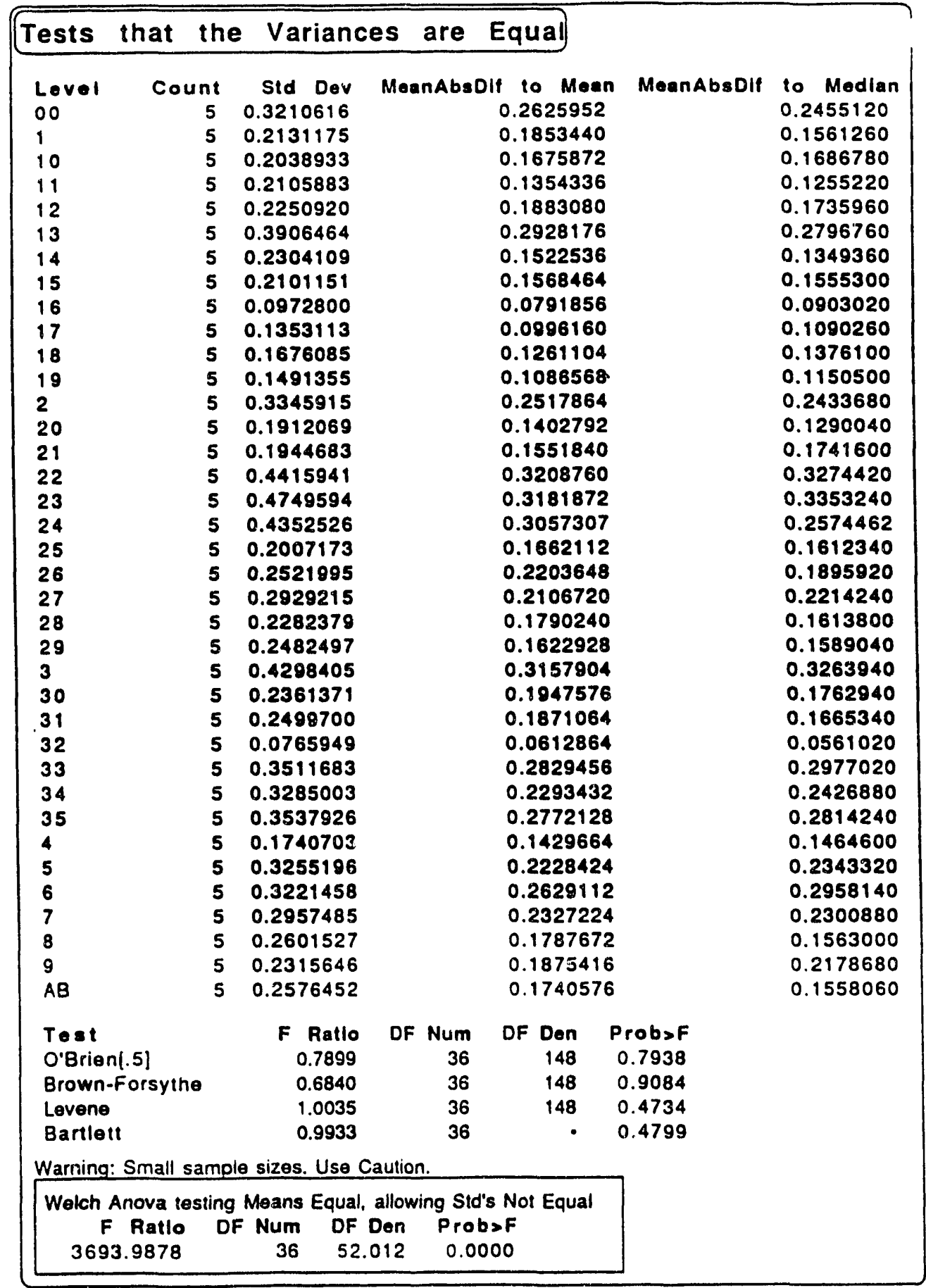


Table 4.3: Summary of Solution Matrix Data by Sample

Benzene Values in ppm $\quad A B=$ air blank

\begin{tabular}{|c|c|c|c|c|c|c|c|}
\hline Rows & Time (hrs) & Sample & Matrix & $\mathbf{N}$ & $\operatorname{Mean}(B \in n$ Std) & Mean(Ben Meas) & Std(Ben Meas) \\
\hline 1 & - & 00 & $10 \%$ METH & 5 & 0 & -0.410504 & 0.32106164 \\
\hline 2 & 1.316 & 1 & $10 \%$ MEIH & 5 & 0 & -0.5689 & 0.21311747 \\
\hline 3 & 2.179 & 10 & $10 \%$ MEIH & 5 & 8,5 & 10.549894 & 0.20389328 \\
\hline 4 & 0.613 & 11 & $10 \%$ METH & 5 & 30 & 39.909224 & 0.21058825 \\
\hline 5 & 0.000 & $\sqrt{12}$ & $10 \%$ MEIH & 5 & 30 & 39.60842 & 0.22509201 \\
\hline 6 & 2.091 & 13 & $10 \%$ MEIH & 5 & 30 & 39.477588 & 0.39064643 \\
\hline 7 & 1.620 & 14 & $10 \%$ METH & 5 & 30 & 38.227394 & 0.23041092 \\
\hline 8 & 2.003 & 15 & $10 \%$ MEIH & 5 & 30 & 39.832058 & 0.21011513 \\
\hline 9 & 0.105 & 16 & $10 \%$ METH & 5 & 50 & 66.464692 & 0.09728004 \\
\hline 10 & 1.419 & 17 & $10 \%$ MEIH & 5 & 50 & 66.55678 & 0.13531133 \\
\hline 11 & 0.421 & 18 & $10 \%$ METH & 5 & 50 & 65.839982 & 0.16780846 \\
\hline 12 & 1.910 & 18 & $10 \%$ MEIH & 5 & 50 & 65.935556 & 0.14913547 \\
\hline 13 & 1.811 & 2 & $10 \%$ MATH & 5 & 0 & -0.354862 & 0.33459153 \\
\hline 14 & 2.265 & 20 & $10 \%$ METH & 5 & 50 & 63.210856 & 0.1912069 \\
\hline 15 & 0.000 & 21 & PHA & 5 & 0 & 0.4631 & 0.1844683 \\
\hline 16 & 0.555 & 22 & PHA & 5 & 0 & 0.88713 & 0.1415941 \\
\hline 17 & 0.369 & 23 & PHA & 5 & 0 & 0.771284 & 0.47495942 \\
\hline 18 & 1079 & 24 & PHA & 5 & 0 & -0.2943266 & 0.43525263 \\
\hline 19 & 0.974 & 25 & $\mathrm{PHA}$ & 5 & 0 & 0.911556 & 0.20071729 \\
\hline 20 & 1.178 & 26 & PHA & 5 & 30 & 40.691804 & 0.25219951 \\
\hline 21 & 0.776 & 27 & PHA & 5 & 30 & 42.08909 & 0.29292151 \\
\hline 22 & 0.660 & 28 & PHA & 5 & 30 & 40.2593 & 0.22823786 \\
\hline 23 & 0.181 & 29 & PHA & 5 & 30 & 39.389788 & 0.24824972 \\
\hline 24 & 0.714 & 3 & $10 \%$ MEIH & 5 & 0 & -0.426178 & 0.42984048 \\
\hline 25 & 0.088 & 30 & PHA & 5 & 30 & 40.030578 & 0.23613707 \\
\hline 26 & 0.875 & 31 & PHA & 5 & 50 & 63.802358 & 0.24996999 \\
\hline 27 & 1.273 & 32 & PHA & 5 & 50 & 68.287622 & 0.07659488 \\
\hline 28 & 0.459 & 33 & PHA & 5 & 50 & 65.056082 & 0.35116828 \\
\hline 29 & 0.282 & 34 & PHA & 5 & 50 & 65.970786 & 0.32850032 \\
\hline 30 & 2.444 & 35 & $10 \%$ MEIH & 5 & 50 & 65.6769 .54 & 0,35379256 \\
\hline 31 & 0.212 & 4 & $10 \%$ METH & 5 & 0 & 0.089918 & 0.17407026 \\
\hline 32 & 2.350 & 5 & $10 \%$ MFTH & 5 & 0 & 0.314578 & 0.32551962 \\
\hline 33 & 0.518 & 6 & $10 \%$ METH & 5 & 8.5 & 11.284626 & 0.32214583 \\
\hline 34 & 0.326 & 7 & $10 \%$ MEIH & 5 & 8.5 & 10.996592 & 0.29574848 \\
\hline 35 & 1.715 & 8 & $10 \%$ METH & 5 & 8.5 & 10.996638 & 0.26015271 \\
\hline 36 & 1.526 & 9 & 10\% METH & 5 & 8.5 & 11.001772 & 0.23156456 \\
\hline 37 & $\cdot$ & $A B$ & & 5 & 0 & -0.414836 & 0.25764518 \\
\hline
\end{tabular}


Table 4.4: Linear Calibration Fit for Solution Matrix Data

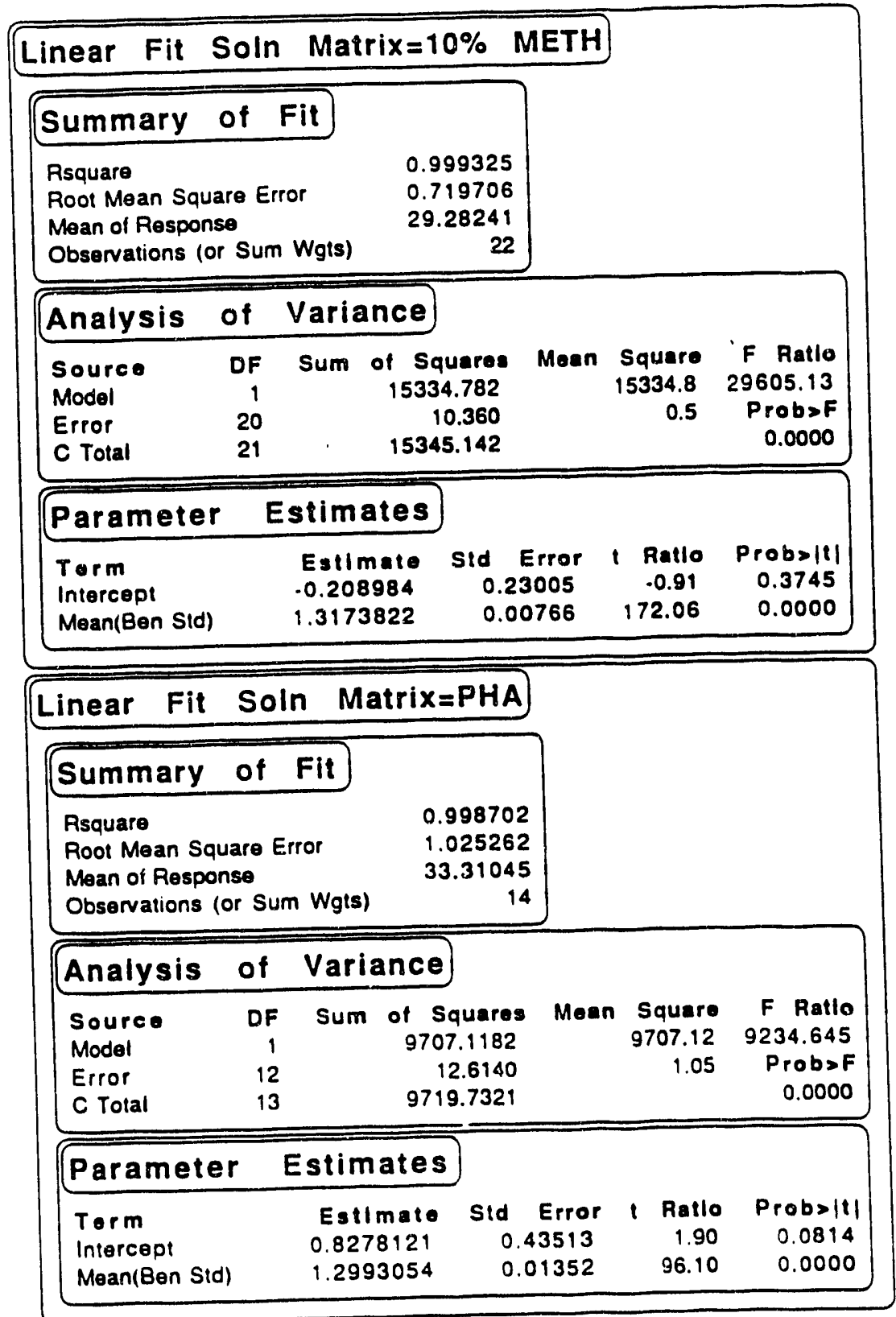


Table 4.5: Quadratic Calibration Fit for Solution Matrix Data

\begin{tabular}{|c|c|c|c|c|c|c|c|c|}
\hline Polynomial & Fit, & \multicolumn{2}{|c|}{ degree $=2$} & Soln & \multicolumn{3}{|c|}{ Matrix $=10 \%$} & $\%$ METH \\
\hline \multicolumn{9}{|c|}{ Summary of Fit } \\
\hline \multicolumn{3}{|c|}{$\begin{array}{l}\text { Rsquare } \\
\text { Root Mean Square Error } \\
\text { Mean of Response } \\
\text { Observations (or Sum Wgts) }\end{array}$} & \multicolumn{2}{|c|}{$\begin{array}{r}0.999328 \\
0.736734 \\
29.28241 \\
22\end{array}$} & & & & \\
\hline \multicolumn{9}{|c|}{ Analysis of Variance } \\
\hline $\begin{array}{l}\text { Source } \\
\text { Model } \\
\text { Error } \\
\text { C Total }\end{array}$ & $\begin{array}{r}\text { DF } \\
2 \\
19 \\
21\end{array}$ & sum & $\begin{array}{r}\text { of Squi } \\
15334 . \\
10 \\
15345 .\end{array}$ & $\begin{array}{l}829 \\
313 \\
142\end{array}$ & Mean & $\begin{array}{l}\text { Squ } \\
7667\end{array}$ & $\begin{array}{l}\text { uare } \\
7.41 \\
0.54\end{array}$ & $\begin{array}{c}\text { F Patio } \\
14126.28 \\
\text { Prob>F } \\
0.0000\end{array}$ \\
\hline \multicolumn{9}{|c|}{ Parameter Estimates } \\
\hline $\begin{array}{l}\text { Torm } \\
\text { Intercept } \\
\text { Mean(Ben Std) } \\
\text { Mean(Ben Std) }\end{array}$ & & $\begin{array}{l}\text { Est } \\
-0.2 \\
1.32 \\
-0.0\end{array}$ & $\begin{array}{l}\text { tlmate } \\
249473 \\
265886 \\
00183\end{array}$ & $\begin{array}{l}\text { sid } \\
0 \\
0.0 \\
0.0\end{array}$ & $\begin{array}{l}\text { Error } \\
0.2729 \\
03232 \\
00062\end{array}$ & 1 & $\begin{array}{l}\text { Ratlo } \\
.0 .91 \\
41.04 \\
.0 .29\end{array}$ & $\begin{array}{c}\text { Probs }>11 \mid \\
0.3721 \\
0.0000 \\
0.7723\end{array}$ \\
\hline
\end{tabular}

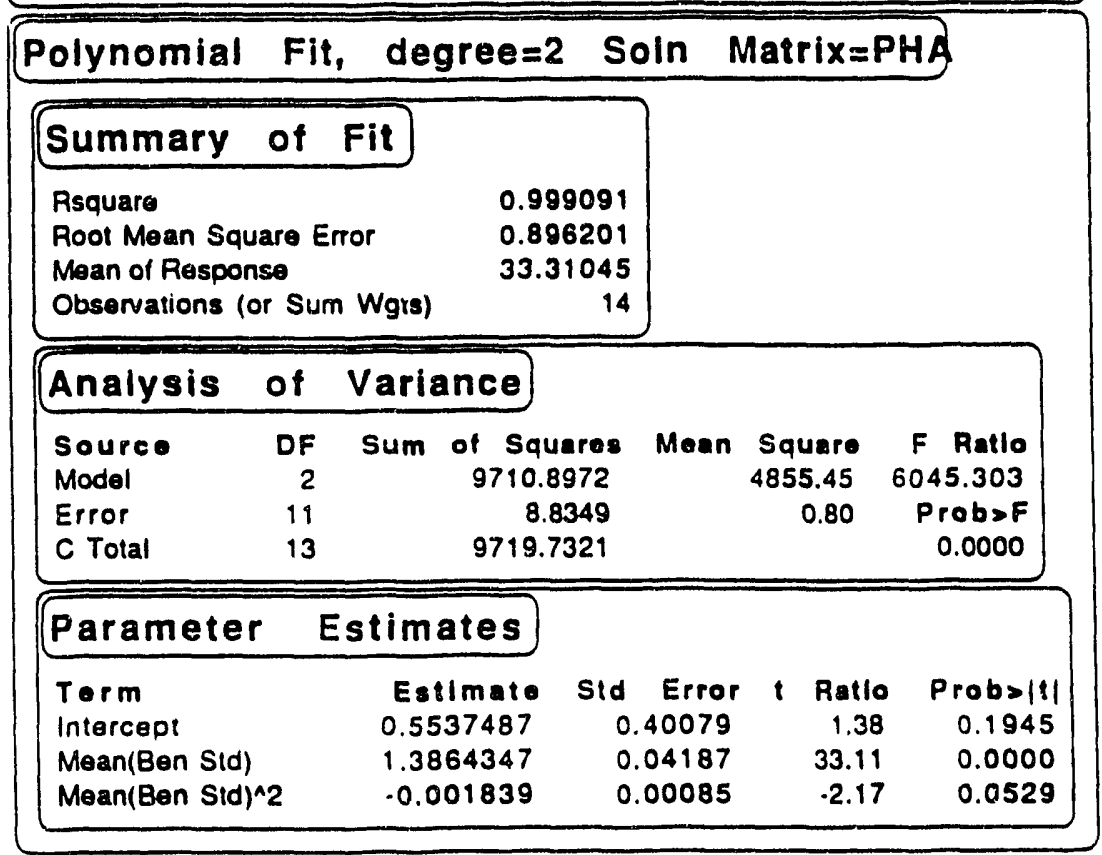


Table 4.6: Time Stability of 10\% Methanol Preparation

Mean(Ben Meas) By Time (hrs)

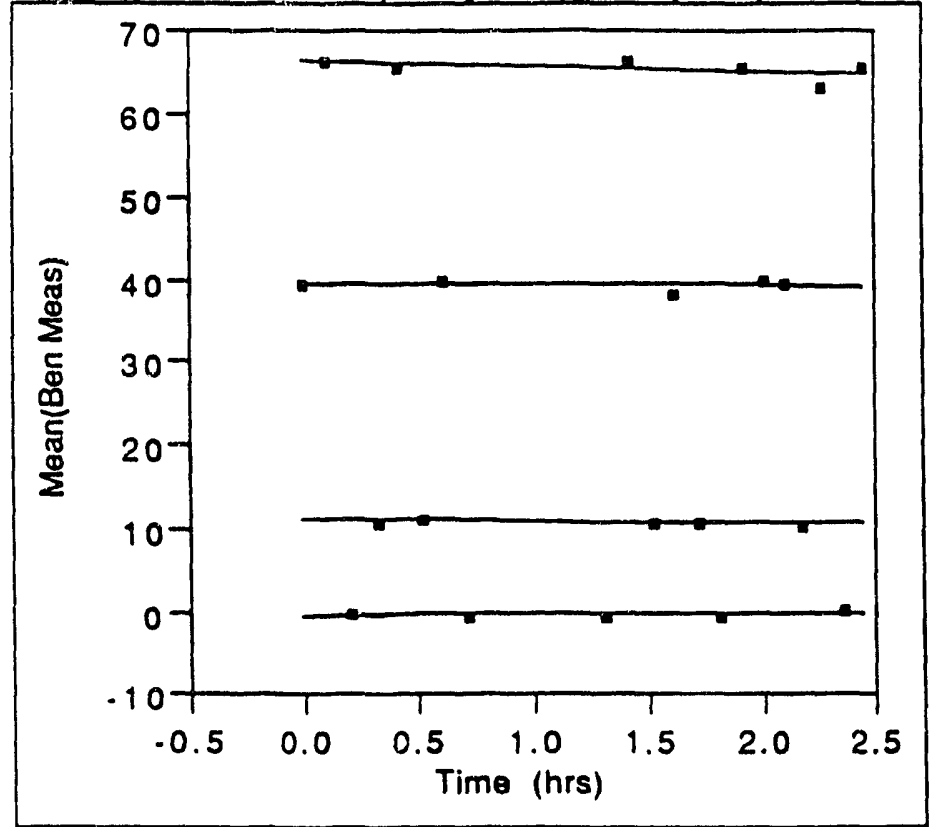

Fitting

- Linear Fit Mean(Ben Std) $=0$

- Linear Fit Mean(Ben Std) $=8.5$

- Linear Fit Mean(Ben Sid) $=30$

- Linear Fit Mean(Ben Sid) $=50$ 
Table 4.6 (con't): Time Stability of 10\% Methanol Preparation

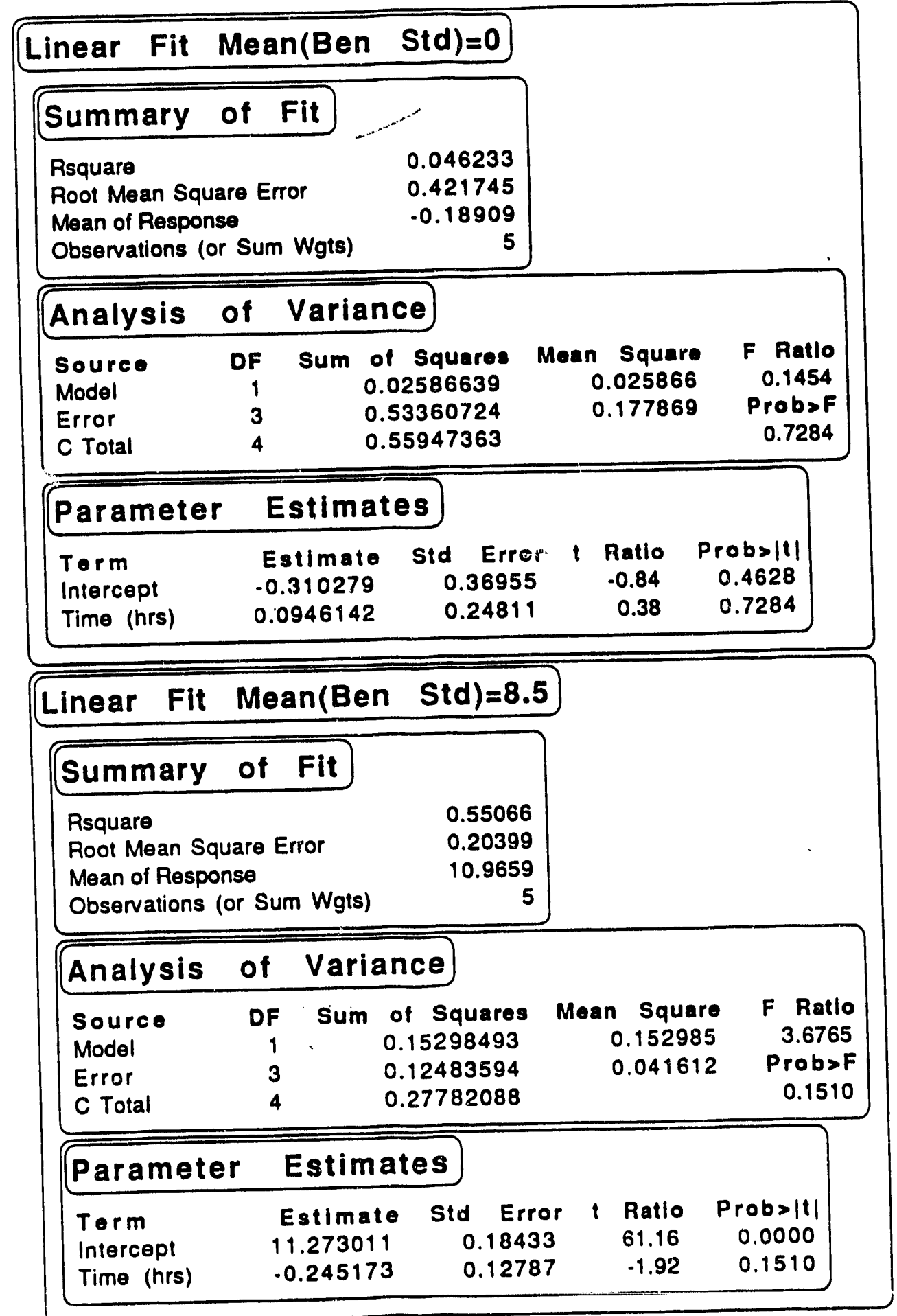


Table 4.6 (con't): Time Stability of 10\% Methanol Preparation

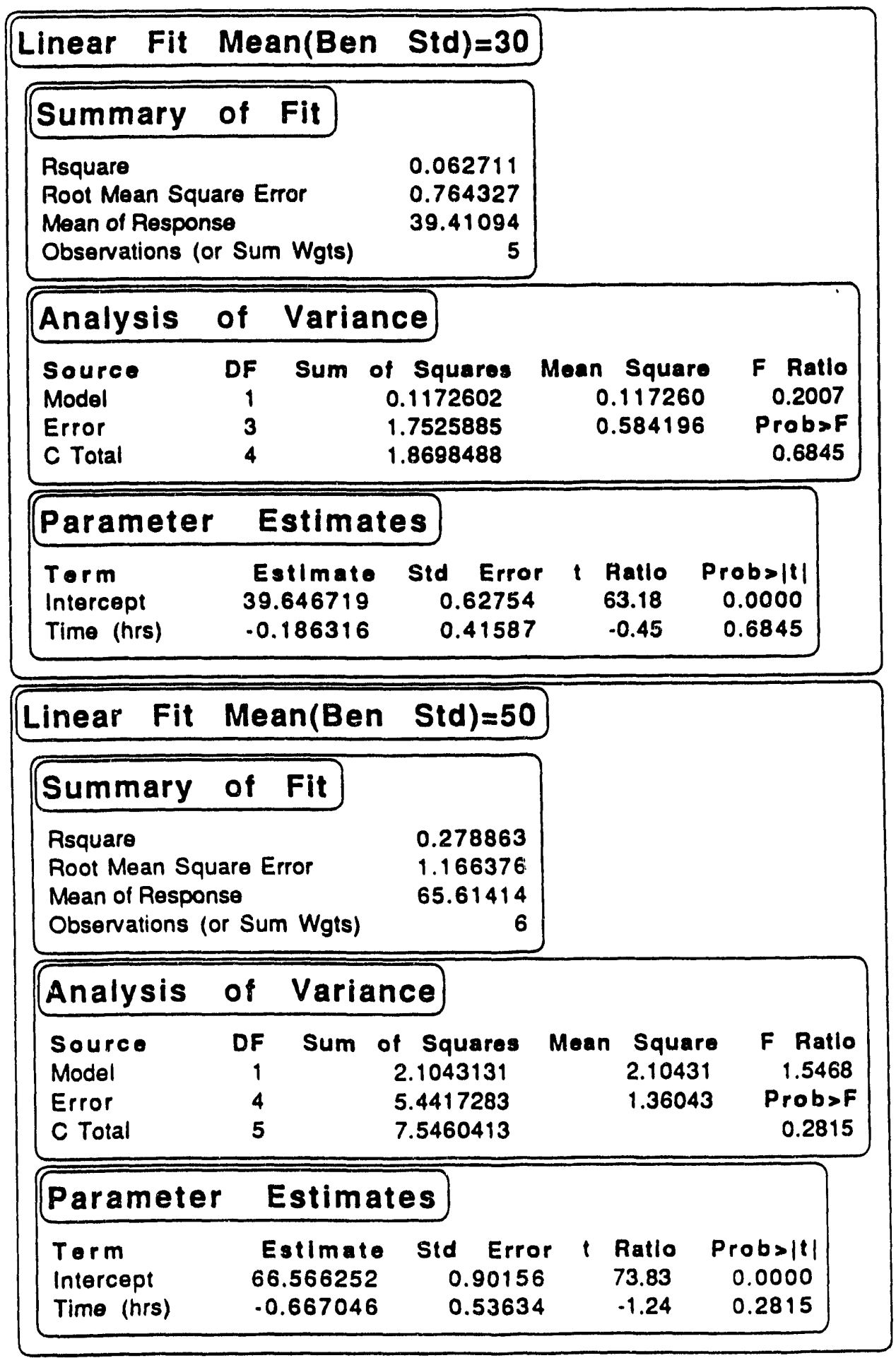


Table 4.7: Time Stability of PHA Preparation

\section{Mean(Ben Meas) By Time (hrs)}

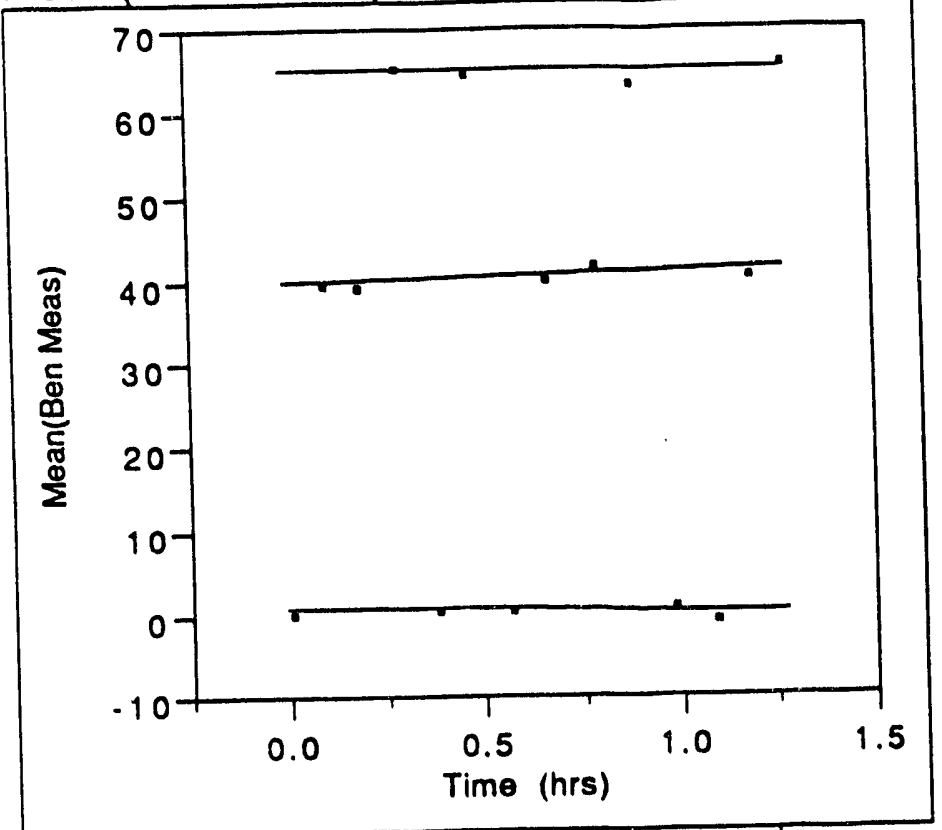

Fitting

- Linear Fit Mean(Ben Std)=0

- Linear Fit Mean(Ben Sid) $=30$

- Linear Fit Mean(Ben Std) $=50$ 
Table 4.7 (con't): Time Stability of PHA Preparation

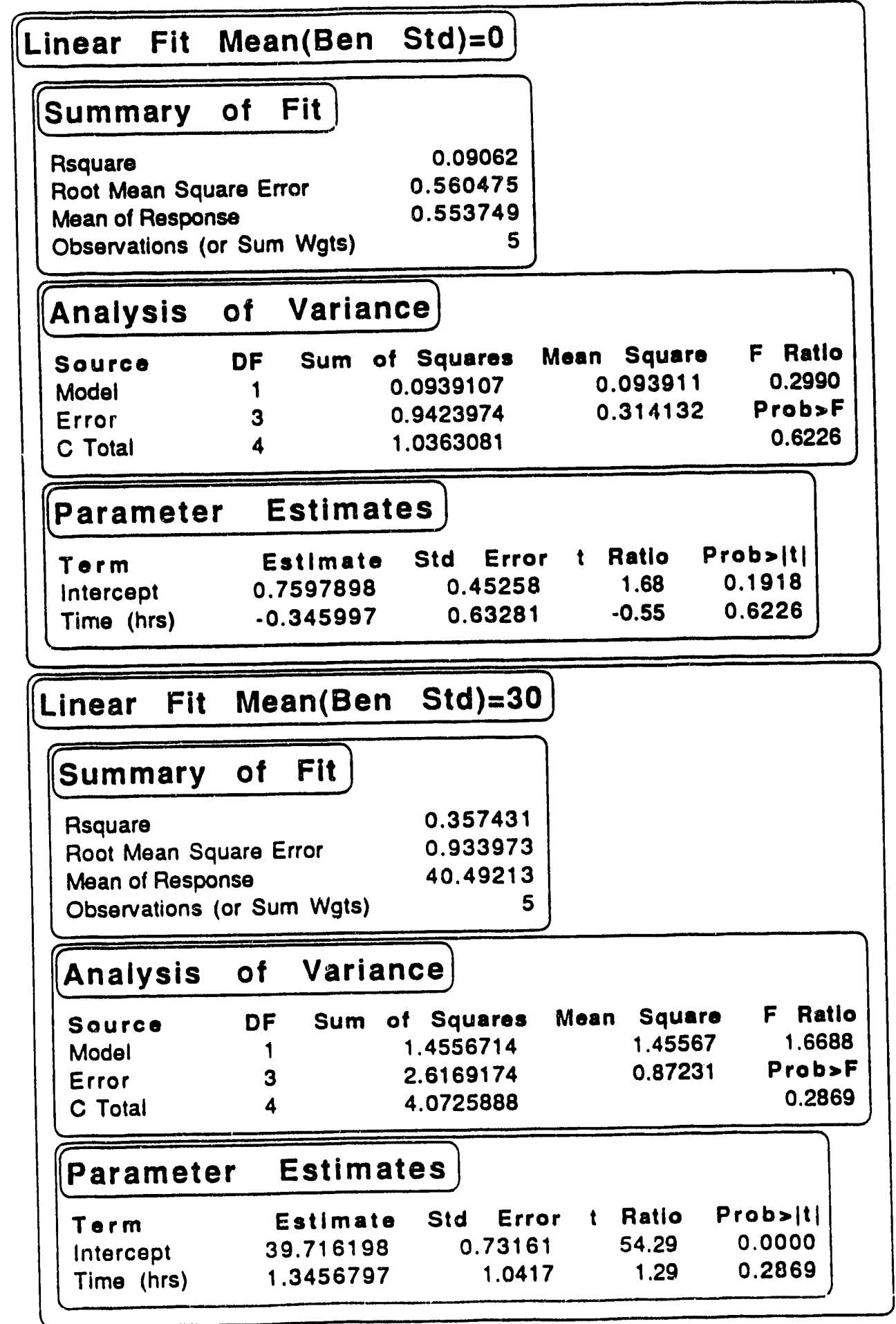


Table 4.7 (con't): Time Stability of PHA Preparation

\begin{tabular}{|c|c|c|c|c|c|}
\hline \multicolumn{3}{|c|}{ Linear Fit Mean(Ben Std) $=50$} & & & \\
\hline \multicolumn{6}{|c|}{ Summary of Fit } \\
\hline \multicolumn{2}{|c|}{$\begin{array}{l}\text { Rsquare } \\
\text { Root Mean Square Error } \\
\text { Mean of Response } \\
\text { Observations (or Sum Wgts) }\end{array}$} & $\begin{array}{r}0.003167 \\
1.362764 \\
65.27921 \\
4\end{array}$ & & & \\
\hline \multicolumn{6}{|c|}{ Analysis of Variance } \\
\hline $\begin{array}{l}\text { Source } \\
\text { Model } \\
\text { Error } \\
\text { C Total }\end{array}$ & $\begin{array}{rr}\text { DF } & \text { Sum of } \\
1 & 0 \\
2 & 3 \\
3 & 3 \\
\end{array}$ & $\begin{array}{l}\text { Squares } \\
0.0117996 \\
3.7142504 \\
3.7260501\end{array}$ & Moan & $\begin{array}{l}\text { Square } \\
0.01180 \\
1.85713\end{array}$ & $\begin{array}{r}\text { Fatlo } \\
0.0064 \\
\text { Prob }>F \\
0.9437\end{array}$ \\
\hline \multicolumn{6}{|l|}{ Parameter } \\
\hline $\begin{array}{l}\text { Term } \\
\text { Intercept } \\
\text { Time (hrs) }\end{array}$ & $\begin{array}{l}\text { Estimate } \\
65.177052 \\
0.1414519\end{array}$ & $\begin{array}{c}\text { Std Error } \\
1.45151 \\
1.77458\end{array}$ & t & $\begin{array}{r}\text { Ratio } \\
44.90 \\
0.08\end{array}$ & $\begin{array}{c}\text { Probs }>|t| \\
0.0005 \\
0.9437\end{array}$ \\
\hline
\end{tabular}


SCS-ASG-92066

September 16, 1992

Task 92-022-0

Page 41 of 54

Table 5.1: Data from PR Study

Ben Meas in ppm
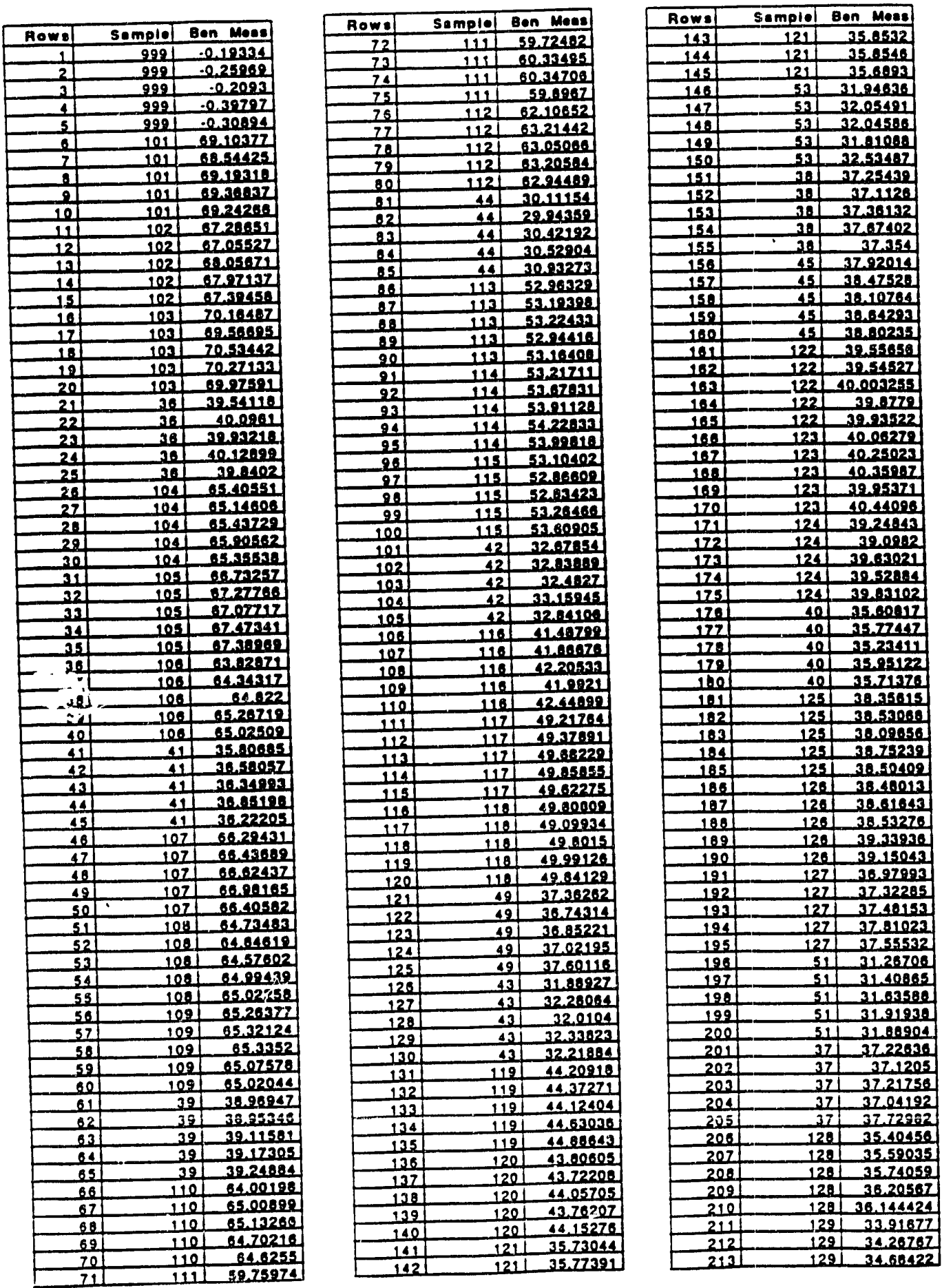

\begin{tabular}{|c|c|c|}
\hline Rowal & Sample & Ben moes \\
\hline 214 & 122 & 34.75734 \\
\hline 215 & 129 & 34.88004 \\
\hline 216 & 130 & 33.57625 \\
\hline 212 & 130 & 33.77693 \\
\hline 218 & 130 & 33.76514 \\
\hline 219 & 130 & 34.15701 \\
\hline 220 & 130 & 3406004 \\
\hline 222 & 47 & 36.9254 \\
\hline 222 & 47 & 39.7548 \\
\hline 221 & 47 & 39.24451 \\
\hline 224 & 47 & 3709752 \\
\hline 225 & 47 & 36.66148 \\
\hline 228 & 50 & 38,46927 \\
\hline 227 & 50 & 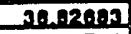 \\
\hline 228 & 50 & 38.89738 \\
\hline 222 & 30 & 19.09215 \\
\hline 230 & 30 & 39.27453 \\
\hline 232 & 134 & 313.125as \\
\hline 232 & 1314 & 33,5423 \\
\hline 233 & 131 & 32,55012 \\
\hline 234 & 131 & 31.91424 \\
\hline 235 & 311 & $2 \ln 39792$ \\
\hline 238 & 132 & s0. \\
\hline 232 & 132 & 30.97098 \\
\hline 2381 & 132 & 31.22563 \\
\hline 232 & 132 & 10.92902 \\
\hline 240 & 122 & 21.051 .42 \\
\hline 241 & $133 !$ & 30.44893 \\
\hline 242 & 133 & 30.75428 \\
\hline 243 & 132 & $30.795 \mathrm{~Pa}$ \\
\hline 244 & 133 & 14200.11 \\
\hline 245 & 133 & 216162 \\
\hline 268 & 18 & 32.51242 \\
\hline 247 & 40 & 39.19:22 \\
\hline 24: & 49 & 39.61759 \\
\hline 222 & 48 & 39.5FEL1 \\
\hline 250 & 19 & 19.97181 \\
\hline 251 & 998 & 0.00429 \\
\hline 252 & 929 & 0.30439 \\
\hline 253 & 298 & 0.31 .045 \\
\hline 254 & 292 & 0,57052 \\
\hline 255 & 922 & 0.09 \\
\hline
\end{tabular}


Table 5.2: Summary Data from PR Study

Ben Meas in ppm

\begin{tabular}{|c|c|c|c|c|}
\hline Row 8 & Sample & $N$ & Mean(Ben Meas) & Elapsed Time \\
\hline 1 & 36 & 5 & 39.90773 & $\bullet$ \\
\hline 2 & 37 & 5 & 37.267232 & $\dot{.}$ \\
\hline 3 & 38 & 5 & 32351266 & $\cdot$ \\
\hline 4 & 39 & 5 & 39.092126 & $\cdot$ \\
\hline 5 & 40 & 5 & 35,656346 & $\cdot$ \\
\hline 6 & 41 & 5 & 36.362276 & 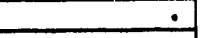 \\
\hline 7 & 42 & 5 & 32.800128 & $\bullet$ \\
\hline 8 & 43 & 5 & 32,147476 & $\bullet$ \\
\hline 9 & 44 & 5 & 30.387764 & $\cdot$ \\
\hline 10 & 45 & 5 & 38.389668 & 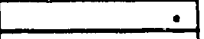 \\
\hline 11 & 47 & 5 & 36.876754 & $\bullet$ \\
\hline 12 & 48 & 5 & 39.551432 & $\cdot$ \\
\hline 13 & 49 & 5 & 37116216 & $\bullet$ \\
\hline 14 & 50 & 5 & 38.892428 & $\cdot$ \\
\hline 15 & 51 & 5 & 31,624002 & - \\
\hline 16 & 53 & 5 & 32.078576 & $\bullet$ \\
\hline 17 & 101 & 5 & 69.090446 & $e$ \\
\hline 18 & 102 & 5 & 67.552888 & 0.01666667 \\
\hline 19 & 103 & 5 & 70.102696 & 0.03333333 \\
\hline 20 & 104 & 5 & 65,449972 & 0.43353333 \\
\hline 21 & 105 & 5 & 67.1901 & 0.45 \\
\hline 22 & 106 & 5 & 64.657232 & 0.46666667 \\
\hline 23 & 107 & 5 & 66.548608 & 0.81666667 \\
\hline 24 & 108 & 5 & 64.794802 & 0,83333333 \\
\hline 25 & 109 & 5 & 65.203286 & 0.85 \\
\hline 26 & 110 & 5 & 64.694258 & 1.15 \\
\hline 27 & 111 & 5 & 60.012654 & 1.16666667 \\
\hline 28 & 112 & 5 & 62.904466 & 1,18333333 \\
\hline 29 & 113 & 5 & 53.097988 & 2.48333333 \\
\hline 30 & 114 & 5 & 53.806642 & 2.5 \\
\hline 31 & 115 & 5 & 53.13561 & 2.51666667 \\
\hline 32 & 116 & 5 & 42.000234 & 2,9 \\
\hline 33 & 117 & 5 & 49.552028 & 291666667 \\
\hline 34 & 118 & 5 & 49.708296 & 2.93333333 \\
\hline 35 & 119 & 5 & 44.444544 & 4.15 \\
\hline 36 & 120 & 5 & 43.900002 & 4.16666667 \\
\hline 37 & 121 & 5 & 35.78029 & 4.18333333 \\
\hline 38 & 122 & 5 & 39.783641 & 4.73333333 \\
\hline 39 & 123 & 5 & 40.213512 & 4.75 \\
\hline 40 & 124 & 5 & 39,46734 & 4.76666667 \\
\hline 41 & 125 & 5 & 38.447974 & 5.13333333 \\
\hline 42 & 126 & 5 & 38.823822 & 5.15 \\
\hline 43 & 127 & 5 & 37.429972 & 5.16666667 \\
\hline 44 & 128 & 5. & 35.8171188 & 6.15 \\
\hline 45 & 129 & 5 & 34.496408 & 6.16666662 \\
\hline 46 & 130 & 5 & 33.868734 & 6.18333333 \\
\hline 47 & 131 & 5 & 33.7184 & 6.51666667 \\
\hline 48 & 132 & 5 & 30.9542128 & 6.53333333 \\
\hline 49 & 133 & 5 & 30.872276 & 6.55 \\
\hline 50 & 998 & 5 & 0.124848 & $\cdot$ \\
\hline 51 & 999 & 5 & $=0.273848$ & $\cdot$ \\
\hline
\end{tabular}


Table 5.3: Tests for Equal Variances for Repeated Measurements

Level = sample number

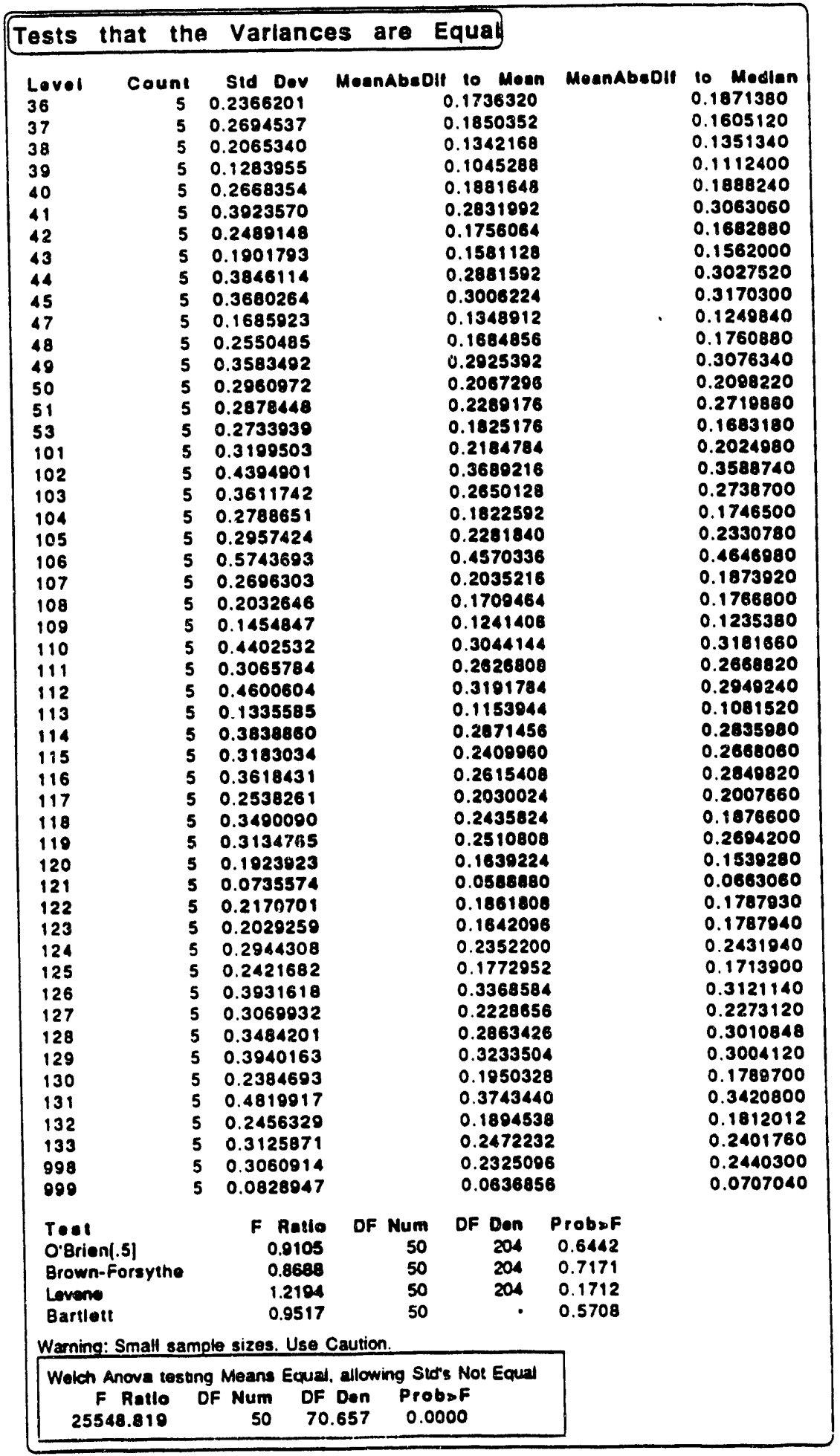


SCS-ASG-92066

Table 5.4: Time Study of PR Data

Ln(Ben) By Elapsed Time

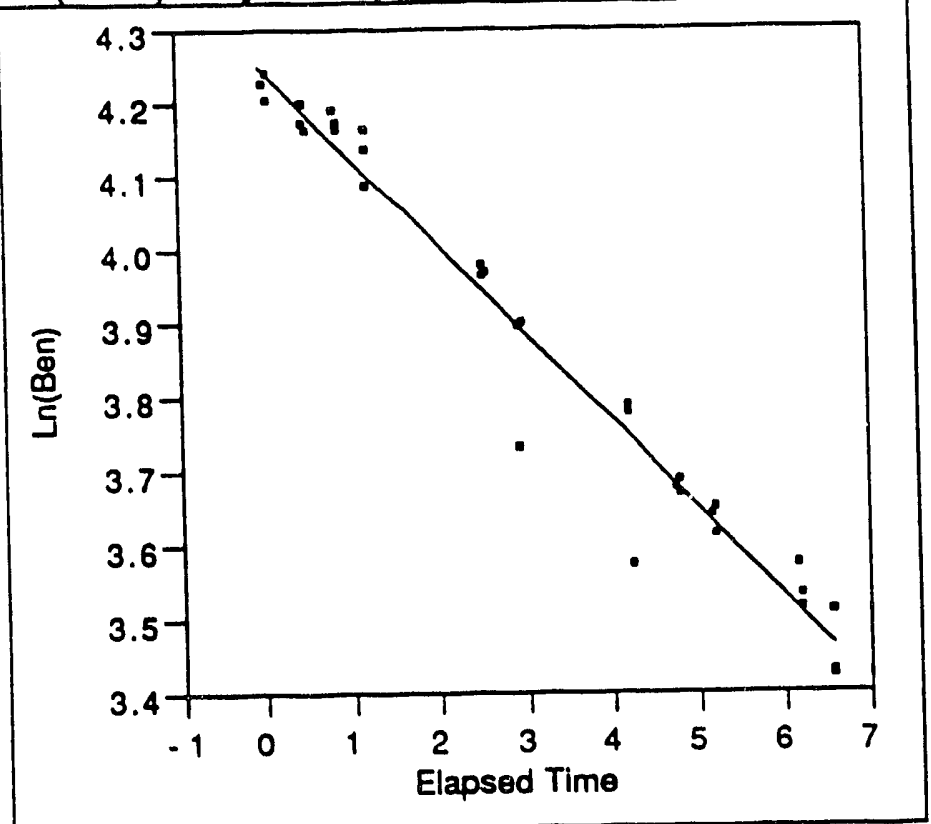

Fitting

Linear Fit

\begin{tabular}{|lr|}
\hline Linear Fit \\
\hline Summary of Fit \\
Rsquare & 0.965824 \\
Root Mean Square Error & 0.051828 \\
Mean of Response & 3.874111 \\
Observations (or Sum Wgts) & 33 \\
\hline
\end{tabular}

\begin{tabular}{|lrrrrr|}
\hline Analysis & of & Variance & & & \\
Source & DF & Sum of Squares Mean & Square & F Ratio \\
Model & 1 & 2.3532717 & 2.35327 & 876.0724 \\
Error & 31 & 0.0832710 & 0.00269 & Prob $>$ F \\
C Total & 32 & 2.4365427 & & 0.0000 \\
\hline
\end{tabular}

\section{Parameter Estimates}

Term

Intercept

Elapsed Time
Estimate Std

4.2502021

0.01558

1 Ratlo

272.73

$-29.60$
Probs $|t|$

0.0000

0.0000 
Table 6.1: PHA Standards with 10\% Methanol Calibration

Ben Meas in ppm

\begin{tabular}{|c|c|c|c|c|}
\hline Roweisamplel & Soln & Malrix & Ben Sidl & Ben Meas \\
\hline $111 / 21$ & PHA & & 0 & 0.52471 \\
\hline 112121 & PHA & & 0 & 0.65728 \\
\hline 113121 & PHA & & e & 292435 \\
\hline 114121 & PHA & & 2 & 0.90801 \\
\hline 115121 & PHA & & 0 & 0.98603 \\
\hline 116130 & PHA & & 30 & 30.09866 \\
\hline 117130 & PHA & & 30 & 30.28685 \\
\hline $118 / 30$ & PHA & & 30 & 30.46665 \\
\hline 119130 & PHA & & 30 & 30.33013 \\
\hline 120130 & PHA & & 30 & 30.47381 \\
\hline 121129 & PHA & & 30 & 29.59662 \\
\hline 122129 & PHA & & 30 & 29.59842 \\
\hline 123129 & PHA & & 30 & 29.84984 \\
\hline$1 2 4 \longdiv { 2 9 }$ & PHA & & 30 & 29.99616 \\
\hline$1 2 5 \longdiv { 2 9 }$ & PHA & & 30 & 30.21155 \\
\hline$1 2 6 \longdiv { 3 4 }$ & PHA & & 50 & 50.13058 \\
\hline 127134 & PHA & & 50 & 50.31184 \\
\hline 128134 & PHA & & 50 & 50.32833 \\
\hline 129134 & PHA & & 50 & 5051561 \\
\hline$1 3 0 \longdiv { 3 4 }$ & PHA & & 50 & 50.68206 \\
\hline$1 3 1 \longdiv { 2 3 }$ & PHA & & 0 & 0.66721 \\
\hline $132 / 23$ & LPHA & & 0 & 0.90075 \\
\hline 133123 & PHA & & 0 & 0.99622 \\
\hline $134 / 23$ & PHA & & 0 & 0.9927 \\
\hline 135123 & PHA & & 0 & 1.40823 \\
\hline $136 / 33$ & PHA & & 50 & 49.30 .22 \\
\hline 137133 & PHA & & 50 & 4950616 \\
\hline $138 / 33$ & PHA & & 50 & 49.68357 \\
\hline $139 \sqrt{3.3}$ & PHA & & 50 & 49.7509 \\
\hline $140 / 33$ & PHA & & 50 & 49.63065 \\
\hline 141122 & PHA & & e & 0.71252 \\
\hline $142 / 22$ & PHA & & 2 & 0.6851 \\
\hline $143 / 22$ & PHA & & e & 0.888332 \\
\hline $144 / 22$ & PHA & & L & 124241 \\
\hline 145$] 22$ & PHA & & e & 117701 \\
\hline $146 / 28$ & PHA & & 30 & 30.09102 \\
\hline $147 / 28$ & PHA & & 30 & 30.1141 \\
\hline \begin{tabular}{l|l}
148 & 28 \\
\end{tabular} & PHA & & 30 & 30.27688 \\
\hline $149 / 28$ & PHA & & 32 & 30.42872 \\
\hline 150$] 28$ & PHA & & 30 & 30.42011 \\
\hline $151 / 27$ & PHA & & 30 & 31.93026 \\
\hline$1 5 2 \longdiv { 2 7 }$ & PHA & & 30 & 31.96146 \\
\hline $153 / 27$ & PHA & & 30 & 31.80143 \\
\hline 154$] 27$ & PHA & & 30 & 32.00945 \\
\hline 155127 & PHA & & 30. & 32.12294 \\
\hline $156 / 31$ & PHA & & 50 & 48,5326 \\
\hline $157 / 31$ & PHA & & 50 & 48.72649 \\
\hline 158131 & PHA & & 50 & 48.89215 \\
\hline 159131 & PHA & & 50 & 4914115 \\
\hline 160131 & PHA & & 50 & 49.19444 \\
\hline 161125 & PHA & & 0 & 0.82569 \\
\hline 162125 & PHA & & e. & 0.99483 \\
\hline $163 / 25$ & PHA & & 01 & 125912 \\
\hline $164 \sqrt{25}$ & PHA & & 0 & 1,08209 \\
\hline$1 6 5 \longdiv { 2 5 }$ & $\mathrm{PHA}$ & & 0 & 127337 \\
\hline $168 \mid 24$ & $\mathrm{PHA}$ & & 0 & 0.16516 \\
\hline$1 6 7 \longdiv { 2 4 }$ & PHA & & 2 & 0.44898 \\
\hline$1 6 8 \longdiv { 2 4 }$ & $\mathrm{PHA}$ & & 2 & 0.6287 \\
\hline $169 / 24$ & $\mathrm{PHA}$ & & 2 & 0.78075 \\
\hline 170124 & PHA & & 2 & 0.79055 \\
\hline 171126 & PHA & & 30 & 30.6975 \\
\hline 172126 & $\angle P H A$ & & 301 & 3083247 \\
\hline $173 / 26$ & IPHA & & 30 & 30.90329 \\
\hline 174126 & PHA & & 30 & 30.96179 \\
\hline 175126 & PHA & & 30 & 3125518 \\
\hline 176132 & $\mathrm{PHA}$ & & 50 & 50.54341 \\
\hline 177126 & IPSA & & 50 & $50.8 B 159$ \\
\hline
\end{tabular}

\begin{tabular}{|c|l|r|r|}
\hline Roweisample & Soln Motrix & Ben Sid & Ben Meas \\
\hline 178132 & PHA & 50 & 50.73755 \\
\hline 179132 & PHA & 50 & 50.9556 \\
\hline 180132 & PHA & 50 & 50.93818 \\
\hline
\end{tabular}


Table 6.2: Tests for Equal Variances for Repeated Measurements

Level $=$ sample number

Ben Meas By Sample

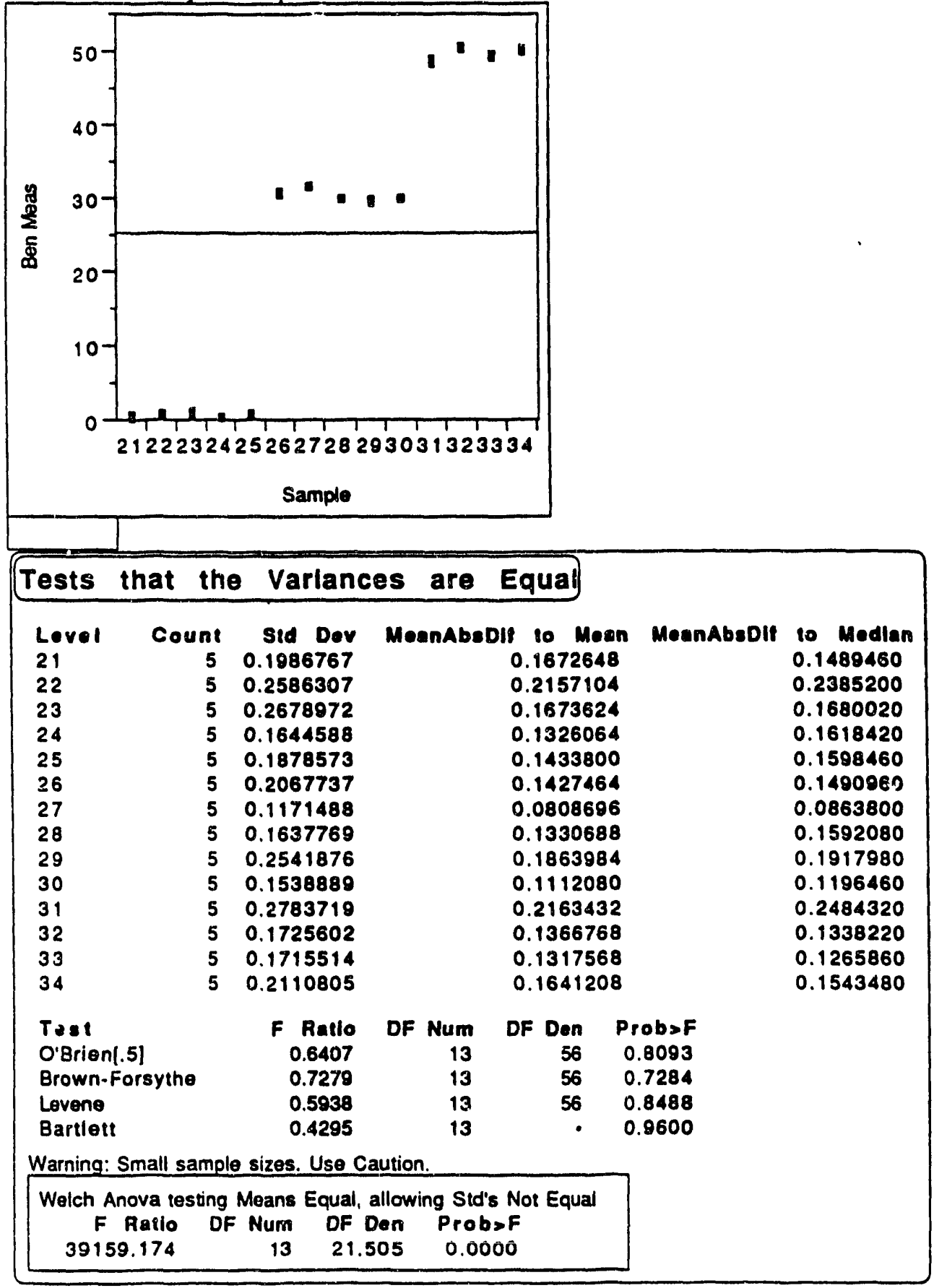


Table 6.3: Linear Calibration Fit for PHA Standards Data

Response: Mean(Ben Meas)

\begin{tabular}{|lr|}
\hline Summary of Fit & \\
\hline Rsquare & 0.99902 \\
Root Mean Square Error & 0.673505 \\
Mean of Response & 25.53132 \\
Observations (or Sum Wgts) & 14 \\
\hline
\end{tabular}

\begin{tabular}{|lrrrrr|}
\hline Lack of Fit & & & & \\
Source & DF & Sum of Squares & Mean Square & F Ratlo \\
Lack of Fit & 1 & 0.3972860 & 0.397286 & 0.8661 \\
Pure Error & 11 & 5.0460142 & 0.458729 & Prob>F \\
Total Error & 12 & 5.4433001 & & 0.3720 \\
\hline
\end{tabular}

\begin{tabular}{|lccccc|}
\hline Parameter & Estimates & & & \\
Torm & Estlmato & Std Error & Ratio & Prob $>|t|$ \\
Intercept & 0.9774651 & 0.28584 & 3.42 & 0.0051 \\
Mean(Ben Std) & 0.9821543 & 0.00888 & 110.58 & 0.0000 \\
\hline
\end{tabular}

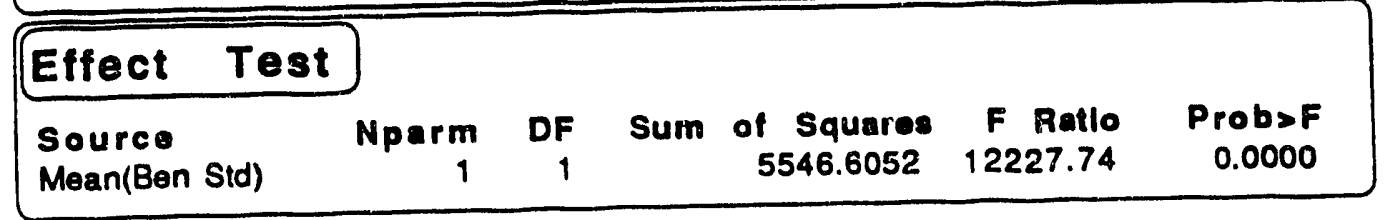


Table 6.4: Quadratic Calibration Fit for PHA Standards Data

Mean(Ben Meas) By Mean(Ben Std)

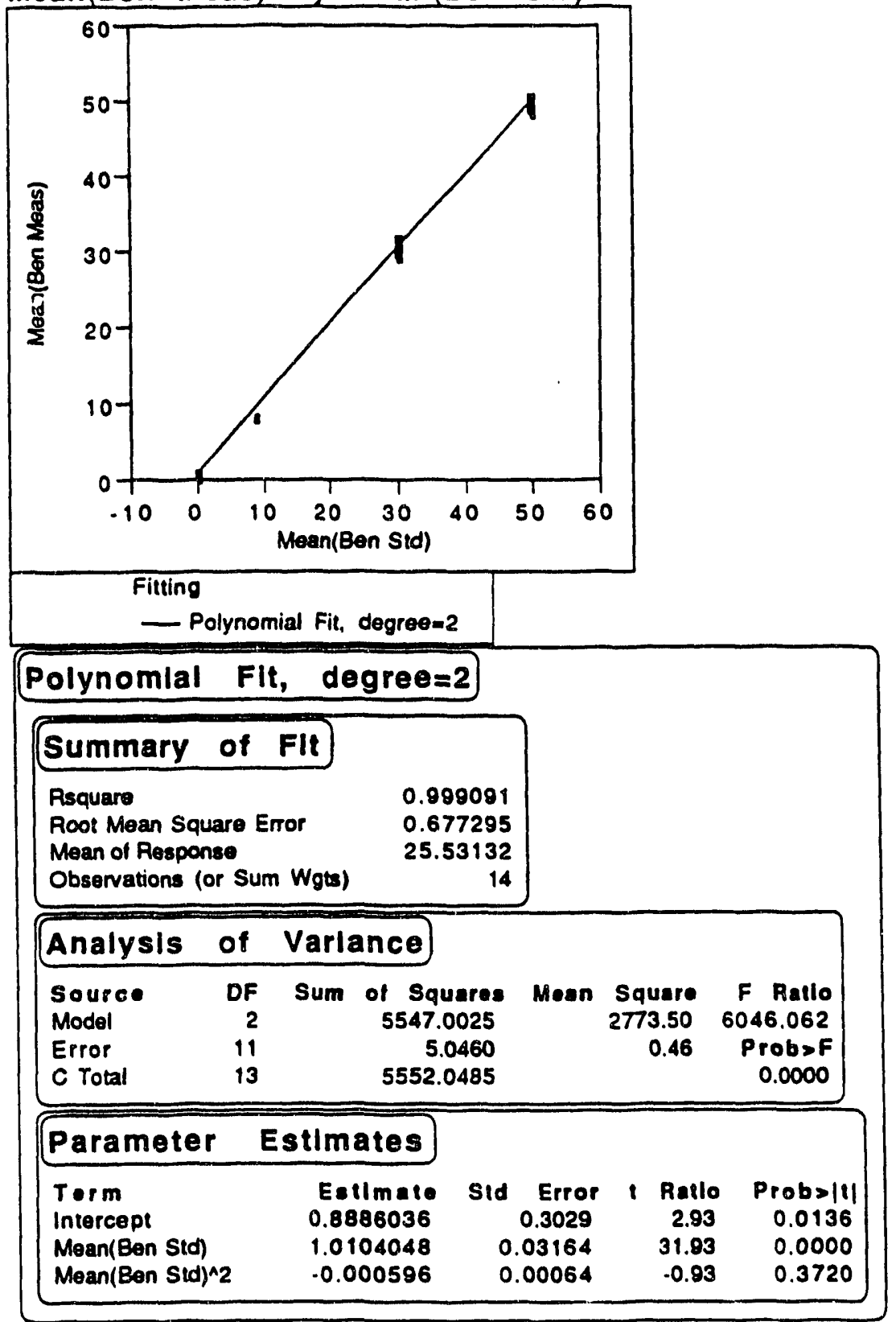


Table 6.5: Predicted Benzene Measurements

Ben Meas in ppm

\begin{tabular}{|c|c|c|c|c|c|c|c|}
\hline Rows & Samplo & $\mathbf{N}$ & Mean(Ben Std) & Mean(Bon Meas) & Predicled MeaniBen Meas & Lower $95 \%$ & Indlv Mean(Ben Mess, \\
\hline 15 & 21 & 5 & 0 & 0.800076 & 0.97746511 & & -0.6166693 \\
\hline 16 & 22 & 5 & 0 & 0.940072 & 0.97746511 & & -0.6166693 \\
\hline 17 & 23 & 5 & e & 0.993022 & 0.97746511 & & .0 .6166693 \\
\hline 18 & 24 & 5 & e & 0.622828 & 0.97746511 & & -0.6166693 \\
\hline 19 & 25 & 5 & 0 & 1.08702 & 0.97746511 & & .0 .6166693 \\
\hline 20 & 26 & 5 & 30 & 30.930042 & 30.442093 & & 28.920067 \\
\hline 21 & 27 & 5 & 30 & 31.965108 & 30.142093 & & 28,920067 \\
\hline 22. & 28 & 5 & 30 & 30,264346 & 30.442093 & & 28.920067 \\
\hline 23 & 29 & 5 & 30 & 29.830518 & 30.142093 & & 28.920067 \\
\hline 25 & 30 & 5 & 30 & 30.33122 & 30.442093 & & 28.920067 \\
\hline 26 & 31 & 5 & 50 & 48.897366 & 50.0851783 & & 48.4910439 \\
\hline 27 & 32 & 5 & 50 & 50.811326 & 50.0851783 & & 48.4910439 \\
\hline 28 & 33 & 5 & 50 & 49.571876 & 50.0851783 & & 48.4910439 \\
\hline 29 & 34 & 5 & 50 & 50,393684 & 50,0851783 & & 48.4910439 \\
\hline
\end{tabular}

\begin{tabular}{|r|r|r|}
\hline Row & Upper 95\% Indlu Mean(Ben Meas & SidErr Indiv Mean(Ben Meas \\
\hline 15 & 2.57159954 & 0.73165169 \\
\hline 16 & 2.57159951 & 0.73165169 \\
\hline 17 & 2.57159954 & 0.73165169 \\
\hline 18 & 2.57159954 & 0.73165169 \\
\hline 19 & 2.57159954 & 0.73165169 \\
\hline 20 & 31.9641191 & 0.69855648 \\
\hline 21 & 31.9641191 & 0.69855648 \\
\hline 22 & 31.9641191 & 0.69855648 \\
\hline 23 & 31.9641191 & 0.69855648 \\
\hline 25 & 31.9641191 & 0.69855648 \\
\hline 26 & 51.6793128 & 0.73165169 \\
\hline 27 & 51.6793128 & 0.73165169 \\
\hline 28 & 51.6793128 & 0.73165169 \\
\hline 29 & 51.6793128 & 0.73165169 \\
\hline
\end{tabular}


Table 6.6: SAS Code for Inverse Prediction Problem

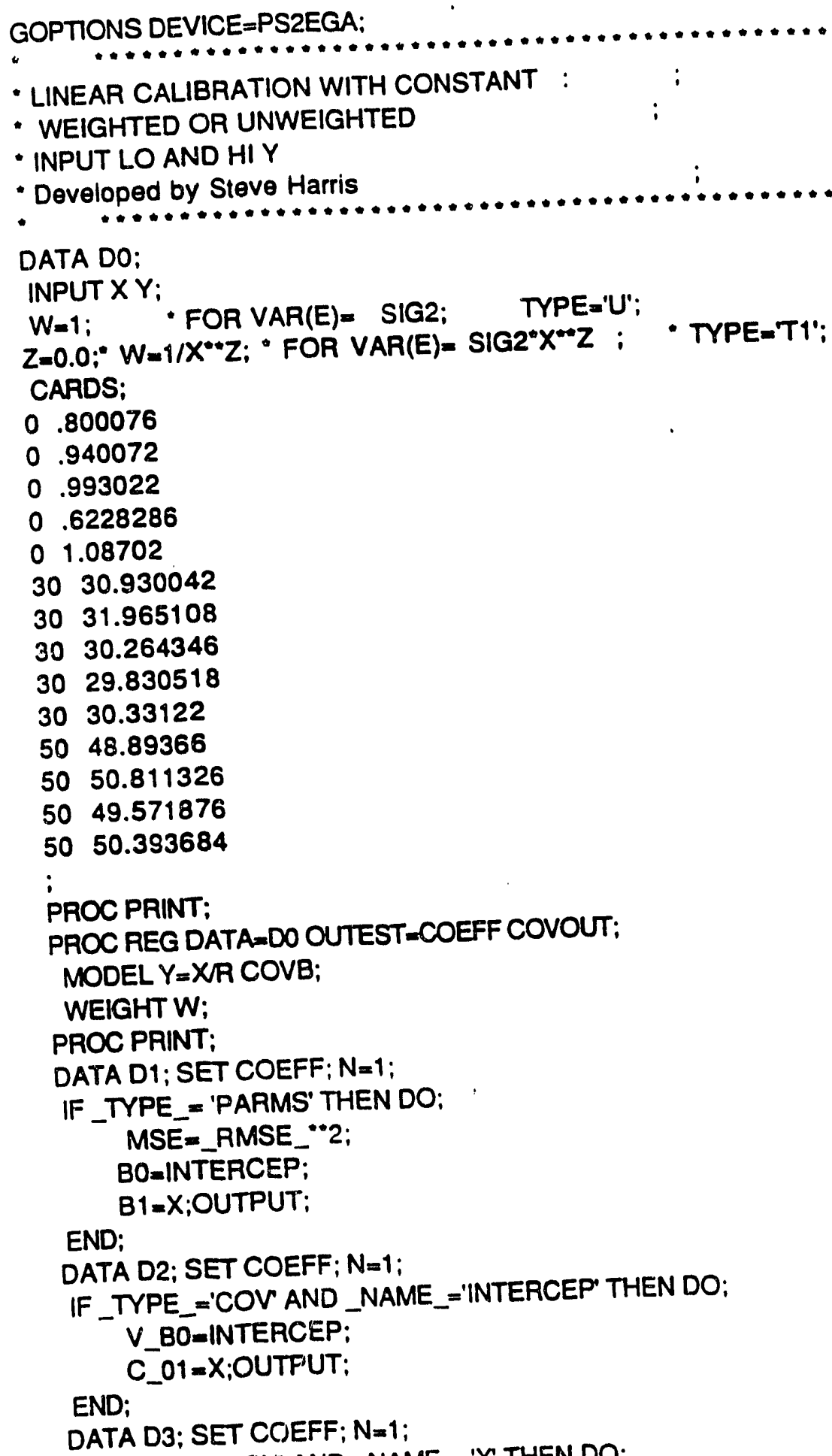

GOPTIONS DEVICE=PS2EGA: 
Table 6.6 (con't): SAS Code for Inverse Prediction Problem

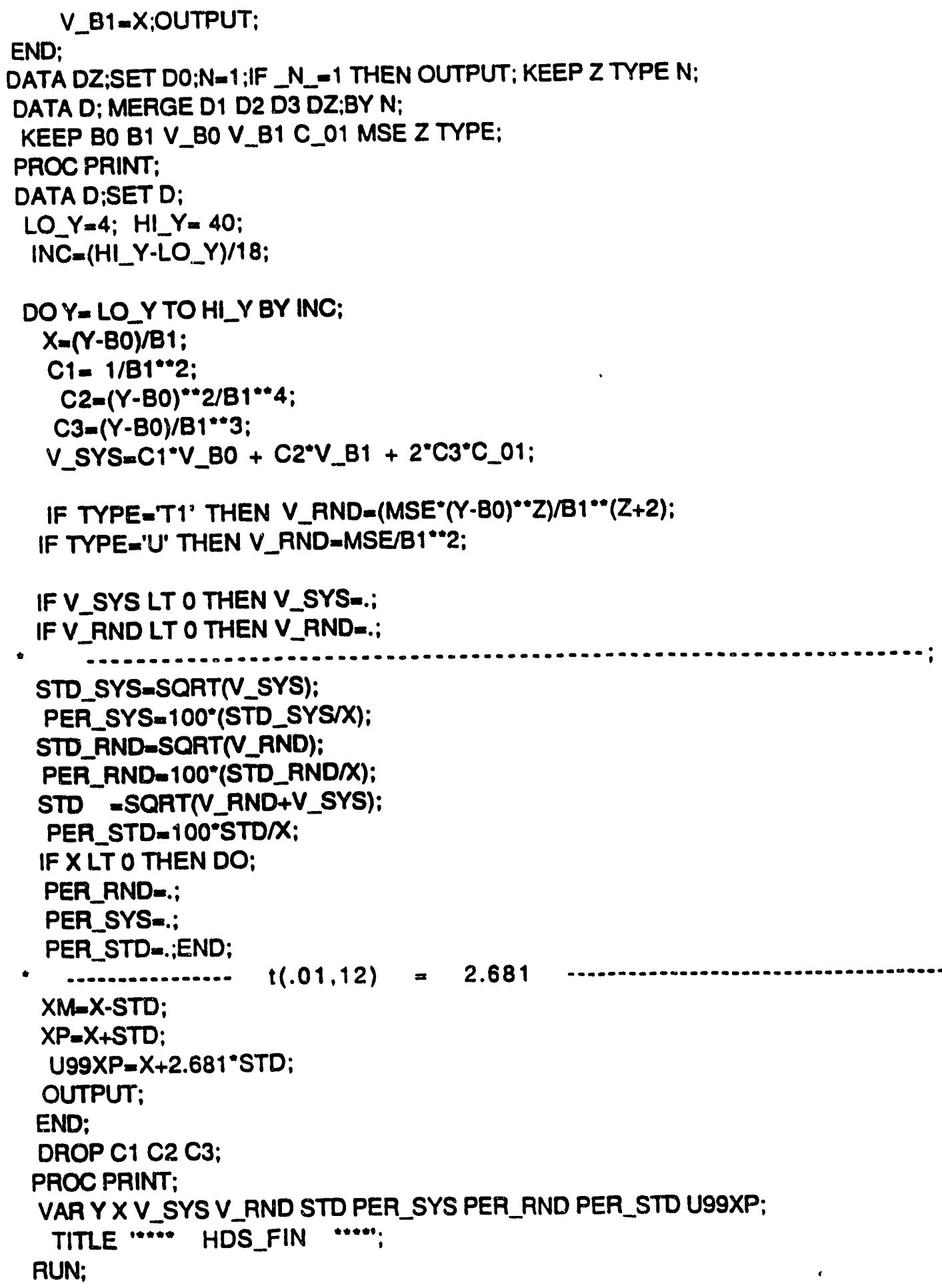


Table 6.7: Inverse Prediction Problem

The following table is a subset of the output from the SAS program listed in Table 6.6.

$\mathrm{Y}=\mathrm{ALBM}$ benzene value (ppm); $\quad \mathrm{X}=$ True Benzene Value $(\mathrm{ppm})$

\begin{tabular}{llllll}
$Y$ & $X$ & $\begin{array}{l}\text { Variance } \\
\text { Systematic } \\
\text { Error }\end{array}$ & $\begin{array}{l}\text { Variance } \\
\text { Random } \\
\text { Error }\end{array}$ & $\begin{array}{l}\text { Standard } \\
\text { Deviation } \\
\text { Total Error }\end{array}$ & $\begin{array}{l}\text { Upper 99\% } \\
\text { Prediction } \\
\text { Limit }\end{array}$ \\
\hline & & & & & \\
4 & 3.08 & 0.073 & 0.47 & 0.74 & 5.05 \\
6 & 5.11 & 0.066 & 0.47 & 0.73 & 7.08 \\
8 & 7.15 & 0.060 & 0.47 & 0.73 & 9.10 \\
10 & 9.19 & 0.054 & 0.47 & 0.72 & 11.13 \\
12 & 11.22 & 0.049 & 0.47 & 0.72 & 13.16 \\
14 & 13.26 & 0.045 & 0.47 & 0.72 & 15.19 \\
16 & 15.30 & 0.41 & 0.47 & 0.72 & 17.21 \\
18 & 17.33 & 0.038 & 0.47 & 0.71 & 19.25 \\
20 & 19.37 & 0.036 & 0.47 & 0.71 & 21.28 \\
22 & 21.40 & 0.035 & 0.47 & 0.71 & 23.31 \\
24 & 23.44 & 0.034 & 0.47 & 0.71 & 25.35 \\
26 & 25.48 & 0.034 & 0.47 & 0.71 & 27.38 \\
28 & 27.51 & 0.034 & 0.47 & 0.71 & 29.42 \\
30 & 29.55 & 0.035 & 0.47 & 0.71 & 31.46 \\
32 & 31.59 & 0.037 & 0.47 & 0.71 & 33.50 \\
34 & 33.62 & 0.040 & 0.47 & 0.71 & 35.54 \\
36 & 35.6593 & 0.043 & 0.47 & 0.72 & 37.58 \\
38 & 37.70 & 0.047 & 0.47 & 0.72 & 39.63 \\
40 & 39.73 & 0.051 & 0.47 & 0.72 & 41.67
\end{tabular}


Appendix B: $\quad$ Inverse Calibration Problem

Let $x$ be the true benzene level and $y$ the ALBM value for a given sample. The linear calibration equation is given by

$$
y=A+B x+\varepsilon
$$

where $A$ and $B$ represent the unknown model parameters and $\varepsilon$ represents the error term. The equation of the inverse calibration is given by

$$
x=\frac{(y-A)}{B}-\frac{\varepsilon}{B}
$$

Estimates $a$ and $b$ of the parameters $A$ and $B$, respectively, of equation (1) are determined from the data. Estimates of the variance of $\varepsilon$ and the variances and covariance of the estimates $a$ and $b$ are also determined by fitting the data to equation (1). Let $\sigma_{a a}, \sigma_{b b}$, and $\sigma_{a b}$ be the estimates of the variance of $a$, the variance of $b$, and the covariance of $a$ and $b$, respectively.

There is a systematic error for estimating $x$ using $a$ and $b$ in equation (2). The variance of this error may be estimated by a propagation of variance (reference 3 ) as follows:

$$
s_{x x} \cong\left(\frac{\partial x}{\partial a}\right)^{2} \sigma_{a a}+\left(\frac{\partial x}{\partial b}\right)^{2} \sigma_{b b}+2\left(\frac{\partial x}{\partial a}\right)\left(\frac{\partial x}{\partial b}\right) \sigma_{a b}
$$

where $\frac{\partial x}{\partial .}$ represents the partial derivative of equation (2).evaluated at the mean level of the random variable. 
Appendix B: $\quad$ Inverse Calibration Problem (con't)

These partials derivatives are:

$$
\frac{\partial x}{\partial a}=-\frac{1}{b}
$$

$$
\frac{\partial x}{\partial b}=\frac{-(y-a)}{b^{2}}
$$

Substituting these partial derivatives into equation (3) gives

$$
s_{x x} \cong\left(-\frac{1}{b}\right)^{2} \sigma_{a a}+\left(\frac{-(y-a)}{b^{2}}\right)^{2} \sigma_{b b}+2\left(-\frac{1}{b}\right)\left(-\frac{(y-a)}{b^{2}}\right) \sigma_{a b}
$$

The variance of the random error for $x$ is given by

$$
r_{x x} \cong \frac{\sigma_{\text {eq }}}{b^{2}}
$$

where $\sigma_{\varepsilon \varepsilon}$ is the variance of the error term $\varepsilon$ estimated from fitting the data to equation (1).

The variance of the total error of $x$ is given by the sum of the systematic error variance in equation (4) and the random error variance in equation (5):

$$
\sigma_{x x} \cong s_{x x}+r_{x x}
$$

A $99 \%$ upper prediction limit for $x$ for a given value of $y$ is

$$
\frac{(y-a)}{b}+t .01, n-2 \sqrt{\sigma_{x x}}
$$

where $t_{.01}, n-2$ is the critical value of Student's $t$ with $n-2$ degrees of freedom and $n$ equals the number of standards analyzed during the fit of the calibration curve for the ALBM. 

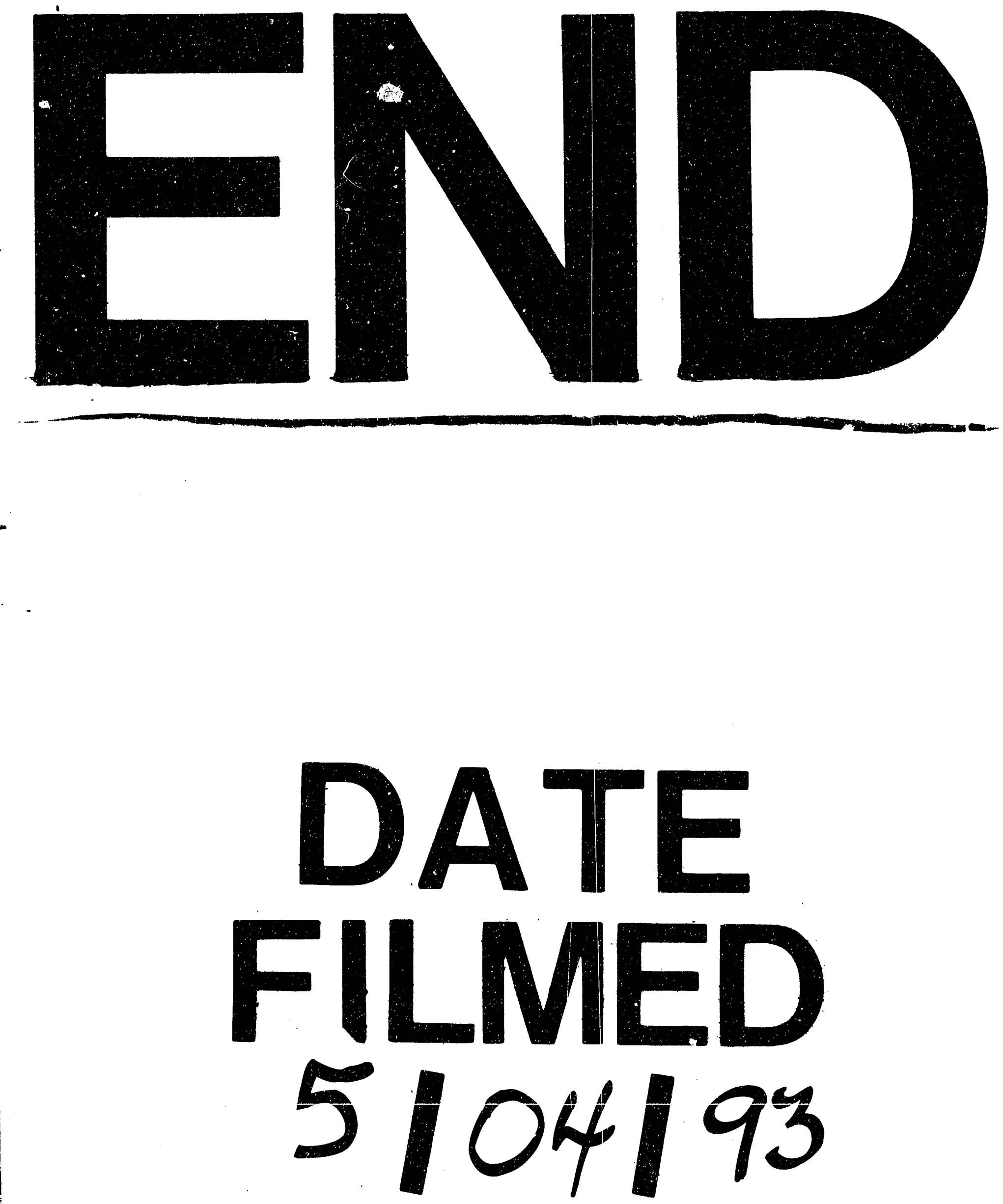
